\title{
A Linear, Time-Varying Simulation of the Respiratory Tract System
}

DOE/ER/60707--T3

DE93 004515

A Thesis

by

Oscar Hernandez

\author{
Submitted to the Office of Graduate Studies of \\ Texas A\&M University \\ in partial fulfillment of the requirements for the degree of \\ MASTER OF SCIENCE \\ FGO5 - 88ER 60707
}

November 1992

Major Subject: Health Physics

\section{DISCLAIMER}

\begin{abstract}
This report was prepared as an account of work sponsored by an agency of the United States Government. Neither the United States Government nor any agency thereof, nor any of their employees, makes any warranty, express or implied, or assumes any legal liability or responsibility for the accuracy, completeness, or usefulness of any information, apparatus, product, or process disclosed, or represents that its use would not infringe privately owned rights. Reference herein to any specific commercial product, process, or service by trade name, trademark, manufacturer, or otherwise does not necessarily constitute or imply its endorsement, recommendation, or favoring by the United States Government or any agency thereof. The views and opinions of authors expressed herein do not necessarily state or reflect those of the United States Government or any agency thereof.
\end{abstract}




\section{CHAPTER 1 \\ INTRODUCTION.}

The ability to accurately assess the retention of long-lived radionuclides in the human respiratory system is an important component in the development of radiation protection guidelines for workers. At present, the biological and chemical processes of radionuclide clearance and absorption to blood are described using constant transfer rates in a linear distribution of compartments representing three physiological regions of the respiratory system. However, these biokinetic processes are more correctly represented by timevarying exponential functions involving nonlinear parameters.

In 1984, the International Commision on Radiological Protection (ICRP) appointed a task group to review and revise, as necessary, the ICRF Dosimetric Model for the Respiratory System. This revision would allow for improved dose estimates for radiation workers based upon new advances in both our understanding of lung morphology (James 1988; Rudolf 1984) and the deposition and clearance of inhaled aerosols (Schlesinger 1988). This proposed model represents the respiratory system by three generic compartments representing the three main physiological regions of the respiratory tract. In contrast to the eleven compartmental model of ICRP Publication 30 (ICRP 1979), the new respiratory model simplifies the handling of ex jerimental retention and excretion data through the use of empirical functions to describe time-varying rates of clearances pathways from the lung (Cuddihy 1984). However, the new ICRP model requires the use of time-varying functions for the transfer of material between the different compartments of the respiratory system, and is simulated by the use of a much more complex system of differential equations. The solutions to these equations represent the amount of radioactive material concentrated in each region of the respiratory tract. This amount can then be integrated over the 50 -year lifetime of the worker to obtain the cumulated activity, $U_{S}$, as well as, the committed dose equivalent, $\mathrm{H}_{50, \mathrm{~T}}$. 
At present, linear first-order kinetics is used to represent nonlinear transport processes such as absorption to blood through the nasal, bronchial, and alveolar epithelia, as well as nonlinear biological processes such as slow clearance by julmonary macrophages ( James and Birchall 1989). In this way, the resulting linear chain of compartments representing the slow and fast clearance processes can be modeled ty linear biokinetic computer codes such as GENMOD (Dundford 1987). While this methodology is designed to simplify the simulation of non-inear processes such as dissolution and mechanical clearance in the lung, theses processes are better described by the use of timevarying transfer rates. Therefore, the main goal of this research is to simulate the deposition and clearance of inhaled aerosols by the use of a time-varying biokinetic representation of respiratory kinetics for long-lived radionuclides.

The research proposed here has resulted in the development of a computer model which can be used to determine values of cumulated activity, $\mathrm{U}_{\mathrm{S}}$, in the different regions of the lung for long-lived radionuclides. The key approach is to use a semiempirical model to describe the deposition of inhaled aerosols (Rudolph 1990), including those aerosols of very small particle size, as well as a theoretical treatment of particle removal from the lung in which mechanical clearance competes with clearance by absorption to blood (Bailey 1985). Recently developer morphometric models of lung geometry have been used (James 1988), and recently measured values of air flow and breathing rates for persons of various ages (Hoffmann 1989) have also been incorporated.

Evaluation of the lung burden can be accomplished by considering two main areas of research. The first is concerned with the development of theoretical models of deposition to assess the fraction of inhaled material deposited in the different regions of the lung. The second is related to the development of biokinetic models of retention and clearance for different radionuclides in the lung.

Deposition calculations for various sized aerosol particles in different regions of the lung are required since subsequent calculation of particle clearance, transfer and retention of 
inhaled material will depend on the site of deposition. The prediction of aerosol behavior in the respiratory system is made difficult by the complex geometrical structure of the lung and the associated patterns of airflow within the airways. The first attempt to model the various physical processes of deposition in the lung v'us made by Findiensen (Findiensen 1935), whose work was later extended by ! andahl and Beeckmans (Landahl 1950; Beeckmans 1965). Indeed, a slightly modified version of Findiensen's model was used by the ICRP Task Group in Lung Dynamics (ICRP1966) as part of their lung model and has since formed the basis of ICRP PLblication 30 (ICRP1979). The essential features of these models are as follows. The lung was represented by a series of well-mixed compartments. Breathing was simulated by considering constant inspiratory and expiratory flow rates and, within the respiratory system, particles not deposited in one cornpartment were transfered to the next. Particle deposition due to the combined actions of Brownian diffusion, impaction and sedimentation were calculated using expressions that are striculy applicable only within a fairly narrow range of flow conditions (i.e., fully developed laminar flow in pipes).

Another model of deposition developed by Yeh (1980), will be used as part of the next Respiratory Tract Dosimetric Model of the National Council on Radiation Protection and Measurements (NCRP). Again the deposition equations are similar to those of Landahl and Beeckmans. This model contains physiological parameters such as breathing frequencies, tidal volumes, and functional residual capacities (FRC) . In addition, aerosol parameters such as particle diameter and density are used to both adjust for lung airway sizes corresponding to different degrees of inflation and to compute deposition efficiencies.

At the present time, most of the algorithms developed to simulate deposition in the respiratory system are very complex in structure and are not readily accessible to general users. Nevertheless, it is possible to express regional deposition in terms of relatively simple algebraic models which yield essentially the same results as the rigorous mathematical models mentioned before. Therefore, as will be described in Chapter 2 of 
this work, a semi-empirical model developed by Rudolf (Rudolf 1990), combined with theoretical and experimental calculations of regional deposition in man developed by Egan, has been used to assess regional deposition fractions in the respiratory tract (Chan 1980; Stahlhofen 1980; Egan 1989). The election of this model is based on the following set of characteristics: (1) the model is simple in structure compared to the previous models described above; (2) it includes experimental results of human deposition in nasal airways developed more recently; (3) it allows the calculation of regional depositions for very small size aerosol particles $(0.001 \mathrm{~mm}$ to $0.1 \mathrm{~mm}) ;(4)$ it is flexible to the inclusion of all the physiological and aerodynamic parameters mentioned above as a function of age; and (5), it includes the description of convective diffusive processes for the deposition of very high turbulent flows in the first 10 generations of the bronchial tree.

In addition to the previous analysis, models of clearance kinetics are also important since mechanical and absorptive clearance rates of inhaled radioactive material in the respiratory system determine the dose to tissues of the respiratory tract, as well as the doses from deposition in other organs following systemic uptake to the blood. The models described Chapter 3, are mathematical representations of the physico-chemical and biological processes which regulate the transportation of inhaled radioactive material to the gastrointestinal tract (GIT), to the circulatory system, and to the regional lymph nodes. These models subdivide the respiratory system into three main dosimetric regions (James 1988). The first region includes structures such as the nose, mouth, pharynx, and larynx. In this region, material is cleared by mucociliary transport, sneezing, nose wiping and blowing, and dissolution followed by absorption to the blood. The second region, which includes the first sixteen bifurcations of the bronchial tree (generations 0-16), is cleared by absorption of material to the blood and to the gastrointestinal tract by mechanical mucociliary transport. The third region, is associated with very slow clearance processes and includes the bronchioles, the alveolar sacs, and the thoracic lymph nodes (generations 17-25 of bronchial tree). In this region, all the lung structures contribute to clearance: 
airway secretions, alveolar surfactant, and epithelial cells dissolve and metabolize particles; these substances are then moved toward interstitium, lymphatics, and blood capillaries, or are retained in the tissues. However, one of the most important lung clearance mechanisms is alveolar macrophage transport of material. In addition, particles that dissolve in the alveolar fluid can diffuse through the epithelium and interstitium into the lymph or blood capillary vessels.

The first model of clearance (ICRP 1959) assumed that for soluble material, of inhaled, $25 \%$ was exhaled, $50 \%$ went to GIT, and $25 \%$ was rapidly absorbed to the blood. In the case of insoluble material, $25 \%$ was exhaled, $50 \%$ went immediately to GIT, and, of the $25 \%$ deposited in the lung, $12.5 \%$ went to GIT after 24 hrs. and $12.5 \%$ remained in the lung with a biological half-life of 120 days. This model was simple in structure, but was not very representative of the physiological pathways of clearance and did not account for the full range of particle solubility and retention in the lung.

The second model of clearance was published in 1972 (ICRP1972) and is summarized in ICRP Publication 30 (ICRP 1979). This model considered three regions of the respiratory tract, and included the pulmonary lymph nodes. Absorption of material into the systemic circulation was projected to occur from all regions of the respiratory tract. The clearance rates and absorbed fractions were determined by three pulmonary clearance classifications; D,W, and Y. In comparison with the model published by ICRP in 1959, this model represented mechanical clearance and clearance by absorption to the blood which was closer to the real physiological behavior of material in the respiratory system. However, in the methodology developed in ICRP 30 , it is assumed that $40 \%$ of the pulmonary deposit of a relatively insoluble (Class $Y$ ) material is removed with a half-time of one day from compartment " $\mathrm{f}$ ", and the rest with a half-time of 500 days. There have, however, been some experimental work made on people and laboratory animals in which this rapid clearance was not observed (Bailey 1985; Cuddihy 1979). Consequently, the 
research proposed here includes a new methodology using a compartmental time-varying system to represent pulmonary clearance of the respiratory tract.

Main characteristics of this model can be summarized as follows:

a) Absorption of inhaled material to the blond and mechanical clearance to the GIT are considered as competitive processes. In fact, all these processes were considered by ICRP 30 completely independent of each other, and they were mathematically simulated by the use of constant transfer rates. Recently the Task Group on Human Respiratory Tract Models for Radiological Protection of the ICRP has developed another model of clearance describing mechanical clearance and absorption to the blood using again constant transfer rates (James 1989); however, the research proposedhere simplifies the analysis of long-lived radionuclides by the use of time varying transfer rates considered in a competitive fashion. The importance of this approach is based on the fact that exponential time varying transfer rates are the result of direct experimental work performed to determine rates of absorption to the blood, avoiding the general tendency to fit measured data from exposed individuals to the structure of the model.

b) Slow mechanical clearance due to the action of macrophages in the pulmonary region is assumed to be the same for all materials and it is also described by exponential time varying functions (Cuddihy 1984 ).

c) The dissolution of inhaled particles is described by empirical and surface area models (Mercer 1967).

d) A portion of the material that is dissolved in the pulmonary region is tound to tissue constituents and therefore exhibits different clearance kinetics (James 1989).

In summary, the structure of the model used in this research assumes items a) and b) above, but in modeling insoluble long-lived radionuclides, items c) and d) will be replaced by the use of empirical dissoluticn transfer rates to describe absorption of material from the lung into the blood based on the experimental work of Cuddihy (Cuddihy 1984). The 
importance of the research proposed here is been based on the development of new software to assess models of deposition and clearance to simulate the behavior of the respiratory system. The deposition models include calculations for any member of the population at different levels of physical activity and at different ages. In addition, they have been designed to cover aerosol releases not only in the nuclear power industry, but alsc releases of chemical pollutants of different size distributions within industrial facilities. At the same time, models of pulmonary clearance have been used to assess doses to the lung tissues of workers in the nuclear power industry, as well as to help in the diagnosis of lung disease for smokers and non-smokers.

A menu-driven computer simulation package has been developed to facilitate the the calculation of model parameters such as regional deposition fractions for polydisperse and monodisperse aerosols and values of cumulated activity. The main features of the package include: (1) Calculation of regional fractional deposition and clearance in the nasal, oral, tracheobronchial airways, and pulmonary region; (2) scaling of respiratory tract airway size and breathing parameters for people of all sizes; and (3) the incorporation of dissolution and mechanical clearance as two competing mechanisms.

The model of deposition is based in three groups of parameters. The first group is related to the determination of average diameters and lengths of the airways and alveoli in the acinar region. These dimensions are based on morphometric measurements on silicon rubber casts obtained by ITRI (Inhalation Toxicology Research Institute) and the models of Hansen and Ampaya ( Hansen 1975). The second group is related to deposition equations developed in an algebraic model by Rudolf (Rudolf 1990) which incorporate the deposition mechanisms of diffusion, sedimentation, and impaction. The third group of parameters contains physiological parameters including breathing frequency, tidal volumes, and functional residual capacity, all as a function of the level of activity, mode of breathing, and age. In addition, aerosol parameters such as particle diameter, density, and air speed at the site of exposure are included. These sets of parameters are used to adjust for sizes of the 
lung airways and to compute regional deposition efficiencies for monodisperse and polydisperse aerosols.

The model of clearance is based on the dosimetric representation shown in Fig. 3.3 of Chapter 3. It consists of three main dosimetric regions interconnected to the main routes of contamination by time-varying transfer rates. In this model, the GIT and blood are considered as repository pools for radionuclides in which the lung is the critical organ so as to assure mass balance of the compartmental distribution. When the lung is not the critical organ (as in the case of exteremly soluble material such as transuranic boneseekers), the model of clearance shown in Fig 3.3 is interconected with linear biokinetic representations of the other organs of the body. Moreover, the input to every compartment is considered for single acute intakes of activity distributed in every region of the respiratory system according to the corresponding fractions of total inhaled radioactive material predicted by the deposition model. Therefore, the set of differential equations describing the retention of inhaled material at every region of the respiratory system are solved numerically by the use of the Adams-Gear method.

Finally, to estimate the burden at the three main physiological regions of the lung after the inhalation of transuranic elements such as plutonium oxide, americium oxide, uranium hexafluoride and curium oxide, another subroutine written in FORTRAN was used to perform the numerical integration of the retained material as a function of time $q_{i}(t)$ to determine the values of cumulated activity $\left(U_{S}\right)$ over periods of fifty years. Therefore, with the new estimations of $U_{S}$ and following the new recomendations of ICRP Publication 60 (ICRP 1991), calculations of ALI (Anual Limit of Intake) and DAC (Derived Air Concentration) were made and are presented in chapter 4. 


\section{CHAPTER 2 \\ DEPOSITION OF INHALED AEROSOLS}

\subsection{INTRODUCTION}

Deposition calculation for various sized aerosol particles in different regions of the lung are required since subsequent calculation of particle clearance, transfer and retention of inhaled material will depend on the site of deposition. The prediction of aerosol behavior in the respiratory system is made difficult by the complex geometrical structure of the 'ung and the associated patterns of airflow within the airways. The first attempt to model the various physical processes of deposition in the lung was made by Findiensen (Findiensen 1935), whose work was later extended by Landahl and Beeckrnans (Landahl 1950; Beeckmans 1965). Indeed, a slightly modified version of Findiensen's model was used by the ICRP Task Group in Lung Dynamics (ICRP 1966) as part of their lung model and has since formed the basis of ICRP Publication 30 (ICRP 1979). The essential features of these models are as follows. The lung is represented by i series of well-mixed compartments. Breathing is simulated by considering constant inspiratory and expiratory flow rates and, within the respiratory system, particles not deposited in one compartment are transferred to the next. Particle deposition due to the combined actions of Brownian diffusion, impaction, and sedimentation is calculated using expressions that are strictly applicable only within a fairly narrow range of flow conditions (i.e. fully developed laminar flow in pipes).

Another model of deposition developed by Yeh (1980) will be used as part of the next NCRP Respiratory Tract Dosimetric Model. Again, the deposition equations are similar to those of Landahl and Beeckmans. This model contains physiological parameters such as breathing frequencies, tidal volumes, and functional residual capacities (FRC). In addition, aerosol parameters such as particle diameter and density are used to both adjust 
for lung airway sizes corresponding to different degrees of inflation and to compute deposition efficiencies.

At the present time, most algorithms developed to simulate deposition in the respiratory system are complex in structure and are not readily accessible to general users. Moreover, it is possible to express regional deposition in terms of relatively simple algebraic models which yield essentialiy the same results as the rigorous mathematical models mentioned above. Therefore, in the thesis work proposed here, a semi-empirical model developed by Rudolf (Rudolf 1990), based on theoretical and experimental calculations of regional deposition in man (Chan 1980; Stahlhofen 1980; Egan 1990), will be used. The election of this model is based on the following set of characteristics: (1) the model is simple in structure compared to the previous models described above; (2) it includes experimental results of human deposition in nasal airways developed more recently; (3) it allows the calculation of regional depositions for very small size aerosol particles $(0.001 \mu \mathrm{m}$ to $0.1 \mu \mathrm{m}) ;(4)$ it is flexible to the inclusion of all the physiological and aerodynamic parameters mentioned above as a function of age; and (5), it includes the description of convective diffusive processes for the deposition of very high turbulent flows in the first 10 generations of the bronchial tree.

\subsection{LUNG VENTILATION PARAMETERS}

Lung ventilation plays an important role in assessing the fraction of inhaled material deposited within the different regions of the respiratory system. In fact, changes in parameters such as tidal volume, breathing frequency, and functional residual capacity FRC (all of which are functions of age, gender, and level of activity), will produce corresponding changes in the distribution of deposited material (Hofmann 1989).

Functional lung volumes such as tidal volume (TV), inspiratory reserve volume (IRV), expiratory reserve volume (ERV), and residual volume (RV), are experimentally 
determined by the use of a water sealed recorder (spirometer). The calculation of these fundamental quantities is important for the determining secondary parameters which are generally denominated by lung capacities. Lung capacities are defined as the sum of two or more primary volumes, and will include parameters such as total lung capacity (TLC), vital ( apacity (VC), inspiratory capacity (IC), and functional residual capacity (FRC).

Although there are significance differences in lung volume between the sexes, no sex differences are obsirved when the RV or the FRC are expressed as a fraction of TLC (i.e., RV/TLC, FRC/TLC) (Lim 1983). Lung volumes.also change with age such that the ratios RV/TLC and FRC/TLC tend to increase with age. Because of these sex and age variations, normal values of lung volumes are lisually expressed as percentages of the predicted normal volume of reference man and (ICRP 62 In press) correction factors are used in every region of the lung. Estimations of lung volumes as a function of age and for both sexes have been calculated by Zapletal and Hofmann (Hofmann 1989; Zapletal 1987) and are used in the model of deposition proposed in this work.

Definition of lung ventilation volumes to be used in the deposition model proposed in this work are defined as follow:

Tidal volume (TV): The amount of gas inspired or expired during a normal breathing cycle. ICRP Publication 62 reports of typical values are $1250 \mathrm{ml}$ for males and $1000 \mathrm{ml}$ for females both under light activity.

Expiratory reserve volume (ERV): The maximum amount of gas which can be expired from the end-expiratory resting level. This is the volume of air that is pushed out when forcibly exhaled and is about $1200 \mathrm{ml}$ for males.

Besidual volume (RV): The amount of gas which remains in the lung after maximum expiration $(2000 \mathrm{ml})$.

Eunctional residual capacity (FRC): The amount of gas remaining in the lung at the end-expiratory resting level $(F R C=E R V+R V)$. 
Other lung ventilation parameters inclucle the concepts of minute volume ventilation rate (MV) and volume of the dead spaces $V_{D}$. The minute volume ventilation rate is defined as the amount of gas inspired or expired during one minute of breathing [i.e., $\mathrm{MV}=\mathrm{TV}(\mathrm{ml}) \times$ breathing frequency $\left.\left(\mathrm{min}^{-1}\right)\right]$.

Finally, not all of the air inspired goes to alveoli to take part in gas exchange. Some portion of the inspired volume must remain in the airways in which there is no gas exchange. This volume is called a dead space volume $V_{D}$.

\subsection{MORPHOMETRY OF HUMAN LUNG STRUCTURES}

The geometry of the respiratory system is another important factor in the analysis of deposition and clearance of inhaled aerosols. Functional structures of the respiratory system can be subdivided in three main regions of interest according to their geometry and physioiogical functions: (1) anterior and posterior nasal airways which constitute the upper compartment of the extrathoracical region (ICRP 1962); (2) the first 16 generations of the bronchial tree composed of the trachea, main bronchi, bronchi, bronchioles, and terminal bronchioles; and (3), the pulmonary acinus composed of respiratory bronchioles, alveolar ducts, and alveolar sacs.

For the first geometrical region of the respiratory system, cross sectional areas and perimeters of coronal sections of the right and left nasal airways have been determined as a function of the distance from anterior nares (Guilmette 1989). These measurements have been performed using non-invasive techniques such as MRI in vivo in order to determine more precisely the patterns of aerosol deposition in nasal airways. Currently, nontheoretical models of deposition in nasal airways have been developed; however, experimental measurement of semi-empirical nasal and oral deposition efficiencies calculated from human oral casts have been performed by Cheng, Gradon, and Bowes 
(Cheng 1990; Gradon 1989; Bowes 1989). A summary of all these results is used to assess the fraction of inhaled material that is deposited in extrathoracical region and will be explicitly described in Section 2.4 .

Geometrical measurements of the second lung region composed of the first 16 generations of the bronchial tree have included the determination of lengths and diameters of bronchial airways. In addition, estimation of gravity and branching angles (to be defined latter) of irregular dichotomous branching airways have been calculated from different experimental works (Weibel 1963; Horsfield 1971; Yeh and Schur 80). However, in the model of deposition proposed in this research, geometrical parameters are taken from the data base published by Raabe and Yeh resulting from extensive work carried out at ITRI (Inhalaticn Toxicology Research Institute) (Raabe 76) and summarized by one paper published by Yeh in 1980 ( $Y$ sh 1980).

Measurements of lengths, diameters, and branching angles were performed at ITRI from human and animal silicone rubber casts of the bronchial tree. These casts were trimmed to the level of the terminal bronchioles (about generation 16) before being subject to measurement. The identification of terminal bronchioles was accompanied by examining the surface of the airway under low (x 10) magnification to identify the presence of small protrusions corresponding to alveoli. Real lung segments are superimposed to a idealized model represented by segment vectors expressed as $(N, L, D, \theta, \varphi, R)$ where $N$ is a binary identification number, $L$ and $D$ are the length and the diameter of the correspondent airway stem, $\theta$ and $\varphi$ are the branching and gravity angles. These angles are defined as the angle formed with the airway axis and the angle formed with the vertical axis pointing in the direction of the gravity force, respectively. Fig. 2.1 gives a schematic representation of all these geometrical parameters and will be used as a reference during the development of this work.

Extrapolation of morphometric parameters to very small airways is carried out from the knowledge of the number of airways per generation which is equal to $2^{\mathrm{N}}$ if symmetrical 


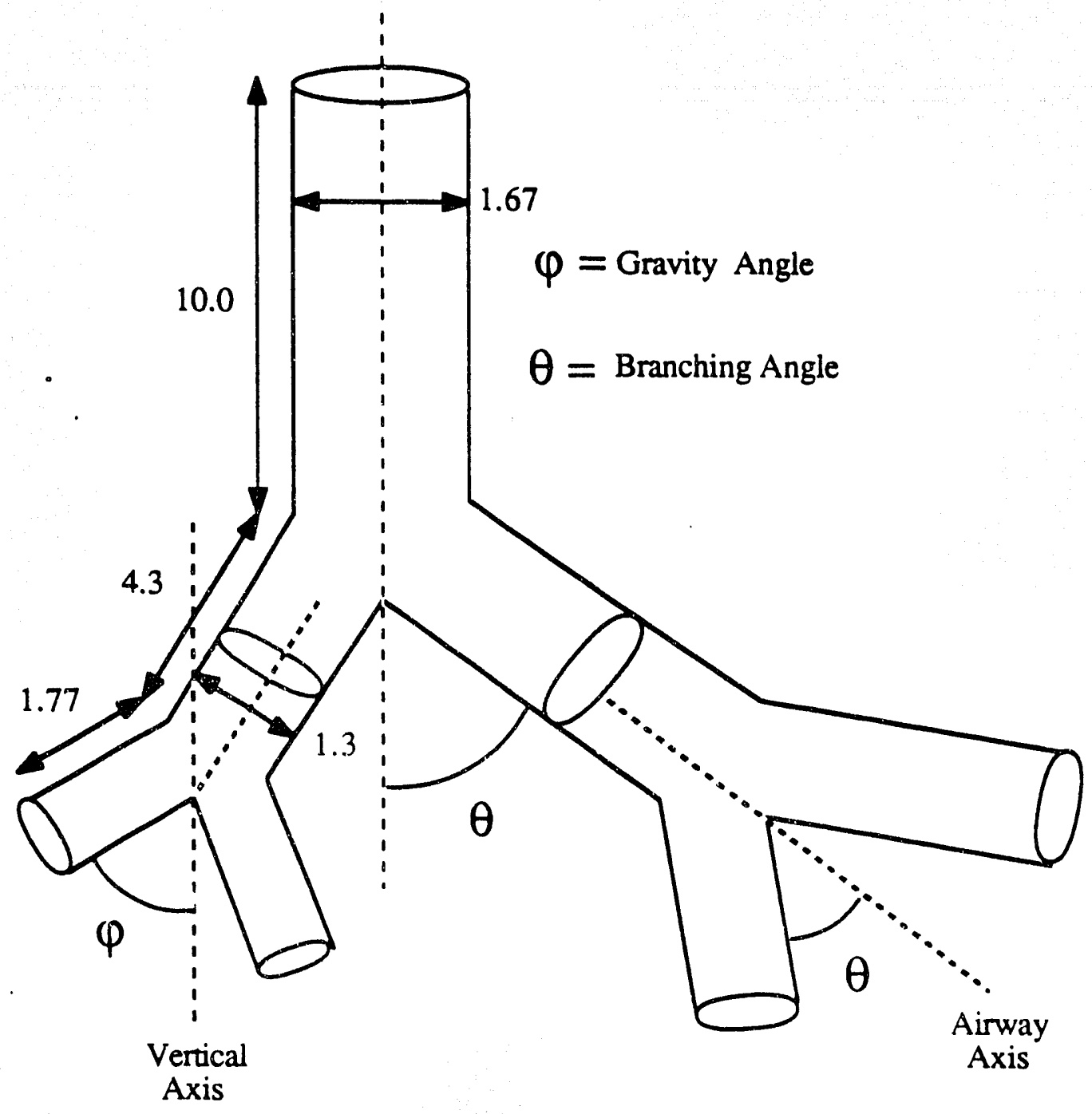

Figure 2.1 Geometry of the bronchial tree (dimensions are given in $\mathrm{cm}$ ). 
dichotomy is assumed. In consequence, analysis of airflow patterns inside of the bronchial cast are used to determine $\mathrm{D}$ and $\mathrm{L}$, and the change in direction of bulk air-flows from the parent segment into the daughter segment is used to determine $\theta$ and $\varphi$. Horsfield has proposed a matiematical relationship between the radius of the daughter airway stems as a function of the radius of the main stem when the counting is done in the downward direction (Horsfield 1971) given by :

$$
\mathrm{r}_{\mathrm{N}}=\mathrm{K}^{\mathrm{N}} \mathrm{r}_{\mathrm{o}}
$$

where $\mathrm{K}=\mathrm{a}$ constant less than unity, $\mathrm{N}=$ level of bifurcation or generation number, and $r_{0}=$ radius of the main stem.

If the counting is done upward, the equivalent relationship is given by:

$$
\mathrm{r}_{\mathrm{N}}^{\mathrm{u}}=\mathrm{K}_{1}^{\mathrm{N}} \mathrm{r}_{\mathrm{o}}
$$

where $\mathrm{K}_{1}=$ is a constant greater than 1 .

Knowledge of the length at every branch can be indirectly inferred from the pressure gradient summed along any pathway in the bronchial tree by assuming that Poiseuille Law is applicable to cylindrical pipes. Under the assumption that the flow rate of gas in any given branch will be directly proportional to the number of distal respiratory bronchioles arising from that branch, then the average length of an airway is calculated from relationship:

$$
P_{1}-P_{2} \alpha \frac{L E}{D^{4}}
$$

where $E=$ Number of end branches, $D=$ diameter of a branch, $P_{1}-P_{2}=$ pressure gradient between the ends of a tube or branch, and $\mathrm{L}=$ length of a branch.

Experimental measurements of lengths and diameters of the airways in the bronchial tree were carried out at ITRI in rubber casts representing lung volumes corresponding to a maximum level of inflation; in other words, the effect of the place occupied by the silicone injected inside of the bronchial airways at a pressure of 0.5-1.0 psig, produced a cast with a shape corresponding to a maximum volume of inflation equal to the TLC. Therefore, 
lengths and diameters corresponding to a normal volume of inflation are found by adjusting the experimental values reported by ITRI.

Scaling factors are defined in terms of the ratio of the previous lung ventilation parameters described above, and result to be of extreme utility to adjust the gesmetry of the bronchial tree corresponding to different degrees of inflation. This fact has been considered since the appearance of the deposition model developed by Yeh ( Yeh 1980 ) and is used in later models. The adjustment of airway dimensions is done under four assumptions.

First, the normal lung volume LV is considered equal to FRC + 0.5TV. Second, the functional residual capacity is considered to be $60 \%$ of the total lung capacity. Third, the conducting airway diameters expand as the square root of volume expansion; in this way, the diameter of the first 16 generations reported by ITRI is divided by the scaling factor $\eta$ such that:

$$
\eta=\sqrt{\frac{V_{D, T L C}}{V_{D, L V}}},
$$

where $V_{D, Y}$ is the volume of the dead spaces at lung volume $Y$. Fourth, both diameters and lengths in the respiratory region are proportional to the cube root of the lung volume, such that both parameters reported by ITRI are divided by the scaling factor $\xi$ :

$$
\xi=\left(\frac{V_{R, T L C}}{V_{R, L V}}\right)^{\frac{1}{3}}
$$

where $V_{R, Y}$ is the volume of the respiratory airways at lung volume $Y$.

Lengths, diameters, and irregular dichotomous branching and angulation of each branch pair may result in considerable differences on local airflow resistence and the transit times from mouth to the gas exchange sites. Therefore, the simulation of deposition of radioactive inhaled aerosols at the different regions of the lung will strongly depend on a precise determination of the geometrical size of lung structures. 
Table 2.1 shows the values of lengths, diameters, branching angles and gravity angles taken from ITRI Report LF-53 report and adjusted to normal lung volume LV. Values of TLC, FRC, TV, and $V_{D}$ correspond to the new lung volumes employed in ICRP Publication 62 for a reference man involved in light activity. Figs. 2.2 and 2.3 display the average values of lengths and diameters of the bronchial tree as a function of airway generation or level of bifurcation through the bronchial tree as calculated by differt $i$ models. As a result of the calculations represented in Figs. 2.2 and 2..3, the knowledge of the number of airways per generation, and from the assumption of a cylindrical pipe airway geometry, the total cross sectional area of bronchial airways per generation is plotted in Fig. 2.4 against the level of bifurcation. A general increase in airway cross sectional area results in a decrease of the average speed of the gas flowing down through the bronchial tree. As shown in Fig. 2.4, the rate of change in total cross sectional area per generation increases with increasing generation number and results in a greater decrease in air speed through the airways. A first consequence of this anatomical behavior of the bronchial tree will be reflected in the high turbulence of air passing through the first 10 generations of the bronchial tree and in a characteristic laminar flow of the air passing close to the respiratory bronchioles. Developed laminar flows are considered an important physiological factor to allow physicai conditions for the diffusion of gas through alveolar membranes in the gas exchange zone. On the other hand, turbulent convective flows will enhance deposition of aerosol particles due to axial diffusive mixing in trachea, main bronchi, and bronchi.

Finally, the geometry of pulmonary acinus (i.e. terminal bronchioles, distal airways and air spaces) has been reconstructed by Hensen and Ampaya (Hensen 1975). Measured parameters include the length and diameter of alveolar ducts and the inner diameters of alveoli . The shapes and frequency distribution of six different geometries associated with alveoli were used to calculate the diameter of sac orifices, the surface area of alveoli, and distance from the center of alveolar orifice to alveolar surface. In addition to these 
Table 2.1 Geometric human lung model.

$T L C=6900 \mathrm{ml}, F R C=3200 \mathrm{ml}, T V=1.250 \mathrm{ml}, V_{D}=150 \mathrm{ml}, \eta=1.204, \xi=1.225$.

\begin{tabular}{|ccccc|}
\hline $\begin{array}{c}\text { Generation } \\
\text { number }\end{array}$ & $\begin{array}{c}\text { Length } \\
(\mathrm{cm})\end{array}$ & $\begin{array}{c}\text { Diameter } \\
(\mathrm{cm})\end{array}$ & $\begin{array}{c}\text { Branching } \\
\text { Angle }(\mathrm{o})\end{array}$ & $\begin{array}{c}\text { Gravity } \\
\text { Angle (o) }\end{array}$ \\
\hline 1 & 10.0000 & 1.6689 & 0 & 0 \\
2 & 4.3600 & 1.2953 & 33 & 20 \\
3 & 1.7800 & 0.9383 & 34 & 31 \\
4 & 0.9650 & 0.6867 & 22 & 43 \\
5 & 0.9950 & 0.5405 & 20 & 39 \\
6 & 1.0100 & 0.4766 & 18 & 39 \\
7 & 0.8900 & 0.3612 & 19 & 40 \\
8 & 0.9620 & 0.3097 & 22 & 36 \\
9 & 0.8670 & 0.2674 & 28 & 39 \\
10 & 0.6670 & 0.2134 & 22 & 45 \\
11 & 0.5560 & 0.1644 & 33 & 43 \\
12 & 0.4460 & 0.1295 & 34 & 45 \\
13 & 0.3590 & 0.0980 & 37 & 45 \\
14 & 0.2750 & 0.0764 & 39 & 60 \\
15 & 0.2120 & 0.0606 & 39 & 60 \\
16 & 0.1680 & 0.0498 & 51 & 60 \\
17 & 0.1094 & 0.0441 & 45 & 60 \\
18 & 0.0980 & 0.0408 & 45 & 60 \\
19 & 0.0751 & 0.0384 & 45 & 60 \\
20 & 0.0653 & 0.0367 & 60 & 60 \\
21 & 0.0572 & 0.0359 & 45 & 60 \\
22 & 0.0514 & 0.0359 & 45 & 60 \\
23 & 0.0465 & 0.0351 & 45 & 60 \\
24 & 0.0433 & 0.0351 & 45 & 60 \\
& & & & \\
\hline
\end{tabular}




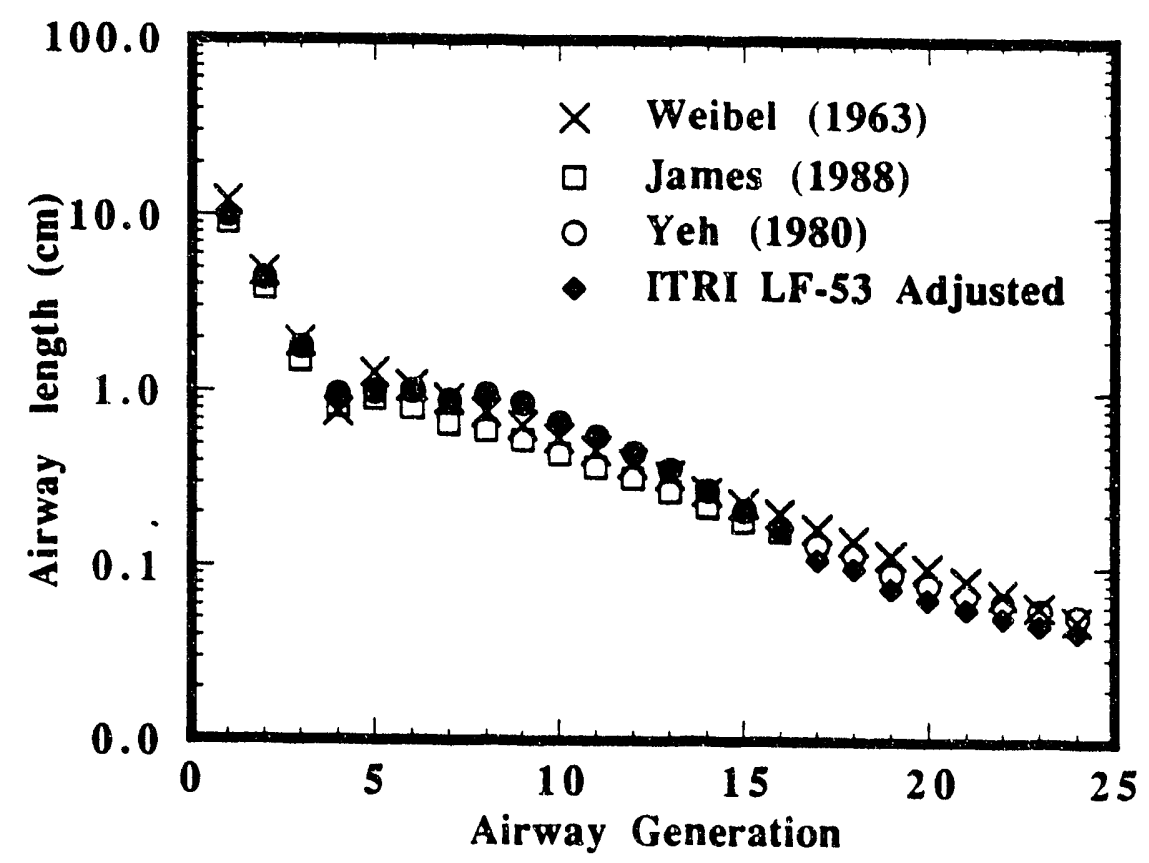

Figure 2.2 Comparison of geometrical estimations of airway lengths in the human lung.

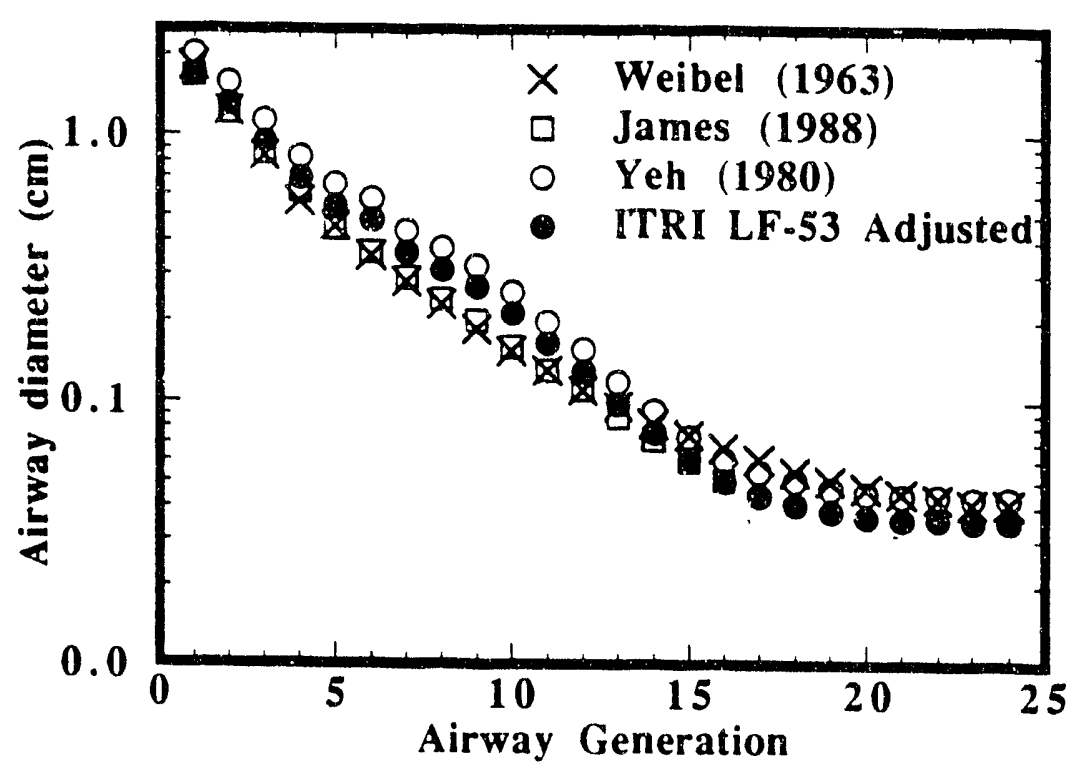

Figure 2.3 Comparison of geonetrical estimations of airway diamaeters in the human lung. 


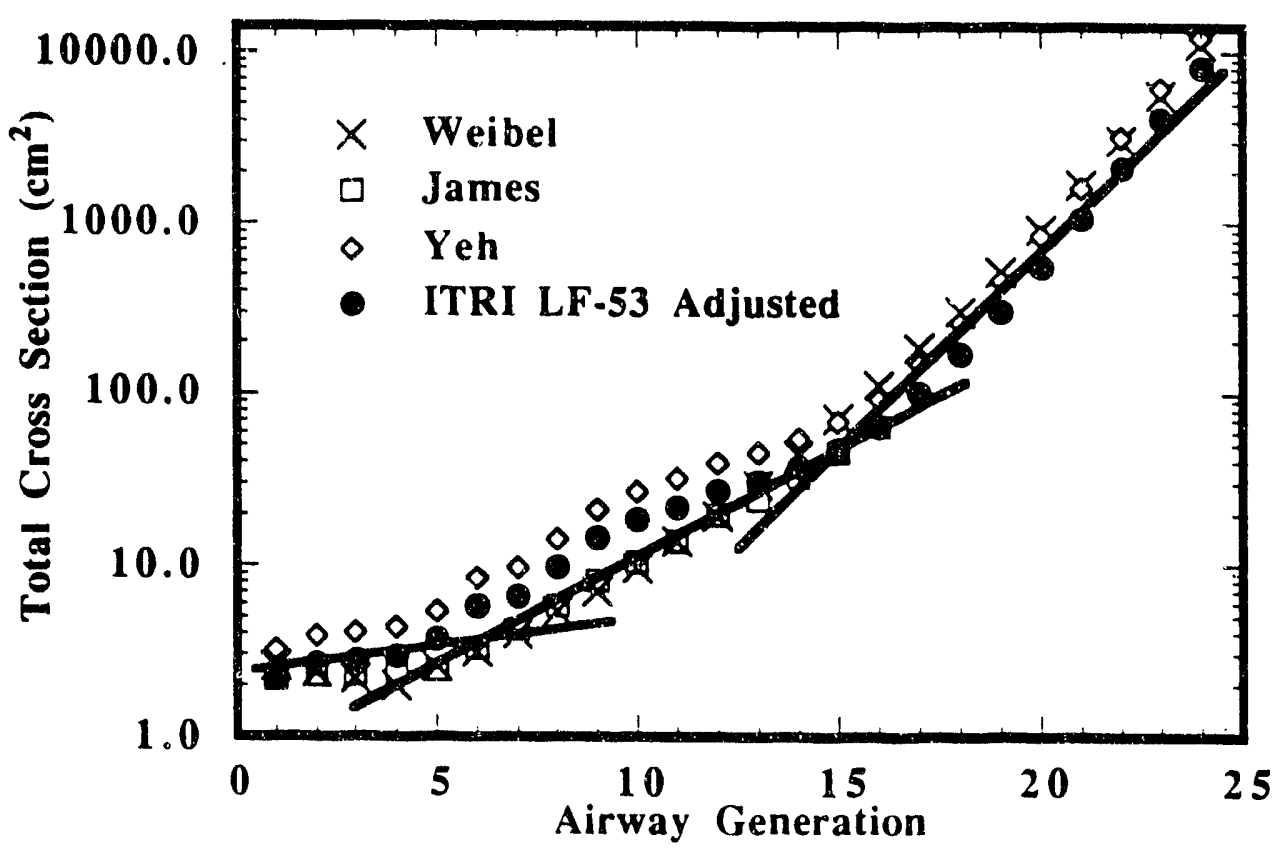

Figure 2.4 Total cross sectional area per generation in the human lung. 
calculations, average volumes of acinus predicted by this model is $182.8 \mathrm{~mm}^{3}$ (Hensen 1975) which compares well with a value of $187 \mathrm{~mm}^{3}$ predicted by Haefeli (Haefeli-Bleuer 1987).

Assuming the appearance of terminal bronchioles at the 15 th generation and using Weibel's data for the first ten generations, Hensen has established empirical relationships for the lengths and diameters of each airway generation :

$$
\begin{aligned}
& D_{N}=12 e^{-(0.27-0.005 N) N}, \text { and } \\
& L_{N}=25 e^{-187 N},
\end{aligned}
$$

where $D_{N}$, and $L_{N}$ are the diameter and length at the $N$ th generation of the bronchial tree $(\mathrm{N}=1-26)$. This particular model concerns provides a specific reconstruction of the pulmonary acinus which gives a large increase in respiratory and bronchial ductal cross-sectional areas, as well as alveol:ur volumes and surface areas, when compared with the model described by Weibel (Weibel 1963).

\subsection{PHYSICAL PROCESSES OF LUNG DEPOSITION}

Deposition calculations for various sized aerosol particles in different regions of the lung are required since subsequent calculation of particle clearance, transfer, and retention of inhaled material will depend on the site of deposition and the fraction of inhaled material deposited. Consequently, aerosol deposition in the respiratory system has been described by models that fit into two main categories: (1) pure theoretical models of aerosol deposition; and (2), semi-empirical madels of aerosol deposition. These models are generally supported by experimental results measured by Stahlhofen (Stahlhofen 1980) and Chan (Chan 1980) which depend on physical deposition processes such as inertial impaction, sedimentation, and diffusion. These deposition processes will depend on physical parameters such as aerosol particle size, shape, and density, hygroscopicity, respiratory-tract geometry (airway calibers, branching patterns, and path length to terminal 
airways), the mode of breathing (oronasal, oral, nasal), breathing frequencies and tidal volumes as a function of age, flow rates and velocities, and the interlobular distribution of ventilation .

Impaction is the inertial deposition of a particle onto an airway surface as shown in Fig. 2.5 . Impaction occurs when the particle's momentum prevents it from changing course in an area where there is a rapid change in the direction of bulk airflow; in other words, particles deviate from the air flow stream lines by inertia. Impaction is the main mechanism by which particles having diameters greater than or equal to five $\mu \mathrm{m}$ deposit in the upper respiratory tract at or near branching points in the tracheobronchial tree. The probability of impaction increases with increasing air velocity, rate of breathing, and particle density and size.

Sedimentation is deposition due to gravity forces. When the gravitational force on an airborne particle is balanced by the total of forces due to air buoyancy and air resistance, the particle will fall out of the airstream at a constant rate known as the terminal settling velocity. For deposition to occur, this velocity must be reached before the particle exits the airway. The probability of sedimentation is proportional to the particle's residence time in the airway and to the particle size and density, and it decreases with increasing the breathing rate. Sedimentation is an important deposition mechanism for particles with diameters greater than or equal to $0.5 \mu \mathrm{m}$ that penetrate to those airways where the air velocity is relatively low (mid to small bronchi and bronchioles).

Submicrometer-size particles, especially those with diameters less equal to $0.2 \mu \mathrm{m}$, acquire a random motion owing to their bombardment by surrounding air molecules; this motion may then result in particle contact with the airway wall. The displacement sustained by the particle is a function of the diffusion coefficient, which is inversely related to the particle cross-sectional area. Brownian diffusion is a major mechanism of deposition in airways where bulk flow is low or absent (bronchioles and alveoli). However, extremely 

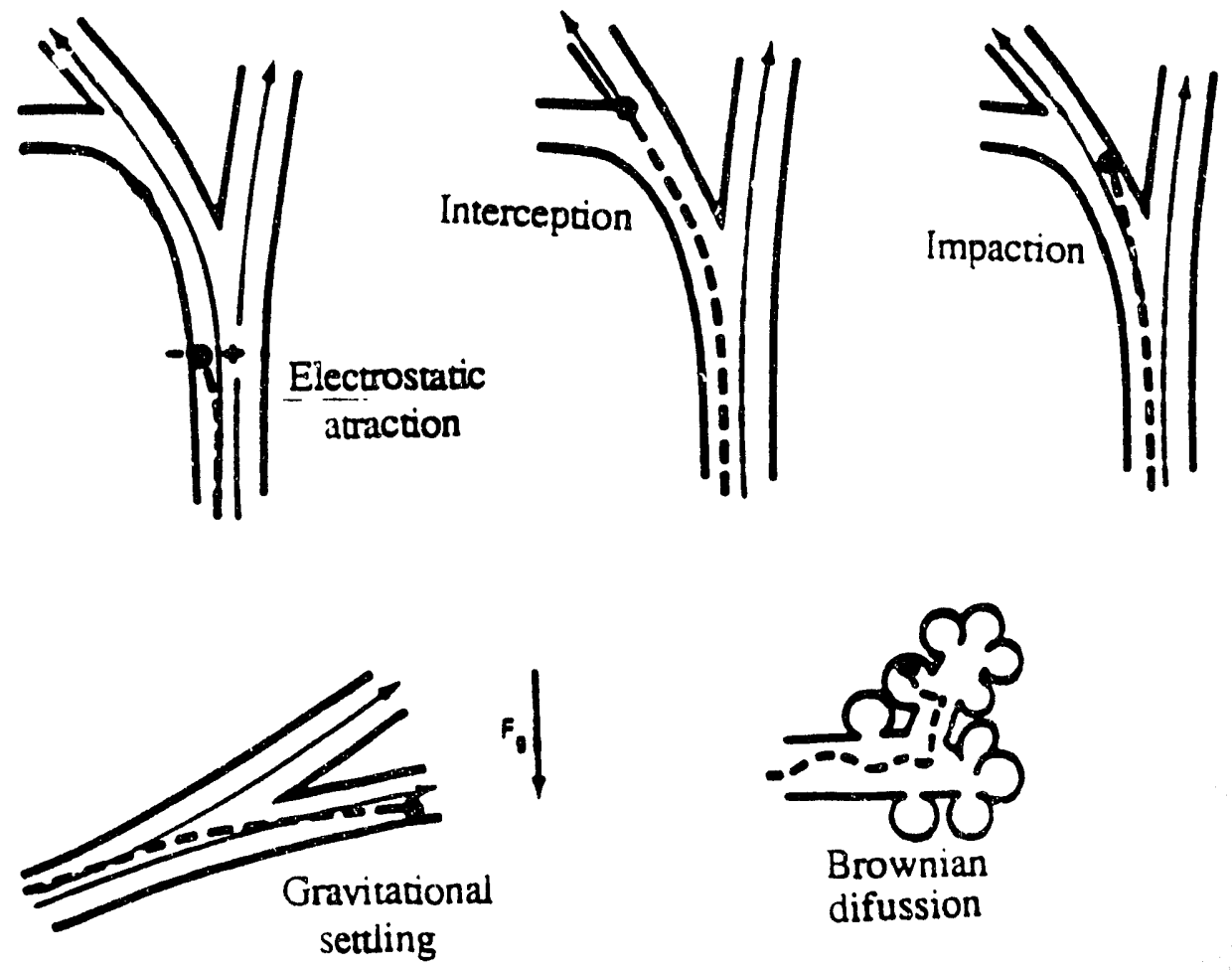

Figure 2.5 Deposition mechanisms onto an airway surface 
small particles may deposit by convective diffusion in the upper respiratory tract, trachea, and larger bronchi due to flow turbulences.

Since 1930, extensive work has been performed in developing theoretical models of aerosol deposition. A summary of these achievements corresponding to different methodologies can be found in the deposition models of Landahl (Landahl 1950), Beeckmans (Beeckmans 1965), Yeh (Yeh 1980), and Egan (Egan 1989). Moreover, to assess deposition fractions of inhaled radioactive material at the different regions of the respiratory system, a semi-empirical model of deposition developed by Rudolf (Rudolf. 1990) has been combined with theoretical calculations of regional deposition efficiencies predicted by the model of Egan during the development of this research.

In the model developed by Egan, the lung is represented as a regular system of branching airways, such that each branch within one generation is taken to have identical dimensions. Any point in the lung airways is characterized by its axial distance, $x$, from the origin of trachea as seen in Fig. 2.6. Associated with each axial distance $\mathrm{x}$ are the properties of the appropriate generation such as the number of branches, the branch diameter, the total cross sectional area of airways and the number of alveoli. The variation of aerosol concentration, $c(x, t)$, is governed by convection at velocity $u(x, t)$ through the airways, diffusion along the airways $D(x, t)$, and deposition onto the various lung surfaces $L(x, t)$. The mass balance equation represented by a convective diffusion equation describing the change in concentration along the airways is given by the equation :

$\frac{\partial\left[A_{T}(x, t) c(x, t)\right]}{\partial t}=-\frac{\partial\left[A_{A}(x, t) u(x, t) c(x, t)\right]}{\partial x}+\frac{\partial}{\partial x}\left[A_{A}(x, t) D(x, t) \frac{\partial(c(x, t))}{\partial x}\right]-L(x, t)$,

where $D(x, t)$ is the effective diffusion coefficient, $A_{A}(x, t)$ is the cumulative airway cross sectional area (summed across all airways at any distance $\mathrm{x}$ and calculated from the number of airways per generation and lung dimensions given in table 2.1$), A_{T}(x, t)$ is a cross sectional area function that allows for the alveolar volume associated with lower airways, 


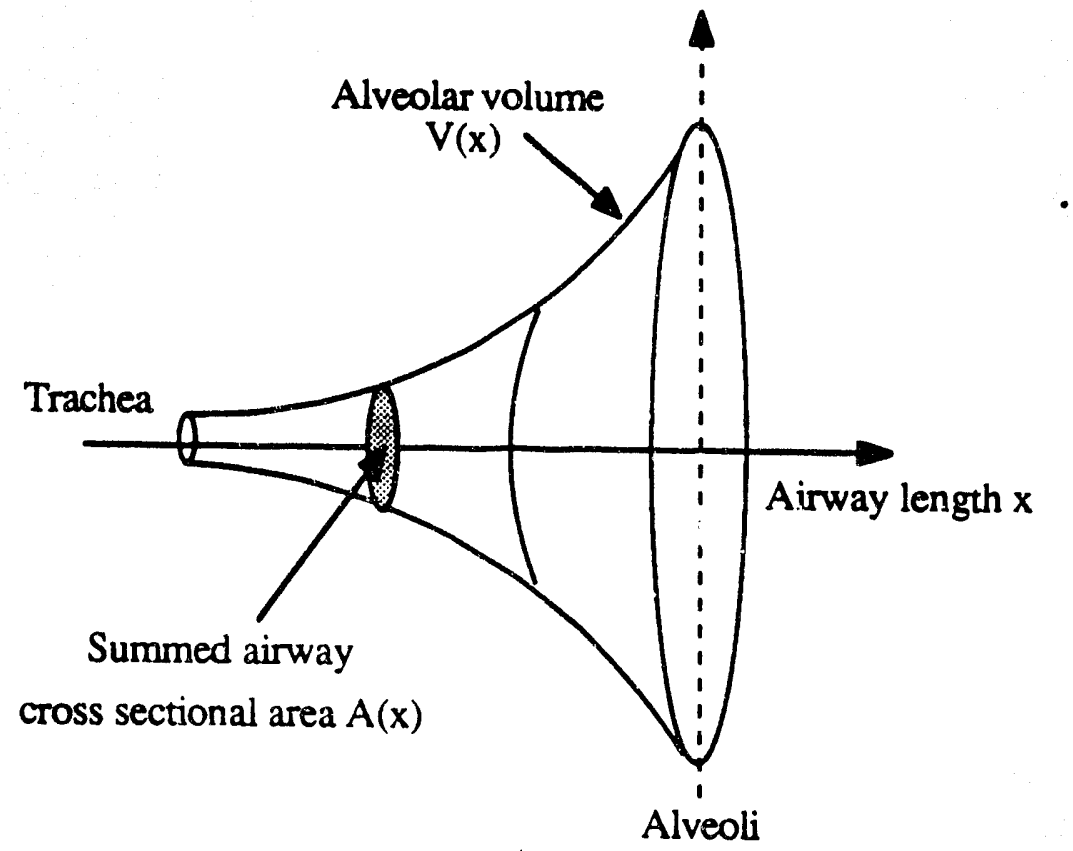

Figure 2.6. "Trumpet" airway model. 
$L(x, t)$ is the deposition rate per unit length of airway, and $u(x, t)$ is the convective flow velocity.

The breathing process is simulated by allowing the cross sectional areas within the alveolar region to expand and contract about their mean values given in Table 2.1. Thus, for both $A_{A}$ and $A_{T}$ in the alveolated airways,

$$
A(x, t)=A(x) f(t),
$$

where $A(x)$ is the mean cross sectional area, and $f(t)$ is a function of time chosen to reflect any form of breathing (e.g., sinusoidal, or sawtooth).

Additionally, $\left(\mathrm{A}_{\mathrm{T}}-\mathrm{A}_{\mathrm{A}}\right)$ times $l$ is the alveolar volume associated with any generation of length 1 . In the abserce of convective flow, the axial transport of particles along the airways would be governed by Brownian diffusion. In the presence of convection, however, the resulting complicated flow fields characteristic of the upper bronchial generations may be such that relative to the mean flow, late bulk irreversible mixing does occur. Thus, assuming that inhaled particles follow the airflow patterns in the lung airways, Scherer (Scherer 1975) has suggested experimental effective diffusivities given by:

$$
\begin{array}{ll}
D(x, t)=D_{B}+1.08 u(x, t) d & \text { (for inspiration) and } \\
D(x, t)=D_{B}+0.37 u(x, t) d & \text { (for expiration), }
\end{array}
$$

where $D_{B}$ is the Brownian diffusion coefficient, and, $d$, is the diameter of an individual airway through which the flow is being considered.

Assuming that the variation in lung dimensions acts on an incompressible fluid, then the convective flux at any point in the lung, $u(x, t) A(x, t)$, is equal to the rate of change of total volume in the airways distal to that point. Therefore,

$$
u(x, t) A_{A}(x, t)=\frac{d}{d t} \int_{x}^{L_{r}} A_{T}(x, t) d x
$$


and

$$
u(x, t)=\frac{1}{A_{A}(x, t)} \int_{x}^{L_{T}} \frac{\partial}{\partial t} A_{T}(x, t) d x
$$

where $L_{T}$ is the distance to the distal extremity of the lung.

Equation (2.4.1) is solved numerically for $c(x, t)$, adopting relevant initial and boundary conditions by the use of the finite difference representation of Crank-Nicholson. Deposition is evaluated as being due to the combined effects of inertial impaction, sedimentation, and Brownian diffusion. The modeling for contributions to the term $L(x, t)$, which represents the removal rate of aerosol from the airstream per unit length of airway, is calculated from the total number of particles at a given generation multiplied by the probability of being deposited in that generation, $\eta$. Therefore, for the non-alveolated airways the loss of material in a given generation of the bronchial tree is given by,

$$
L(x, t)=\frac{c(x, t) A_{A} u(x, t)}{1} \eta
$$

where $\eta$ is the aerosol total deposition efficiency at a given generation of length 1 , which is defined as the ratio of the amount of aerosol deposited in each airway generation to the total amount of material entering within that generation.

Total deposition efficiencies at every generation of the bronchial tree are estimated from the calculation of the exclusion of the probabilities which include the three main mechanisms of deposition in the respiratory system given by,

$$
\eta=1-\left(1-\eta_{s}\right)\left(1-\eta_{d}\right)\left(1-\eta_{i}\right)
$$

where $\eta_{S}$ is the probability of deposition by sedimentation that according to Fuch (Fuch 1964) for laminar flows in a cylindrical tube is given by, 


$$
\eta_{s}=\frac{2}{\pi}\left[2 \phi \sqrt{\left(1-\phi^{2 / 3}\right)}-\phi^{1 / 3} \sqrt{\left(1-\phi^{2 / 3}\right)}+\sin ^{-1} \phi^{1 / 3}\right]
$$

where

$$
\phi=\left(\frac{3 u_{S l} l}{4 u d}\right) \sin \varphi,
$$

and $u_{s}$ is the particle settling velocity, 1 is the airway length for the generation under consideration, $d$ is the airway diameter, $u$ is the mean flow velocity, and $\varphi$ is the gravity angle. Moreover, if the reynolds number $(\operatorname{Re}=u d \rho / \mu)$ for the flow within the pipe exceeds 2000 then equation 2.4 .8 is written for turbulent flow as,

$$
\eta_{s}=1-\exp \left(-\frac{16 \phi}{3 \pi}\right) \text {. }
$$

Even more, the process of deposition due to Brownian diffusion is also included at the lower generations of the bronchial tree during inspiration and expiration, and it is given by the deposition efficiency calculated by Ingham (Ingham 1975) as,

$$
\begin{gathered}
\eta_{d}=1-0.819 \exp (-14.63 \Delta)-0.0976 \exp (-89.22 \Delta) \\
-0.0325 \exp (-228 \Delta)-0.0509\left(-125.9 \Delta^{2 / 3}\right)
\end{gathered}
$$

where

$$
\Delta=\frac{D_{\mathrm{B}} \mathrm{l}}{\mathrm{d}^{2} \mathrm{u}}
$$

In addition, inertial impaction mechanisms are described by the calculation of impaction efficiencies at the upper region of the bronchial tree which are based on measurements of deposition in bronchial casts at relative high stokes numbers. Thus, Nixon and Egan have considered in their calculations (Egan 1989) the next empirical equations,

$$
\begin{gathered}
\eta_{i}=11.5(\mathrm{Stk})^{1.82} \text { in generations } 1 \text { to } 3 \\
\eta_{i}=3.02(\mathrm{Stk})^{1.68} \text { in generations } 4 \text { to } 16 .
\end{gathered}
$$

On the other hand, for those airways completely surrounded by alveoli (alveolar ducts and alveolar sacs) the particle flux to the wall of one individual alveolous is calculated. When this quantity is multiplied by the alveolar number density it yields the deposition rate per unit length. Therefore, considering the $3 / 4$ spheroid alveolar shape 
analyzed by Hensen and Ampaya shown in Fig. 2.7, the sedimentation flux to alveolar wall may be written as,

$$
\phi_{s}=c \iint \vec{u}_{s} \cdot d \vec{s},
$$

where $u_{s}$ is the particle settling velocity, and $c$ is the calculated alveolar concentration of aerosol.

This surface integral is taken over the core surface and the axis of symmetry of the alveolous which is assumed to be perpendicular with respect to gravity such that equation 2.4.14 reduces to

$$
\phi_{s}=\mathrm{cu}_{\mathrm{s}} \mathrm{r}_{\mathrm{c}}^{2}\left(\phi_{\mathrm{c}}-\frac{1}{2} \sin 2 \phi_{\mathrm{c}}\right)
$$

Furthermore, the Peclet number in the alveolar region is usually larger than unity then it is observed that the concentration gradient occurs mainly in a thin boundary layer near the alveolar wall. For a flat surface suddenly exposed to an aerosol concentration $c$, the diffusion deposition to the wall per unit area per unit time is,

$$
\phi_{d}=A D_{B}\left[c /\left(r_{a}-h_{c}\right)\right],
$$

where $r_{a}$ is the effective radius of the alveolous, $\phi_{c}$ is the angle of th: core, and $h_{c}$ is the height of the core.

Finally, to calculate the deposition rate per unit length of airway $L$ in alveolated airways due to the contributions of sedimentation and diffusion, Eqs. (2.4.15) and (2.4.16) are multiplied by the number of alveoli per unit length $\mathrm{N}_{2} / 1$ giving the result:

$$
\mathrm{L}=\left(\phi_{\mathrm{s}}+\phi_{\mathrm{d}}\right)\left(\frac{\mathrm{N}_{\mathrm{a}}}{\mathrm{l}}\right)
$$

where $\mathrm{N}_{\mathrm{a}}$ is the number of alveoli in a given generation.

Therefore, deposition in region $\mathrm{k}$ for non-alveolated and alveolated airways of the respiratory tract is thus obtained from the integration of the particle loss over the entire 


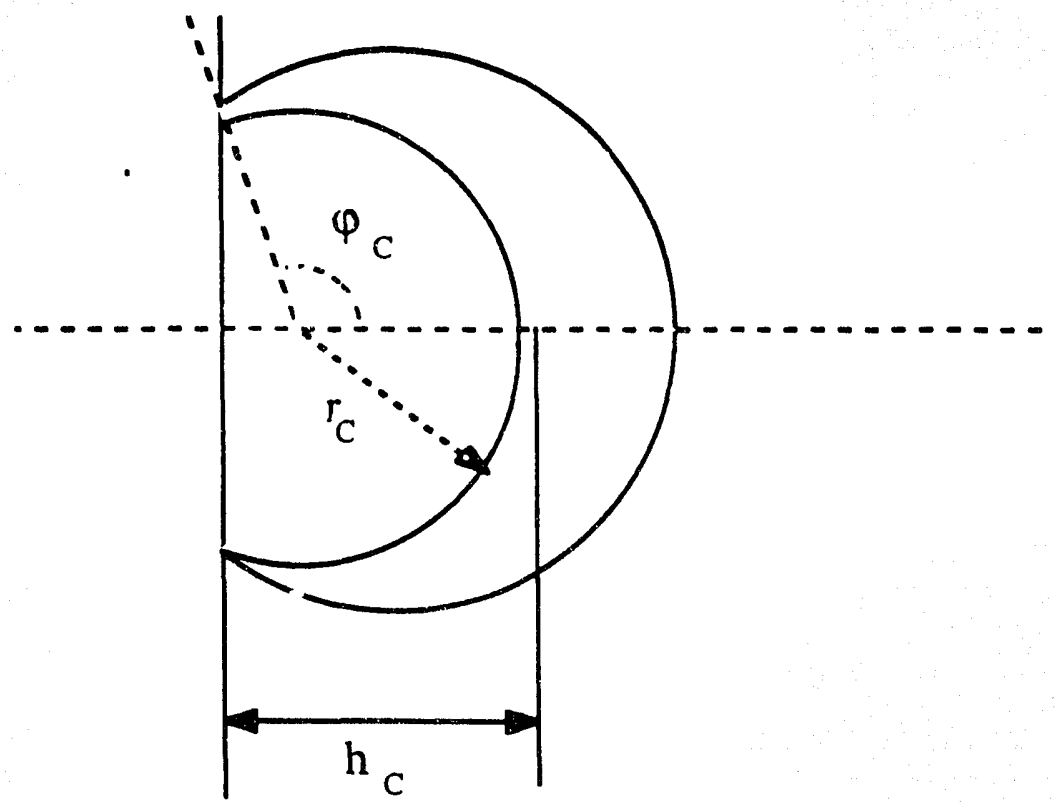

$$
\begin{aligned}
& r_{c}=\text { effective radius of the core } \\
& \phi_{c}=\text { angle of the core } \\
& h_{c}=\text { height of the core }
\end{aligned}
$$

Figure 2.7 Shape of a $3 / 4$ spheroid representing an ainflated alveolus. 
airway length $l(k)$ over the entire breathing-cycle period, and divided by the number of particles inspired:

$$
D E_{k}=\frac{\int_{0}^{t_{i}+t_{e}} \int_{0}^{l(k)} L(x, t) d x d t}{\int_{0}^{t_{i}} c(x=0, t) Q(x=0, t) d t},
$$

where $D E_{k}$ is the fraction of material deposited in region $k$, and $t_{i}, t_{e}$ are the periods of inspiration and expiration, repectively.

Supported by these theoretical calculations developed by Egan and Nixon, the Task Group on Hurnan Respiratory Tract Models for Radiological Protection of the ICRP (ICRP 1992 in press) has proposed a new model of regional deposition founded upon a semiempirical method of modeling particle deposition in the human respiratory tract as developed by Rudolf (Rudolf 1990). This model gives regional deposition fractions which are based upon deposition efficiencies that are directly fitted to experimental data by the use of least squares techniques (Lippmann 1977; Chan 1980). Moreover, the parameters of this fitting process involve regional deposition efficiencies as a function of particle size, airway dimensions, volumetric flow rates, or mean residence times. As a result, the discrepancy between experimental data and theoretical models used to predict thoracic deposition for particles in the size interval 1 to $5 \mu \mathrm{m}$ is generally overcome by this semi-empirical model. However, the structure of this model does not allow the calculation of deposition fractions $\mathrm{DE}_{\mathrm{k}}$ corresponding to specific airway generations of the bronchial tree, since the respiratory tract is lumped into three main compartments considered as particle deposition filters.

A new modality of ICRP Publication 62 methodology considered in this work, includes the concept of inhalability developed in the late 1970's by the American Conference of Govermental Industrial Hygienists. The main idea of this concept states that the only particles which could conceivable pose a potential risk to health by inhalation 
are those which are capable of entering the body during breathing of external air hitting the nose and the mouth in the working place. Therefore, experimental work carried out by Vincent (Vincent 1990) has estimated aspiration efficiencies for breathing patterns corresponding to rest, normal work, and hard work, averaged over all orientations of a head sampler with respect to the wind direction. Inhalability or intake efficiency is given by:

$$
I=1-0.5\left(1-\left[7.6 \times 10^{-4} d_{a C}^{2.8}+1\right]^{-1}\right)+1.0 \times 10^{-5} U^{2.75} \exp \left(0.055 d_{a e}\right),
$$

where $U$ is the average wind speed, and $d_{3 e}$ is the aerodynamic diameter

In modeling thermodynamic and aerodynamic deposition with the deposition data available, Rudolf has proposed a three-compartmental model of the respiratory tract. The methodology to assess the fraction of inhaled material that is deposited at the different regions of the respiratory tract follows essentially three steps. The first step consists of the calculation of regional deposition efficiencies $\eta_{R}$ by solving the system of simultaneous equations describing regional deposition fractions in the three compartments. At this point, regional deposition efficiencies based on experimental data or predicted theoretical data are plotted against deposition parameters such as diffusion length, $\sqrt{D_{\tau_{R}}}$, in the thermodynamic size interval $0.001 \mu \mathrm{m}$ to $.1 \mu \mathrm{m}$, or an inertial impaction parameter, $d_{a e}^{2} \mathrm{Q}$, in the aerodynamic size interval $0.1 \mu \mathrm{m}$ to $100 \mu \mathrm{m}$. For instance, if the fractional extrathoracical deposition efficiency is given by :

$$
D E_{E}=\left(1-\frac{V_{E}}{V_{t}}\right) \eta_{E}
$$

where $\mathrm{DE}_{\mathrm{E}}$ is the fractional deposition efficiency in extrathoracical region (theoretically or experimentally determined), $V_{E}$ is the extrathoracic volume, $V_{t}$ is the tidal volume, then

$$
\eta_{E}=D E_{E}\left(1-\frac{V_{E}}{V_{t}}\right)^{-1}
$$


is plotted against $\sqrt{D \tau_{R}}$ cr $d_{\mathrm{ae}}^{2} \mathrm{Q}$, where $\tau_{R}$ is the mean residence time at the region of interest, and $\mathrm{Q}$ is the volumetric flow rate.

The second step includes analytical approximations of $\eta_{R}$ estimated from exponential least squares fitting processes involving parameters such as diffusion length, inertial impaction parameters, mean residence times, and geometrical scaling parameters. Therefore, assuming that thermodynamic and aerodynamic efficiencies are competing to remove particles in regional deposition, Rudolf has proposed:

$$
\eta=\left(\eta_{t h}^{2}+\eta_{\mathrm{ae}}^{2}\right)^{1 / 2}
$$

where $\eta_{\mathrm{h}}$ is the deposition efficiency in the thermodynamical particle size, and $\eta_{\mathrm{ae}}$ is the deposition efficiency in the aerodynamical particle size.

Thus, the analytical approximation to evaluate the total deposition efficiencies as a function of the parameters mentioned above is carried out by the search of least-squares fitting functions with the next functional form:

$$
\begin{aligned}
& \eta_{\mathrm{E}-\mathrm{T}}=1-\left(\mathrm{aR}^{\mathrm{P}}+1\right)^{-1}, \\
& \eta_{\mathrm{T}-\mathrm{B}, \mathrm{P}-\mathrm{N}}=1-\exp \left(-\mathrm{aR}^{\mathrm{P}}\right),
\end{aligned}
$$

where $\eta_{E-T} \mathrm{~T}$ is the total deposition efficiency in extrathoracical region (nose and mouth), $\eta_{\mathrm{T}-\mathrm{B}}$ is the total deposition efficiency in tracheobronchiolar region (generations $0-16$ of bronchial tree), and $\eta_{\mathrm{P}-\mathrm{N}}$ is the total deposition efficiency in pulmonary or alveolar region (generations $17-24$ of the bronchial tree).

The parameters $a, R$, and $p$ are adjusted by the least squares technique and are empirically determined from experimental and theoretical calculations of fractional depositions (Rudolf 1990). Therefore, $R$ is searched as a function of the diffusion length, inertial impaction parameter, or mean residence time, and parameter, a, is searched as a function of mean residence time or geometrical scaling factors which consider the ratio of trachea diameter of adult reference man to the subject trachea diameter.

Table 2.2 shows the values of a, R, and p estimated by the ICRP Task Group on Human Respiratory Tract Models for Radiological Protection based on the calculations of 
Table 2.2 Regiona! deposition efficiency parameters reported by ICRP Publication 62.

\begin{tabular}{|cccc|}
\hline Efficiency & $\mathrm{a}$ & $\mathrm{R}$ & $\mathrm{p}$ \\
\hline$\eta_{\mathrm{n}, \mathrm{th}}$ & $-18 \mathrm{SFT}$ & $\mathrm{D}^{1 / 2 \mathrm{Q}}$ & $-1 / 8$ \\
$\eta_{\mathrm{n}, \mathrm{ae}}$ & $3 \times 10^{-4} \mathrm{SFT}^{3}$ & $\mathrm{~d}_{\mathrm{ae}}^{2} \mathrm{Q}$ & 1 \\
$\eta_{\mathrm{m}, \mathrm{th}}$ & $-9 \mathrm{SFT}$ & $\mathrm{D}^{1 / 2} \mathrm{Q}$ & $-1 / 8$ \\
$\eta_{\mathrm{m}, \mathrm{ae}}$ & $1.1 \times 10^{-4} \mathrm{SFT}^{2}$ & $\mathrm{~d}_{\mathrm{ae}}^{2} \mathrm{Q} \mathrm{V}^{-0.2}$ & 1.4 \\
$\eta_{\mathrm{B}, \mathrm{th}}$ & $16 \mathrm{SFT}$ & $\mathrm{D} \tau_{\mathrm{B}}$ & $1.15 / 2$ \\
$\eta_{\mathrm{B}, \mathrm{ae}}$ & $4 \times 10^{-6} \mathrm{SFB}^{2.8}$ & $\mathrm{~d}_{\mathrm{ae}}^{2} \mathrm{Q}$ & 1.15 \\
$\eta_{\mathrm{b}, \mathrm{th}}$ & $70+12 \mathrm{SFB}^{5}$ & $\mathrm{D} \tau_{\mathrm{b}}$ & $1.05 / 2$ \\
$\eta_{\mathrm{b}, \mathrm{ae}}$ & $0.009+0.165 \tau_{\mathrm{b}}^{1.5}$ & $\mathrm{~d}_{\mathrm{ac}} \tau_{\mathrm{b}}^{-0.25}$ & 1 \\
$\eta_{\mathrm{A}, \mathrm{th}}$ & $-450+1000 \mathrm{SFA}$ & $\mathrm{D}_{\mathrm{A}}$ & $2 / 3$ \\
$\eta_{\mathrm{A}, \mathrm{ae}}$ & $0.140 \mathrm{SFA}$ & $\mathrm{d}_{\mathrm{ae}}^{2} \tau_{\mathrm{A}}$ & $2 / 3$ \\
\hline
\end{tabular}

SFT = ratio of diameter of trachea in the reference man to that in the subject of interest.

$\mathrm{SFB}=$ ratio of the diameter of airway generation 9 in reference man to that in the subject of interest.

SFA $=$ ratio of the diameters of airways $16-25$ to those in the subject of interest. 
Rudolf, and they are used in combination with the model of Egan as part of the simulation computer code developed for the assessment of fractional deposition efficiencies at the different regions of the respiratory tract. The results and procedures concerned with these calculations will be discussed later.

Finally, the third step consists of the determination of regional deposition fractions extrapolated to all sizes in the thermodynamic and aerodynamic intervals by the use of the analytical expressions fitted to regional deposition efficiencies previously calculated and the estimation of thoracic, bronchiolar and alveolar volume fractions. At the same time, these volume fractions will depend on experimental measurements of tidal volumes and functional residual capacities corresponding to different ages and levels of activity. The expressions employed to calculate the total fraction of inhaled aerosol deposited at every region of the respiratory tract are then estimated from the following analytical representations:

$$
\begin{aligned}
& D E_{E-T}=\phi_{T} \eta_{E-T}, \\
& D E_{T-B}=\phi_{T}\left(1-\eta_{E-T}\right)\left[\eta_{B}+\eta_{b}-\eta_{b} \eta_{B}\right], \text { and } \\
& D E_{P-N}=\phi_{A}\left(1-\eta_{E-T}\right)\left(1-\eta_{B}\right)\left(1-\eta_{b}\right) \eta_{P-N},
\end{aligned}
$$

where

$$
\begin{aligned}
& \phi_{T}=\left[V_{B b_{0}}\left(1-\frac{V_{t}}{F R C}\right)+V_{A}\right] / V_{t}, \\
& \phi_{A}=\frac{V_{A}}{V_{t}}, \\
& V_{A}=V_{t}-V_{E \cdot T}-V_{B b_{0}}\left(1-\frac{V_{t}}{F R C}\right),
\end{aligned}
$$

and where $V_{B b o}$ is the volume of the dead space of the bronchial tree, $V_{E-T}$ is the volume of the extrathoracical region, $V_{\mathfrak{l}}$ is the tidal volume, $V_{A}$ is the alveolar volume, and FRC is the functional residual capacity. 
In summary, the calculated values of total regional efficiencies DE-T, DT-B, and DP-N which represent the fraction of inhaled material that is deposited or that is initially concentrated at the different regions of the respiratory system, are used in conjunction with the values of biological clearance representing the removal of inhaled material from the inner regions of the lung, to assess the amount of radioactive material that is concentrated at every region of the respiratory system, and to calculate the amount of material that is translocated to the blood both as a function of the time after exposure. Therefore, the values of DE-T, DT-B, and DP-N as a function of particle size, and level of physical activity, which when multiplied by the initial concentration of inhaled material define a single acuteintake function at every region of the respiratory system, are used as the initial conditions of the compartmental distribution described in the following chapter. 


\section{CHAPTER 3}

\section{CLEARANCE AND BIOKINETIC MODELING \\ OF INHALED AEROSOLS.}

\subsection{PULMONARY CLEARANCE MECHANISMS}

Assessment of the risk to pulmonary tissue due to the inhalation of radioactive aerosols depends on two facts. The first, is directly related with those mechanisms of deposition of inhaled material over the surfaces of pulmonary tissue, and the second is concerned with those biochernical and biomechanical processes that regulate the transport of inhaled material through the different parts of the respiratory system.

Respiratory clearance mechanisms are regionall!' different in terms of the specific pathways followed and in terms of the values of kinetic parameters of inhaled particles such as the biological retention half-life or the pulmonary dissolution rates. Figure 3.1 shows the principal clearance mechanisms at the three different regions of the respiratory system when inhaled material is deposited over the surfaces of pulmonary tissue. As shown in Fig. 3.1, mechanical removal of insoluble particles deposited in the nasal airways is carried out by the transport of muccciliary flow of the mucus blanket toward the pharynx. On the other hand, since the epithelium of anterior nasa! passages is not ciliated and the flow of mucus blanket is toward the exterior, the clearance of material deposited at this place is executed by sneezing, nose wiping, and blowing.

Concerning soluble material that is deposited in the nasal epithelia, it has been observed that part of this material is accessible to the epithelial cells before being removed from the surfaces of the nasal airways by mucociliary transport. Therefore, due to the vast distribution of vascular vessels around these places, the material that is diffused into the epithelial cells is also able to diffuse through the vascular membranes of the capillary 
Upper respiratory tract $\left[\begin{array}{l}\text { Mucociliary transport } \\ \text { Sneezing } \\ \text { Nose wipping and blowing } \\ \text { Dissolution (for soluble particles) }\end{array}\right.$

$\begin{array}{lll} & \text { Mucociliary transport } \\ \text { Tracheobronchial tree } & \text { Coughing } \\ & \text { Disslution (for soluble particles) }\end{array}$

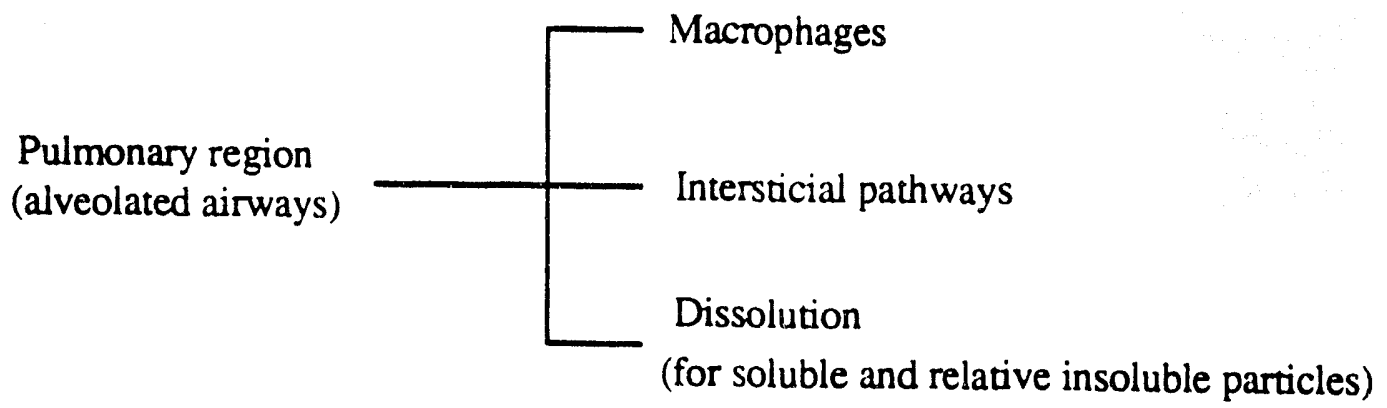

Figure 3.1 Respiratory tract clearance mechanisms. 
vessels surrounding the nasal passageways. Consequently, the material is able to reach the blood and can then be transported to the other organs of the body.

For oral inhalation, insoluble particles deposited in the oral passages are swallowed toward the gastrointestinal system (GIT). Soluble particles are quickly absorbed through the nasal epithelia after the deposition (Swift 1988).

In the tracheobronchial region which includes the first sixteenth generations of the bronchial tree, clearance processes are similar to those in the extrathorasical region. Here insoluble particles that are deposited on the surfaces of the bronchial airways are mainly removed by mucociliary transport. As a result of this process, the net flow of mucus blanket that is regulated by the action of the ciliated cells is brought about from the inner regions of the bronchial tree to the pharynx where the material is swallowed toward the GIT. On the other hand, soluble material that is deposited over the bronchial epithelia can be absorbed through the mucus blanket and can diffuse toward the blood. This process occurs almost instantaneously and will be discused in the next section.

Clearance of material from the pulmonary region occurs via absorptive processes such as dissolution and non-absorptive processes such as macrophage clearance. Figure 3.2 depicts a flow chart representation of non-absorptive clea $n$; pathways for particles deposited in the pulmonary region, of which almost all of them are generally regulated by macrophage cells. These cells of the immune system are able to move freely over the surfaces of pulmonary tissue and have the ability to engulf, transport, and detoxify the material that they contact either by random motion or with the aide of chemo-tactile factors. Although these cells represent about $3 \%$ of the total number of pulmonary cells (for healthy non-smokers), the number of macrophages will depend on the total number of inhaled particles that are deposited in pulmonary surfaces. Therefore, when few particles are deposited there is not an increment in the number of macrophages; however above certain level, the number of macrophages is increased proportionally to the number of 
particles that are deposited until some level of saturation is reached (Adamson and Bowden 1981; Brain 1971).

As a result, since the magnitude of this increment is related to the total number of deposited particles instead of its total weight, it may happen that the same mass of particles corresponding to the same substance will produce a different response if the particle size distribution differes in each case. Thus it is commonly accepted that the description of pulmonary dissolution models can be described in terms of the total surface area of the deposited particles instead of their total mass.

Particles that are trapped by macrophage cells can $t \cdot 9$ removed from the pulmonary region to other places following different pathways some of which have been represented in figure 3.2. The main pathway of transport is via mucociliary transport once that the macrophages have reached the mucus blanket of the terminal bronchioles. However, it is not well known how these cells travel from the inner surfaces of pulmonary alveoli to the distal bronchioles. Some hypotheses to explain this movement propose that macrophages travel along alveolar surfaces because of the surface tension gradients between alveoli and respiratory bronchioles. Other explanations include direct locomotion along the gradients produccd by chemo-tactile factors released at the time of material ingestion (Sorokin and Brain 1975), or the penetration through the alveolar walls to the interstitium where the macrophages can can reach the surface of respiratory ciliated airways.

Those macrophages that are not removed by the mucociliary transport process of the bronchial tree may actively migrate within the interstitium to a nearby lymphatic channel or, along with uningested particles, may be carried in the flow of interstitial fluid toward the lymphatic system. There is some evidence that uningested particles or macrophages in the interstitium may also cross the alveolar capillary endothelium, entering the blood directly. Once in the systemic circulation, transmigrated macrophages as well as free particles can travel to extrapulmonary organs. 


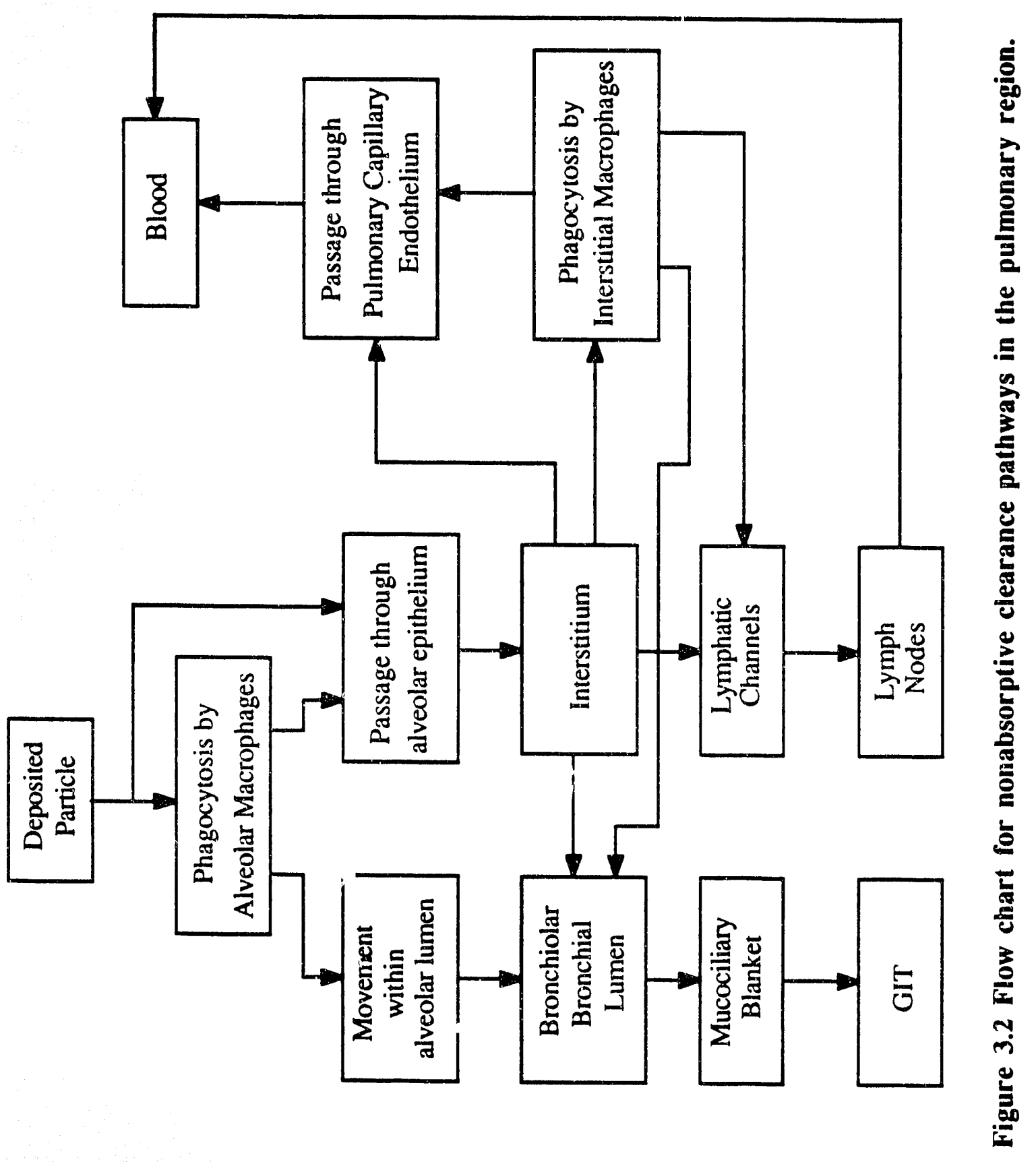


Pulmonary clearance by absorption involves dissolution and this is one of the main pathways to the blood even for those particles that are considered insoluble material (Mercer 1967). Particles that are dissolved in pulmonary fluids can diffuse through the epithelium and interstitium into the lymph or blood, and those translocated to and trapped in iterstitial sites may be absorbed there. Therefore, although the mechanisms that explain pulmonary dissolution across the alveolar walls are not well understood, it is weil known that these mechanisms are influenced by the surface to volume ratio of deposited particles and some other surface properties such as size, shape, porosity, and surface energy when the material of interest is relatively insoluble. Consequently, this material may have high dissolution rates and short dissolution half-times if the particle size is small. In addition, when the material is relatively soluble (such as metalic halide aerosols), transfer to the blood may depend on hydrolysis, adsorption and precipitacion in the alveoli (Kanapilly 1977).

\subsection{CLEARANCE KINETICS OF THE RESPIRATORY TRACT.}

\subsubsection{Extrathoracical Region.}

Biological clearance of inhaled particles in the upper respiratory tract ( larynx, oropharynx, posterior nasal passages, and anterior nasal passages) can not be easily modeled because it is influenced by too many factors (James 1989). However, it is possible to estimate the average time it takes for deposited particulate material to travel through the pathways of these regions.

Flow velocities of mucus blanket in the nasal airways can be studied after instiling or inhaling insoluble beads or powders (inert powders, $I^{131}$-labeled alburnin, $\mathrm{Tc}^{99} \mathrm{~m}_{\text {-labeled }}$

resin beads, and $\mathrm{Tc}^{99 \mathrm{~m}}$-labeled polystyrene particles). Most of these measurements have been focused on the posterior nasal aiways and therefore, particle clearance velocities due 
to mucocilary action have been reported between $0-24 \mathrm{~mm} \mathrm{~min}^{-1}$ with an average of $6 \mathrm{~mm}$ $\mathrm{min}^{-1}$. Because the posterior nasal area is about $6 \mathrm{~cm}$ long, the effective biological retention time for inhaled particles in this area is about $10 \mathrm{~min}$. (Stanley 1985).

On the other hand, those particles deposited in the non-ciliated regions (anterior nasal passages), are very slowly removed $\left(1-2 \mathrm{~mm} \mathrm{hr}^{-1}\right)$ by the mucus blanket that is pushed back by the action of distal ciliated cells. Biological retention times of about $12 \mathrm{~h}$. result in extremely inefficient particle removal. Consequently, the clearance of the material that is deposited in this region is executed by sneezing, nose wiping, and blowing with biological retention times of about $30 \mathrm{~min}$. (Morrow 1977). In modeling the extrathoracical region, this work assumes that the mechanical clearance of particles through the larynx, oropharynx, posterior nasal passages, and nasopharynx has a mean transit time of 10 minutes.

Absorption of deposited material in the nasal epithelia to the blood has not been studied enough. However, there is some evidence that in some of the nasal airways part of the deposited material remains in solution with the mucus blanket before it is absorbed through the nasal epithelia. Bailey has proposed for this process a dissolution rate with a biological half-life of 10 minutes, and ICRP Publication 30 assumes the value of $14.4 \mathrm{~min}$. for any class of inhaled material (D,W, or $\mathrm{Y})$. In the model of clearance proposed in this work, it is assumed that absorption of material to the blood is the same in all three regions of the respiratory tract, and it is described by semiempirical dissolution functions derived by the NCRP.

\subsubsection{Tracheobronchiolar Region.}

Biological clearance of inhaled material that is deposited in the tracheobronchial region due to the action of mucociliary transport is commonly studied by instillation or by the inhalation of radioactive particles and following the clearance of boli moving up the 
trachea by external counting using a gamma camera. Thus, effective particle clearance velocities can be estimated for individual bronchial airway generations using information on respiratory tract airway dimensions, inhaled particle deposition fractions for individual airways, and thoracic clearance measurements.

Indeed, mucus transport of material in the bronchial tree occurs at different rates of removal at the different generations of the bronchial tree, and the mucus velocity tends to be higher close to trachea than in the distal respiratory airways. Measurements of flow velocities for the clearance of insoluble material in trachea and main bronchi of normal humans have been reported between 4 and $20 \mathrm{~mm} \mathrm{~min}^{-1}$ depending on the experimental technique employed (fiberoptic bronchoscopy with teflon disc, fluoroscopy of instilled radiopaque teflon discs, or gamma camera imaging) (James 1988). Because the direct measurement of flow velocities at the distal respiratory airways is very complicated, mathernatical models of mucus transport at the different generations of the bronchial tree have been developed to assess mucus flow rates as a function of the flow velocity measured in trachea.

Consequently, Lee has shown that the mucus transport velocity at every generation of the bronchial tree diminishes inversely proportional to the total diameter of the respiratory airways in that generation, and it is given by the relationship (Lee 1979):

$$
v_{\alpha}=\frac{v_{0} d_{0}}{2^{\alpha} d_{\alpha}}
$$

where $v_{\alpha}$ is the mucous flow velocity at generation $\alpha$ of the bronchial tree, $v_{0}$ is the mucus flow velocity in trachea, $d_{0}$ is the diameter of trachea, and $d_{a}$ is the diameter of respiratory airways at generation $\alpha$ of the bronchial tree. 
On the other hand, total residence times for the removal of inhaled material from the bronchial tree have been shown as an index of the mucociliary function of mucus transport; therefore, it has been found that for healthy non-smokers , $90 \%$ of insoluble material that is deposited in the bronchial tree is removed with a biological half-life between 2.5 and 20 h. after exposure, depending on the subject and the size of the particle being removed. In either the case, Bailey has shown that $99 \%$ of deposited material is always removed in a period no longer than $48 \mathrm{~h}$. (Bailey 1985). As a result, average values of biological residence times corresponding to the removal of deposited material by mucociliary transport at the first 16 generations of the bronchial tree, have been reported by ICRP Publication 30 with an average of $5 \mathrm{~h}$. However, for dosimetry purposes and concerning with residence in the region for the worse cases, James and Birchall have assumed a more conservative value of $10 \mathrm{~h}$ (James 1989). A value of $10 \mathrm{~h}$. is also used in this work.

Absorption to the blood through the bronchial epitelia for transuranic elements such as ${ }^{239} \mathrm{PuO}_{2},{ }^{253} \mathrm{Es}\left(\mathrm{NO}_{3}\right)_{3},{ }^{252} \mathrm{Cf}\left(\mathrm{NO}_{3}\right)_{3},{ }^{249} \mathrm{Bk},{ }^{237} \mathrm{~Np},{ }^{241} \mathrm{AmO}_{2},{ }^{241} \mathrm{Am}\left(\mathrm{NO}_{3}\right)_{3}$, and ${ }^{244} \mathrm{Cm}\left(\mathrm{NO}_{3}\right)_{3}$ is usually classified into two groups, depending on the solubility or insolubility of the material. For example, ICRP Publication 48 ras reported that actinide clearance will occur in two components, with half-times of 20 to 30 days and 500 days, respectively. These two components are genera!ly obtained from fitting proceses resulting from experimental measurements of thoracic radioactivity and will be described by semiempirical exponential functions explained later in this section.

\subsubsection{Pulmonary Region}

Clearance of deposited particles in the alveolar region is carried out by very slow processes due to the absence of an effective mechanisms of biological removal. Deposited particles in this region may be retained in the alveolar interstitium for hundreds of days. Moreover, the determination of the rate of biological removal from the alveolar surfaces 
toward the bronchial tree surfaces and to the gastrointestinal tract have to be studied from the inhalation of highly insoluble material. Thus, these kinds of studies should be long enough to produce information about the slow dissolution and absorptive processes occurring in lung fluids, macrophages, and alveolar membranes.

Clearance from the pulmonary region is generally described by the use of semiempircal exponential functions in which each component represents a different mechanism or route of biological removal. For example, it has been estimated that the first phase, which is denoted "fast mechanical clearance ", has a half-life oscillating between 2 . and 6 weeks depending on the animal species analyzed. Therefore, this phase is generally associated with removal processes occurring from the alveolar region to the bronchial tree due to the action of macrophage cells. The second phase which is denoted "slow clearance", has a biological half-life between months and years and represents the dissolution processes associated with extracellular lining fluid, which is similar to blood plasma, and the intracellular dissolution in alveolar macrophages. Additionally, there is an intermediate phase with a biological half-life of months associated to the removal of particles to the alveolar interstitium due to the action of macrophage cells. In summary, the remotion of inert insoluble material for non-smokers has been observed consisting always of two phases: the first phase with a half-life measured in days and a second phase with a half-life measured in hundreds of days. As a result, ICRP Publication 30 has estimated a value of 1 day and 50 days for the first and second phases for soluble material class $\mathrm{W}$, respectively, and 50 days and 500 days for insoluble material class $Y$.

A summary of the information on particle clearance rates from the pulmonary region has been presented by Cuddihy (Cuddihy 1984 ). In this analysis, it has been shown that at early times the fractional clearance rate is approximately $6 \times 10^{-3} \mathrm{~d}^{-1}$, corresponding to a biological half-time of 115 days. By 200 days after inhalation exposure, this decreases to a value of approximately $1 \times 10^{-3} \mathrm{~d}^{-1}$, corresponding to a biological half-life of 700 days. In fact, rather than arbitrarily partitioning the pathways of clearance between mechanical and 
chemical abso-ption to the blood processes like in the model proposed by ICRP Publication 30 , clearance is treated as a competition between mechanical processes and absorption into the circulating blood, and is assumed to be nonlinear. Therefore the daily mechanical fractional clearance rate of particles from the pulmonary region can be represented by the following mathematical function:

$$
M(t)=0.005 \exp (-0.02 t)+0.001 \text {, }
$$

where $M(t)$ is given in $d^{-1}$, and $t$ is given in days.

In the experimental determination of mechanical transport of particles from the lung to the gastrointestinal tract, $M(t)$ is estimated by the use of relatively inert radiolabeled material with a dissolution rate in the lung as low as possible. Therefore, if $S(t)$ represents the rate of translocation of inhaled material from the lung to the blood, and $M(t)$ is the rate of mechanical transport of particles from the lung to the GIT, then $S(t)$ and $M(t)$ are the fractions of total lung content $\mathrm{L}(\mathrm{t})$, at time $\mathrm{t}$ cleared per day by each route, and can be determined from measurements of the amount of inhaled material retained in the lung and the amounts excreted per day in urine and feces. As a result, the following equations developed by Bailey (Bailey 1989) can be used for the calculation of $M(t)$ :

$$
\begin{aligned}
& U(t)=b_{u} S(t)+g_{u} M(t) \\
& F(t)=g_{f} M(t)+b_{f} S(t),
\end{aligned}
$$

where $U(t)$ and $F(t)$ are the urinary and faecal excretion rates i.e. the amounts excreted per day as a fraction of $L(t), b_{u}$ and $b_{f}$ are the fractions of inhaled material excreted in urine and feces following translocation of the material from lung to blood, and $\mathrm{g}_{\mathrm{u}}$ and $\mathrm{g}_{\mathrm{f}}$ are the fractions of inhaled material excreted in urine and feces after the material particles enter the GIT. Thus $M(t)$ can be writen as

$$
M(t)=\frac{b_{u} F(t)-b_{f} U(t)}{b_{u} g_{f}-b_{f} g_{u}}
$$


With regard to those processes of absorption of radioactive material through the alveolar membranes and interstitium, ICRP Publication 30 has proposed the following values for the biological half-lives of retention : 50 days for soluble material class $\mathrm{W}$, and 500 days for insoluble material class $Y$. However, despite that material with similar chemical form is absorbed to the blood, this process still depends on many other factors such as the surface area of the particles, previous thermal history, specific activity of the isotope, mass and crystalline structure of the particle, and the presence of some other factors affecting the solubility in vivo of the particles being dissolved in pulmonary fluids and macrophage cells.

In addition, the precise composition of actinides with a potential breathing risk in the nuclear power industry is not well understood, so the presence of complex chemical reactions (reversible and side reactions) in pulmonary fluids and macrophages, is another factor that affects the possibility that the actinide will reach the blood. For instance, inhaled particles of ${ }^{239} \mathrm{PuO}_{2}$ in the size interval of microns $(\mu \mathrm{m})$ are transported to the blood with half-lives of hundreds of days, and this is in a good agreement with the classification $Y$ proposed by ICRP Publication 30. However, the rates of dissolution and the transport to the blood will depend on the temperature of formation and the presence of other elements. It has been observed that $238 \mathrm{PuO}_{2}$ within the same size interval $(\mu \mathrm{m})$ is transported to the blood ten times faster than particles of ${ }^{239} \mathrm{PuO}_{2}$. This may be due to a specific activity dependence in the fragmentation of the $\mathrm{PuO}_{2}$ particles that results in a more rapid dissolution or direct translocation of very small particles (Diel 1983). Consequently, these particles should be classified as material class W.

Inhaled actinides such as ${ }^{239} \mathrm{PuO}_{2}$ in the nanometer size interval, as well as soluble compounds of plutonium, einstenium, and californium, are transported to the blood with half-lives of several decades which is in agreement with the classification W of ICRP Publication 30. However, the dissolution and absorption rates will depend on the mass of inhaled material, and the competitive processes of hydrolysis, polymerization, and 
complexation of reactions in the pulmonary fluids. Therefore, it is essential that when pulmonary clearance due to mechanical or absorptive processes are considered describing the kinetics of actinide compounds, all of the available information regarding on solubilities measured in vivo should be employed. The broad spectrum of inhalation classes defined in ICRP Publication 30 was designed only for purposes of radiological protection rather than for predicting the metabolism of specific inhaled actinides in specific individuals.

Mercer (Mercer 1967) has suggested that particle dissolution is one of the major determinants controlling the rate of absorption for material retained in the respiratory tract, and that the dissolution rate is proportional to the particle surface area. Moreover, in order to comply with the need of more specific information, a semiempirical model of dissolution has been designed for the assessment of solubility rate functions representing the translocation of deposited material to the blood (Guilmette 1989). In this model, thoracic radioactivity $L(t)$ is measured as a function of time after inhalation exposure. The subsequent decrease in thoracic radioactivity may result from: (1) clearance of material up the conducting airways to the GIT, (2) absorption into the blood circulation, and (3) radioactive decay. After correcting for radioactive decay, mathematical functions are fitted to the measurements of thoracic radioactivity and the derivatives of the functions are obtained representing the change of thoracic :adioactivity per unit time after inhalation exposure. Thus, the rate at which radioactive material goes into blood is divided by the total lung content to asses the overail daily fractional clearance rate, $\mathrm{FC}(\mathrm{t})$, that can be calculated as:

$$
F C(t)=\frac{d L(t)}{d t} / L(t)
$$

Thus for modeling purposes, the total daily fractional clearance rate for the thorax is composed of clearance rates to the gastrointestinal tract $M(t)$ as given above, and to the blood circulation $S(t)$ : 


$$
F C(t)=M(t)+S(t)
$$

where $S(t)$ is a solubility rate function experimentally obtained from the measurements of lung retention $L(t)$.

When lung clearance is measured in human subjects, the ideal technique is to measure the activity changes $\mathrm{c}$ ived from translocation of uniform radioactive particles. It has been mentioned before that the counter configurations depend on several large scintillation detectors or a gamma camera. In either case, lung field measurements are either designed to provide a total lung content, with internal redistribution effects minimized, or information about several regions of interest. Often a three-zone pattern is used, representing the central hilar region, a mid zone region and a peripheral zone, with the later being a "peel" of the lung perimeter.

Therefore, with the use of these experimental measurements and using equation (3.2.3.2), the solubility rate function can be calculated from the following equation:

$$
S(t)=\frac{g_{f} U(t)-g_{u} F(t)}{b_{u} g_{f}-b_{f} g_{u}}
$$

where all the parameters of this equation are the same as in Eq. (3.2.3.2).

Moreover, during the use of the biokinetic model proposed in this work, it is assumed that the removal of deposited material is represented by the competition between mechanical clearance $M(t)$ to the GIT, and translocation of material to the blood $S(t)$. This is in direct contrast to ICRP Publication 30 which has described mechanical clearance and absorption to the blood circulation as two completely independent processes represented in a compartmental distribution with constant transfer rates.

In this model, translocation to the blood is assumed to be mainly governed by particle dissolution and it is defined as a two-stage process in which each stage is potentially timedependent. These processes include the dissociation of material from inhaled particles, 
followed by the subsequent absorption of the dissociated material, or the absorption of that material originally deposited in a soluble form into blood. For relative insoluble material, dissolution is a slow process and Kreyling has shown that intracellular dissolution in alveolar macrophages can be superior when compared to the dissolution in the blood serum and similar aqueous solvents (Kreyling 1986). Thus, for long term clearance the dissociation is believed to occur primarily in the phagolysosomes of pulmonary macrophages. In addition, some dissociated material may not be absorbed into the blood immediately, as a result of binding to respiratory tract components. Therefore, a semiempirical approach for the absorption rate of material from the lung to blood can be written as:

$$
S(t)=A_{1} e^{-\lambda_{1} t}+A_{2} e^{-\lambda_{2} t}+A_{3},
$$

where the values of $A_{i}$ are constants determined from the goodness-of-fit of $S(t)$ which require a minimal number of terms depending on the material analyzed, and the $\lambda_{i}$ 's are the respective biological removal constants for rapid uptake to the blood, and slow "bounded to tissue" absorbed material to the blood.

Finally, there is also a theoretical approach to the values of $S(t)$ based on the dissolution model developed by Mercer. This model has been employed by Guilmette and Bailey to assess solubility rate functions based on the surface area of the aerosol particles deposited (Guilmette 1989). In this model, is assumed that (1) all inhaled particles are of the same initial size (i.e. the aerosol inhaled is monodisperse), (2) all the particles are dissolved at the same rate, (3) a fraction $q$ of dissolved particles remains infinitely in the lung while the rest is absorbed immediately to blood, and (4) the total number of particles remains constant in the lung. If mechanical clearance is neglected, then the solubility rate function can be written as: 


$$
S(t)=\frac{\frac{(1-q) k \alpha_{s}}{\sqrt[3]{\left(\alpha_{v} \rho\right)^{2}} \cdot \sqrt[3]{\left(m_{0}\right)}} \cdot\left\{1-\frac{(1-q) k \alpha_{s} t}{\sqrt[3]{\left(\alpha_{v} \rho\right)^{2}} \cdot \sqrt[3]{m_{0}}}\right\}^{2}}{q+(1-q) \cdot\left\{1-\frac{(1-q) k \alpha_{s} t}{\sqrt[3]{\left(\alpha_{v} \rho\right)^{2}} \cdot \sqrt[3]{m_{0}}}\right\}^{3}},
$$

where $\alpha_{s}$ is the surface shape factor, $\alpha_{v}$ is the volume shape factor, $\rho$ is the particle density, $\mathrm{k}$ is the surface area dissolution rate constant $\left[\mathrm{gm} / \mathrm{cm}^{2} /\right.$ day], and $\mathrm{m}_{0}$ is the initial mass of the particle.

\subsection{COMPARTMENTAL DISTRIBUTION OF THE RESPIRATORY SYSTEM.}

\subsubsection{A Brief Somparison of the New Lung Model and the Model of ICRP Publication} 30.

As a result of new advances in our understanding of lung morphology, the deposition and clearance of inhaled aerosols, and also the need to improve dose estimates for radiation protection purposes, the ICRP established a Task Group on Human Respiratory Tract Models for Radiologicakl Protection. This task group was assigned to develop a new lung model for inhalation exposures of radioactive material. The proposed model represents the respiratory system by a three generic compartmental distribution.

In contrast to the eleven compartment model described in ICRP Publication 30, the new respiratory system model simplifies the handling of experimental retention and excretion data. However, this simpler model requires the use of time-varying functions for the transfer of material between the different compartments of the respiratory system. As a consequence, a much more complicated set of differential equations whose solution represent the amount of radioactive material concentrated in each region of the respiratory tract, has to be solved to assess the values of cumulated activity $U_{s}$. These values are 
essential for the calculation of the committed dose equivalent, $\mathrm{H}_{50, \mathrm{~T}}$, in every region of the respiratory system.

So far, non-linear transport processes involving mechanical clearance, and the dissolution and absorption of retained material, are simplified and replaced by another first order compartmental distribution with constant transfer rates (ICRP 62 in press). This is accomplished in such a way that the resulting linear chain of compartments which represents the slow and fast clearance processes of the respiratory system can be modeled by linear biokinetic computer codes.

However, this is not the best approximation to the non-linear chemical reactions and dissolution processes occurring in lung fluids and alveolar macrophages, which, at the same time, result in time-varying transport parameters. Therefore, the biokinetic model of lung clearance used in this work, includes the use of a linear time-varying system of compartments to represent the clearance of material from the three main physiological regions of the respiratory system.

A mathematical representation of the compartmental model of clearance proposed here is shown in Fig. 3.3. This model, has three main regions of interest: an extrathoracic region and two thoracic regions, one with fast clearance and one with slow clearance. The extrathoracic region (E-T) includes and represents the clearance and deposition of material in organs such as the nose, mouth, pharynx and larynx. The two thoracic regions, the tracheobronchial region (T-B) and the parenchymal nodular region $(\mathrm{P}-\mathrm{N})$, represent to all the inner organs of the respiratory system. In the tracheobronchial region (T-B), which includes airway generations $0-16$, radioactive material is deposited by physical processes such as impaction, sedimentation, and diffusion. At the same time, radioactive material is absorbed to the blood and cleared to the gastrointestinal tract by processes such as solubility and mechanical clearance described above. These processes are mathematically represented by exponential time-varying functions which are illustrated as $S(t)$ and $G_{f}(t)$ in Fig. 3.3. In the parenchymai nodular region (P-N) which represents airways 17-25 


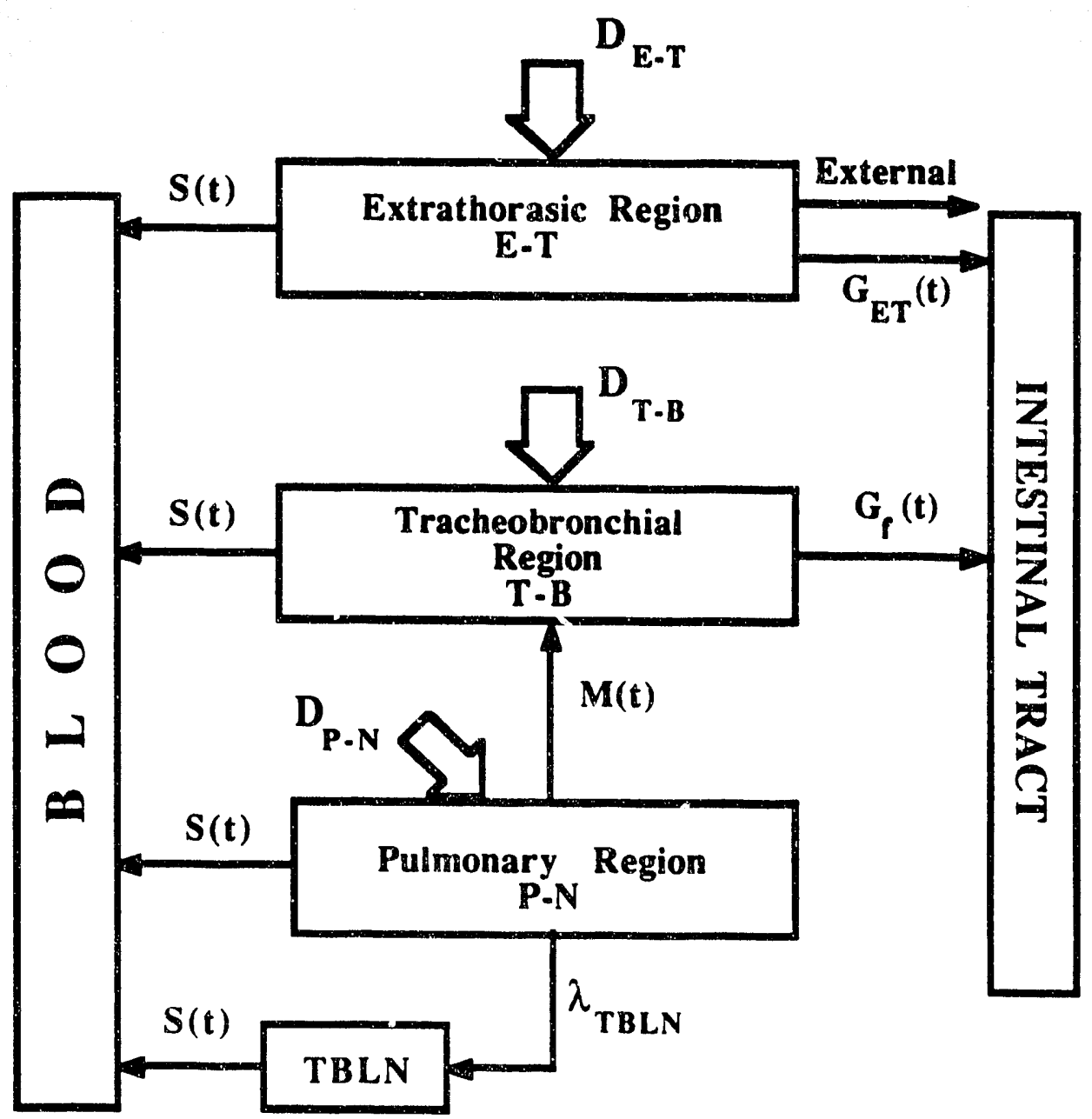

Figure 3.3 Compartmental Distribution of the Proposed Model for t $e$ Respiratory Tract. 


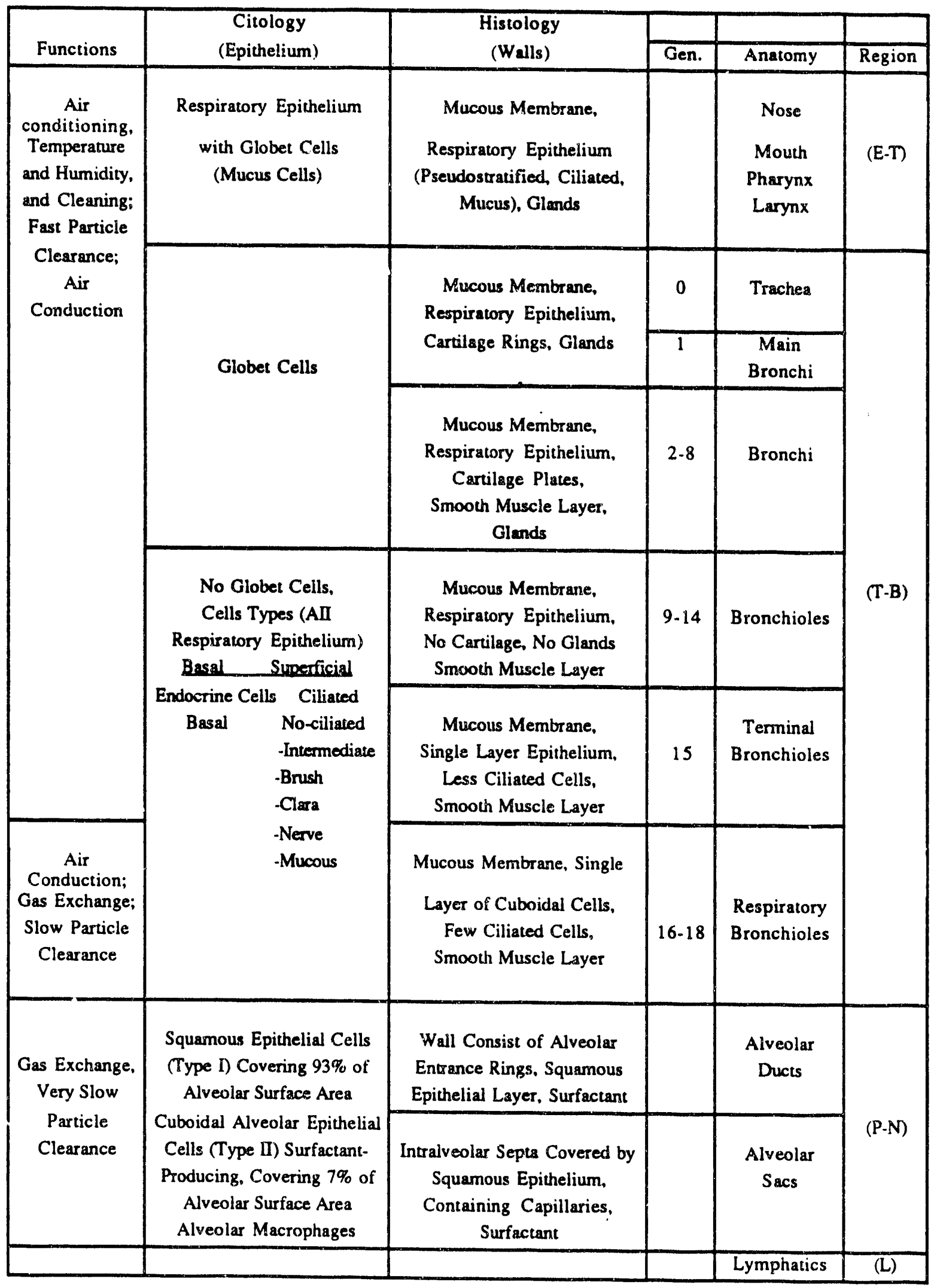

Figure 3.4 Subdivision of the respiratory system. 
(bronchioles, alveolar sacs, alveolar ducts, and thoracic lymph nodes), radioactive material is slowly cleared by mechanical and solubilization processes which compite with one another, both mechanical nonabsorptive processes (controlled by alveolar macrophages) and solubilization mechanisms involve dissolution as described above. Once again, these processes are simulated by the use of exponential time-varying functions that are represented in Fig. 3.3 as $M(t)$ and $S(t)$.

An additional compartment representing the lymph nodes is considered for the permanent residence of insoluble material in the alveolar interstitium and lymph nodes. Figure 3.4 summarizes the main physiological and anatomic characteristics of the human respiratory system that were considered for the design of the mathematical subdivision shown in Fig. 3.3. The subdivision of the respiratory system into three main physiological regions is just a mathematical simplification de igned only with the purpose of modeling, and ncludes all the complex processes and structures that integrate the respiratory system. Finally, Table 3.1 gives a comparative description of the main characteristics of the old methodology followed by ICRP Publication 30 and the model of simulation employed in this work.

\subsubsection{Mathematical considerations.}

The mathematical formalism that is employed to assess the amount of radioactive material that is concentrated at every region of the respiratury tract, is based on the analytic theory of linear compartmental systems. At the same time, this theory is supported on the theory of simultaneous linear differential equations. In such a system, if it is assumed that the volume of material concentrated at every compartment is uniformly distributed, and the total mass of the system is conserved. An arbitrary distribution of n-compartments interconnected with the transfer of material at rates $k_{i j}$ between compartments $i$ and $j$ is shown below: 


\section{Table 3.1 Comparison of two models of the respiratory system}

ICRP 30 LUNG MODEL

Four anatomical regions (N-P,T-B,P,L)

modeled by eleven compartments.

Linear chain of compartments with

constant transfer rates described by linear

processes.

Deposition considers particle size of aerosols between 0.1 to $20 \mu \mathrm{m}$ with a unimodal logncrmal distribution based on a 1 um AMAD.

Considers respiratory rate with respect to the Reference Man of ICRP Pbublication 23.

It makes a classification of chemical compounds according to its tendency to be retained in the respiratory tissues three classes considered: $D, W, Y$.

Clearance rates are constants according to the class of material.

It considers a total risk weighting factor of 0.12 for the whole respiratory system.

\section{THIS LUNG MODEL}

Three anatomical regions (E-T,T-B,P-N)

modeled by 3 compartments.

Linear chain of compartments with time-varying transfer rates described by non-linear processes.

Deposition parameters are based on morphometric models of the lung and experimental data. It includes deposition of very small particles between 0.001 and $100 \mu \mathrm{m}$.

Considers new flow rates, and respiration rates as a function of age and level of physical activity.

For compounds for which reliable human data exist the model uses observed rates of absorption to the blood. For other compounds, the current $D, W, Y$ classification is used.

Clearance competes between mechanical and absorption processes. These processes are represented by time-varying functions.

Weighting factors to assess, $\mathrm{H}_{50, \mathrm{~T}}$ are in the proportions $1 / 6: 2 / 3: 1 / 6$ for E-T,T-B, P-N with respect to a total risk weighting factor of 0.12 . 


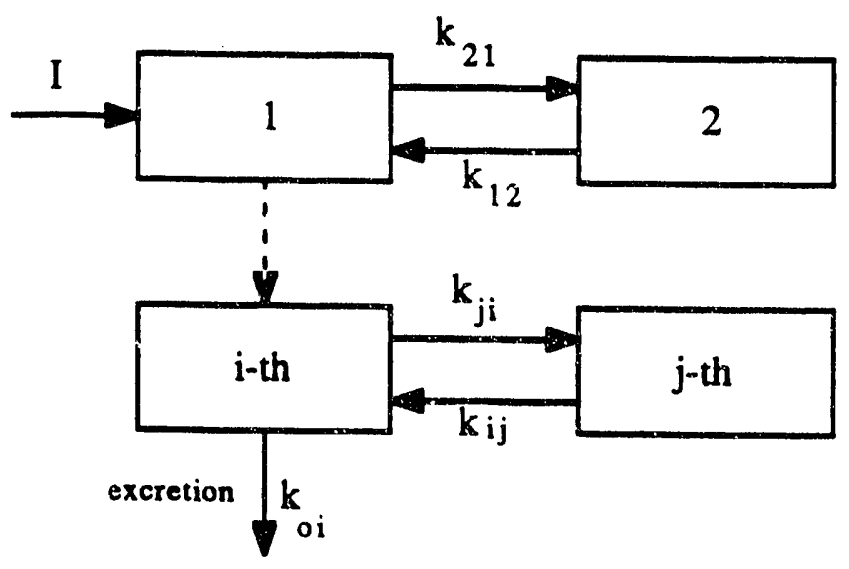

The mass balance equation that describes the dynamical behavior of the amount of material concentrated at the i-th compartment as a function of time is given by the following equation:

$$
\frac{d\left(V_{i} C_{i}\right)}{d t}=-\sum k_{j i} C_{i}+\sum k_{i j} C_{j}+I_{i}-k_{o i} C_{i}
$$

where $V_{i}$ is the volume of material in the $i$-th compartment, $C_{i}$ is the concentration of material in the $\mathrm{i}$-th compartment $\left(\mathrm{Bq} \mathrm{cm}^{-3}\right), \mathrm{k}_{\mathrm{ij}}$ is the rate of material flow from the $\mathrm{i}$-th compartment to the $j$-th compartment $\left(\mathrm{cm}^{3} \mathrm{~min}^{-1}\right)$, and $I_{i}$ is an external input function to the $\mathrm{i}$-th compartment $\left(\mathrm{Bq} \mathrm{min}^{-1}\right)$.

If we define $\mathrm{q}_{\mathrm{i}}=\mathrm{V}_{\mathrm{i}} \mathrm{C}_{\mathrm{i}}$ and $\mathrm{f}_{\mathrm{ji}}=\mathrm{k}_{\mathrm{ji}} / \mathrm{V}_{\mathrm{i}}$, then the matrix equation that represents the dynamical behavior of all the mass balance equations at every compartment is written as:

$$
\frac{\mathrm{d} \overrightarrow{\mathrm{q}}}{\mathrm{dt}}=\overrightarrow{\mathrm{F}} \cdot \overrightarrow{\mathrm{q}}+\overrightarrow{\mathrm{I}}
$$

where $\vec{q}(t)=\left(q_{1}, q_{2}, \cdots, q_{n}\right)$ is a vector of solutions whose components are the amount of radioactive material at every compartment,

$\vec{F}=\left[\begin{array}{ccc}\mathrm{f}_{11} & \cdots & \mathrm{f}_{1 \mathrm{n}} \\ \vdots & \ddots & \vdots \\ \mathrm{f}_{\mathrm{n} 1} & \cdots & \mathrm{f}_{\mathrm{nn}}\end{array}\right]$ is the compartmental matrix of the system, and 
$\vec{I}(t)$ is an external input function to the system.

The use of modern control theory (Jacquez 1988) applied to Eq. (3.3.2.2), allows one to rewrite this matrix equation in terms of the input redistribution matrix $\mathbf{B}$ which indicates how the multiple inputs $I_{i}(t)$ are distributed throughout the system. Therefore, if the components of the external input function vector are written in terms of the elements of B as

$$
I_{i}(t)=\sum_{k=1}^{r} b_{i k} u_{k}(t),
$$

then the matrix equation representing Eq. (3.3.2.2) is described by the following equation:

$$
\begin{aligned}
& \frac{d \vec{q}}{d t}=\vec{F} \cdot \vec{q}+B \vec{u} \\
& \text { with } \vec{q}(0)=\vec{q}_{o} .
\end{aligned}
$$

Moreover, if the elements of the compartmental matrix $\mathbf{F}$ are the biokinetic constant transfer rates as in the lung model of ICRP Publication 30, then the solution of Eq. (3.3.2.3) is given by the following convolution integral:

$$
\overrightarrow{\mathrm{q}}(\mathrm{t})=\exp [\overrightarrow{\mathrm{F}} \mathrm{t}] \cdot \overrightarrow{\mathrm{q}}(0)+\int_{0}^{t} \exp [\overrightarrow{\mathrm{F}}(\mathrm{t}-\tau)] \mathrm{B} \overrightarrow{\mathrm{u}}(\tau) \mathrm{d} \tau .
$$

On the other hand, if the elements of the compartmental matrix $\mathbf{F}$ are piece-wise continous functions of $t$ in an interval $t_{0} \leq t \leq t_{1}$, then the solution is expressed in terms of the state-transition matrix for the time-varying case $\Phi\left(t, t_{0}\right)$. In fact, for the compartmental distribution shown in Fig. 3.3, the resulting compartmental matrix $F$ has elements in the diagonal given by the time-varying transfer rates $M(t), S(t)$, and $G_{f}(t)$; thus, the set of mass balance equations of the resulting time-varying system are given by the following matrix equation: 


$$
\begin{aligned}
& \frac{d \vec{q}}{d t}=\vec{F}(t) \cdot \vec{q}+\vec{B}(t) \vec{u} \\
& \text { with } \vec{q}\left(t_{o}\right)=\vec{q}_{o},
\end{aligned}
$$

where $\overrightarrow{\mathrm{q}}$ is a $\mathrm{n}$-dimensional vector, $\overrightarrow{\mathrm{u}}$ is a $\mathrm{r}$-dimensional vector, $\overrightarrow{\mathrm{F}}(\mathrm{t})$ is a $\mathrm{n} \times \mathrm{n}$ matrix whose elements are piecewise continous functions, $\overrightarrow{\mathrm{B}}(\mathrm{t})$ is a $\mathrm{n} \times \mathrm{r}$ matrix whose elements are piecewise continous functions, and $\vec{q}\left(t_{0}\right)$ is a n-dimentional vector of initial conditions.

Therefore, the solution of the linear time-varying system described by Eq. (3.3.2.5) is given by the following equation:

$$
\overrightarrow{\mathrm{q}}(\mathrm{t})=\Phi\left(\mathrm{t}, \mathrm{t}_{0}\right) \overrightarrow{\mathrm{q}}\left(\mathrm{t}_{0}\right)+\int_{0}^{\mathrm{t}} \Phi(\mathrm{t}, \tau) \overrightarrow{\mathrm{B}}(\tau) \overrightarrow{\mathrm{u}}(\tau) \mathrm{d} \tau
$$

where $\Phi\left(t, t_{0}\right)=\Pi+\int_{b}^{t} \vec{F}(\tau) d \tau+\int_{b}^{t} \vec{F}\left(\tau_{1}\right)\left\{\int_{b}^{\tau} \vec{F}\left(\tau_{2}\right) d \tau_{2}\right) d \tau_{1}+\cdots$, , and $\Pi$ is the identity matrix.

If the compartmental distribution shown in Fig. 3.3 is considered to represent the clearance of inhaled aerosols from the respiratory system, then the set of mass balance equations resulting from the time-varying system describing the biokinetics of the amount of radioactive materiai that is concentrated at every region of the respiratory tract is given by the following system of simultaneous differential equations:

$$
\begin{aligned}
& \frac{d q_{E-T}(t)}{d t}=\dot{I}(t) D_{E-T}-\left[S(t)+G_{E-T}(t)+\lambda_{R}\right] q_{E-T}(t) \\
& \frac{d q_{T-B}(t)}{d t}=\dot{I}(t) D_{T-B}-\left[S(t)+G_{f}(t)+\lambda_{R}\right] q_{T-B}(t)+M(t) q_{P-N}(t) \\
& \frac{d q_{P-N}(t)}{d t}=\dot{I}(t) D_{P-N}-\left[S(t)+M(t)+\lambda_{T B L N}+\lambda_{R}\right] q_{P-N}(t)
\end{aligned}
$$




$$
\begin{aligned}
& \frac{d q_{T B L N}(t)}{d t}=\lambda_{\text {TBLN }} q_{P \cdot N}(t)-\left[S(t)+\lambda_{R}\right] q_{T B L N}(t) \\
& \frac{d q_{b l o o d}(t)}{d t}=S(t)\left[q_{E-T}+q_{T \cdot B}+q_{P-N}+q_{T B L N}\right] \\
& \frac{d q_{G r T}(t)}{d t}=G_{E-T}(t) q_{E-T}(t)+G_{R}(t) q_{T-B}(t),
\end{aligned}
$$

where $\mathrm{q}_{E-T}(\mathrm{t}), \mathrm{qT}_{\mathrm{B}} \mathrm{(t}(\mathrm{t})$, and $\mathrm{q}_{\mathrm{P} \cdot \mathrm{N}}(\mathrm{t})$ are the activities of an inhaled radionuclide at the different

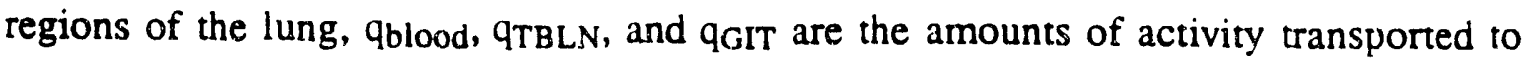
blood, lymph nodes and GIT.

$\dot{I}(t)$ is the rate of inhalation of activity of the radionuclide, $S(t)=\sum_{i=1}^{u} A_{i} e^{-\lambda_{4} t}$ is a solubility function calculated from experimental fitting processes with $A_{i}$ and $\lambda_{i}$ being constants, DE-T , DT-B , DP-N are the total deposition fractions of inhaled material in the different regions of the respiratory tract, $M(t)$ is the slow mechanical clearance rate function (which has the same mathematical form as $S(t)), G_{E-T}(t), G_{f}(t)$ are the extrathoracic and bronchial fast clearance rates, and $\lambda_{R}$ is the radioactive decay constant of the inhaled radionuclide.

The compartmental matrix $F(t)$ associated with the system of differential equations (3.3.2.7) contains all the biokinetic information of the system and is giving in the following array:

$$
\vec{F}(t)=\left[\begin{array}{cccccc}
-\left(S(t)+G_{\left.E-T(t)+\lambda_{R}\right)}\right. & 0 & 0 & 0 & 0 & 0 \\
0 & -\left[S(t)+G_{f}(t)+\lambda_{R}\right] & M(t) & 0 & 0 & 0 \\
0 & 0 & -\left\{S(t)+M(t)+\lambda_{T B L N}+\lambda_{R} \mid\right. & 0 & 0 & 0 \\
0 & 0 & \lambda_{T B L N} & -\left[S(t)+\lambda_{R} i\right. & 0 & 0 \\
S(t) & S(t) & S(t) & S(t) & 0 & 0 \\
G_{E-T(t)} & G_{f}(t) & 0 & 0 & 1 & 0
\end{array}\right]
$$


The application of Eq. (3.3.2.6) allows the knowledge of the retained activities $q(t)$ associated to every region of the respiratory system, which when it is integrated over the time of exposure, results in the values of cumulated activity.

Finally, for the modeling purposes of this work, the input functions $I(t)$ to the system, given by the multiplication of the total regional deposition fraction and the initial rate of activity inhalation, are considered single acute-intakes to compare the calculated values of $U_{s}$ with the model of ICRP Publication 30. 


\section{CHAPTER 4}

\section{RESULTS AND DISCUSION.}

\subsection{A SEMIEMPIRICAL CODE OF DEPOSITION AND LUNG BIOKINETICS.}

A FORTRAN 77 computer simulation code for the assessment of activity concentrations in the respiratory tract was developed based on the calculations of regional deposition efficiencies proposed by the deposition model of Rudolf (Rudolf 1990). The program BIODEP (Biokinetic Deposition) was written in a modular form and runs on a VAX Mainframe computer system. The modular form of this program was intended to simplify the handling of any new information concerning measurements of the geometry of the bronchial tree and the acinar region (in terms of age and gender), and any kind of physical processes governing the deposition of inhaled particles in the respiratory system. In addition, the modular structure of this program allows an easy interconnection of the computed regional efficiencies of inhaled aerosols in the respiratory tract with any kind of compartmental distribution employed to describe the kinetics of clearance of material from the inner regions of the lung.

Figure 4.1 depicts a flow chart of the main structure of the computer simulation code BIODEP which has been designed in a friendly interactive mode such that the user is able to run the code without a full comprehension of specific information related to the physical processes of deposition. However, in the determination of the time dependent-activity concentrations of inhaled radioactive material through the different regions of the respiratory tract, a precise acquaintance of the compartmental equations and transfer rates describing the biokinetics of the specific radionuclide must be known. The following parameters have to be specified in the input: 


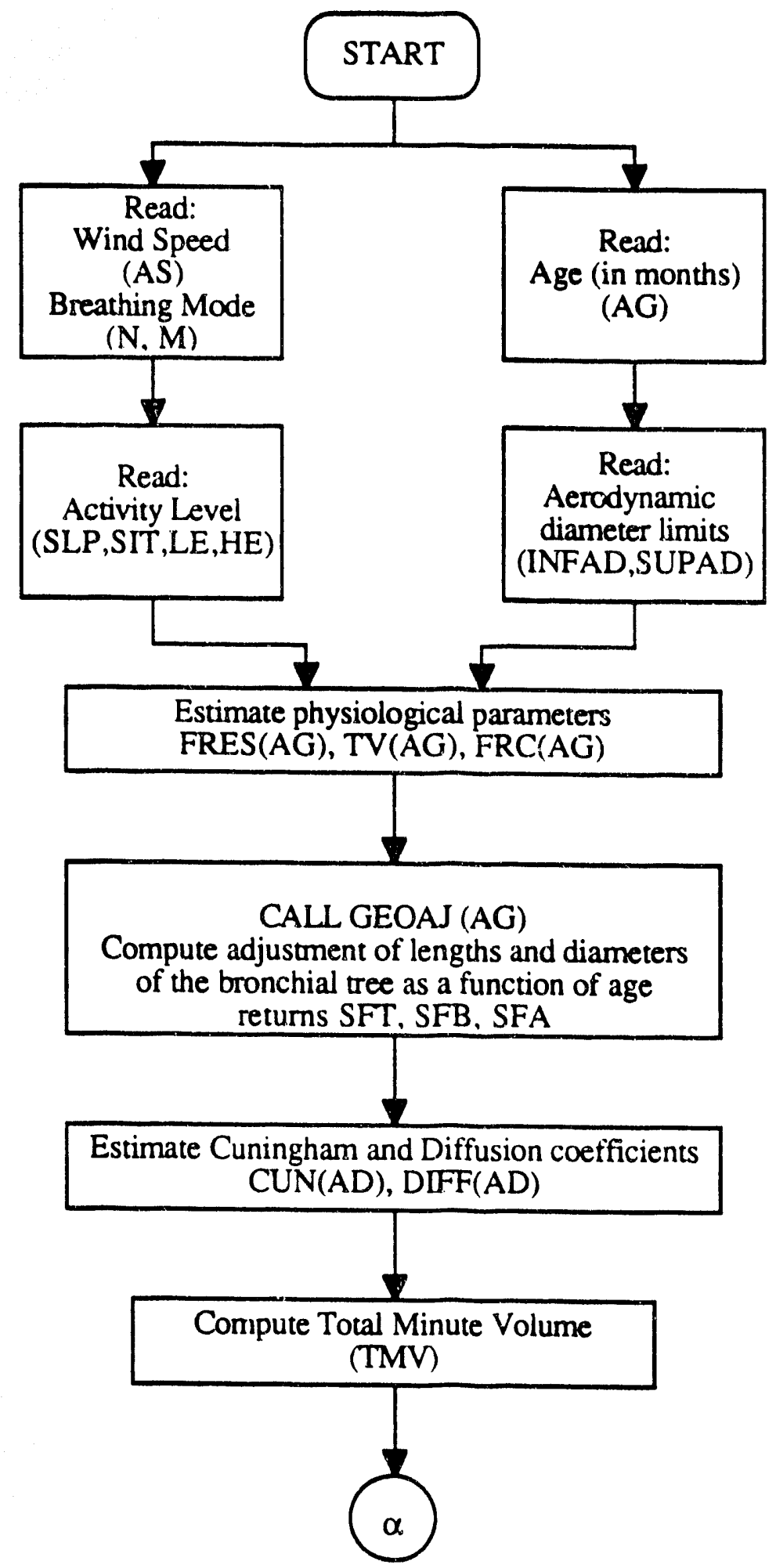

Figure 4.1 Flow chart of the model code employed to simulate the deposition of inhaled radiactive aerosols at the different regions of the respiratory tract. 


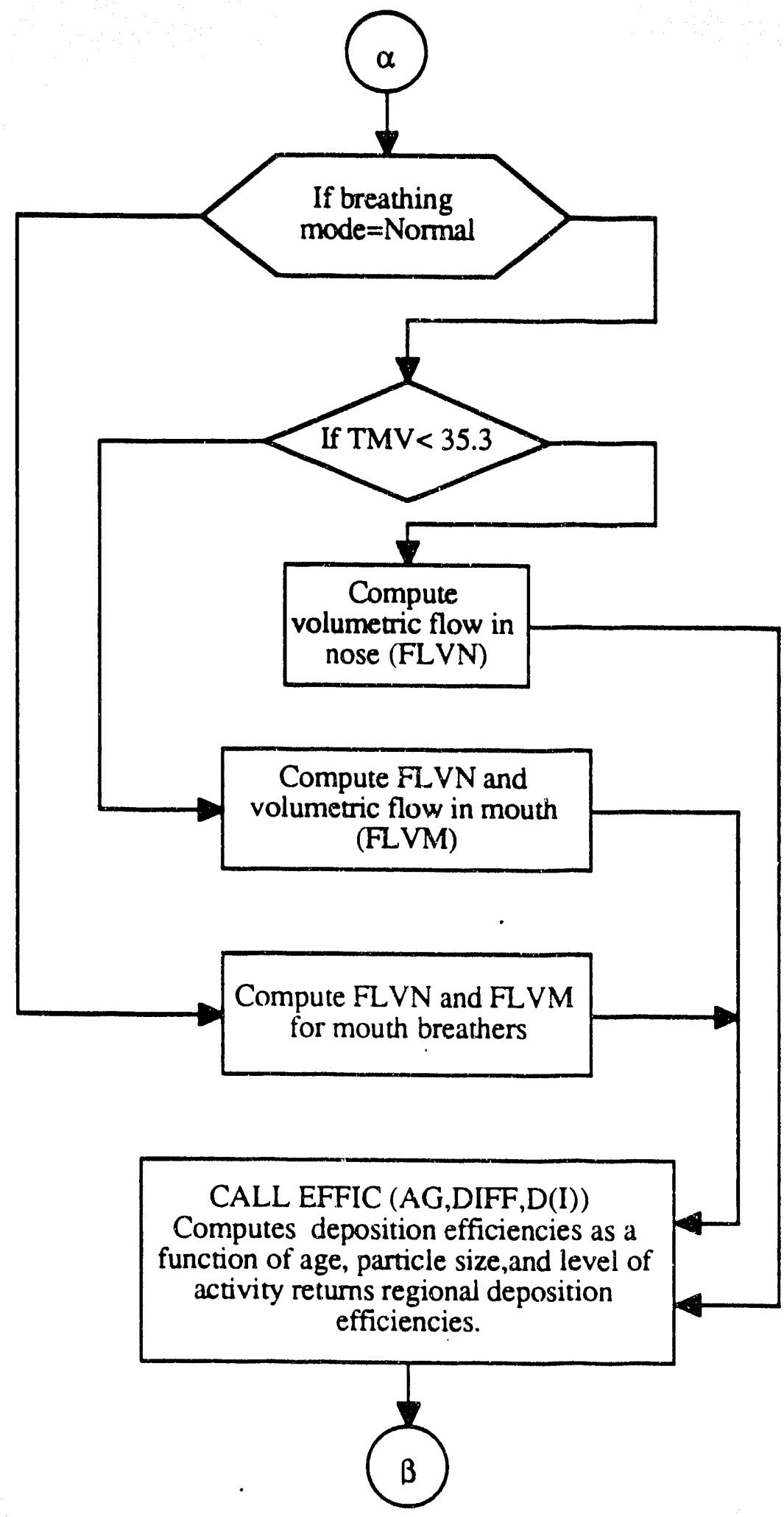

Figure 4.1 (Continued) 


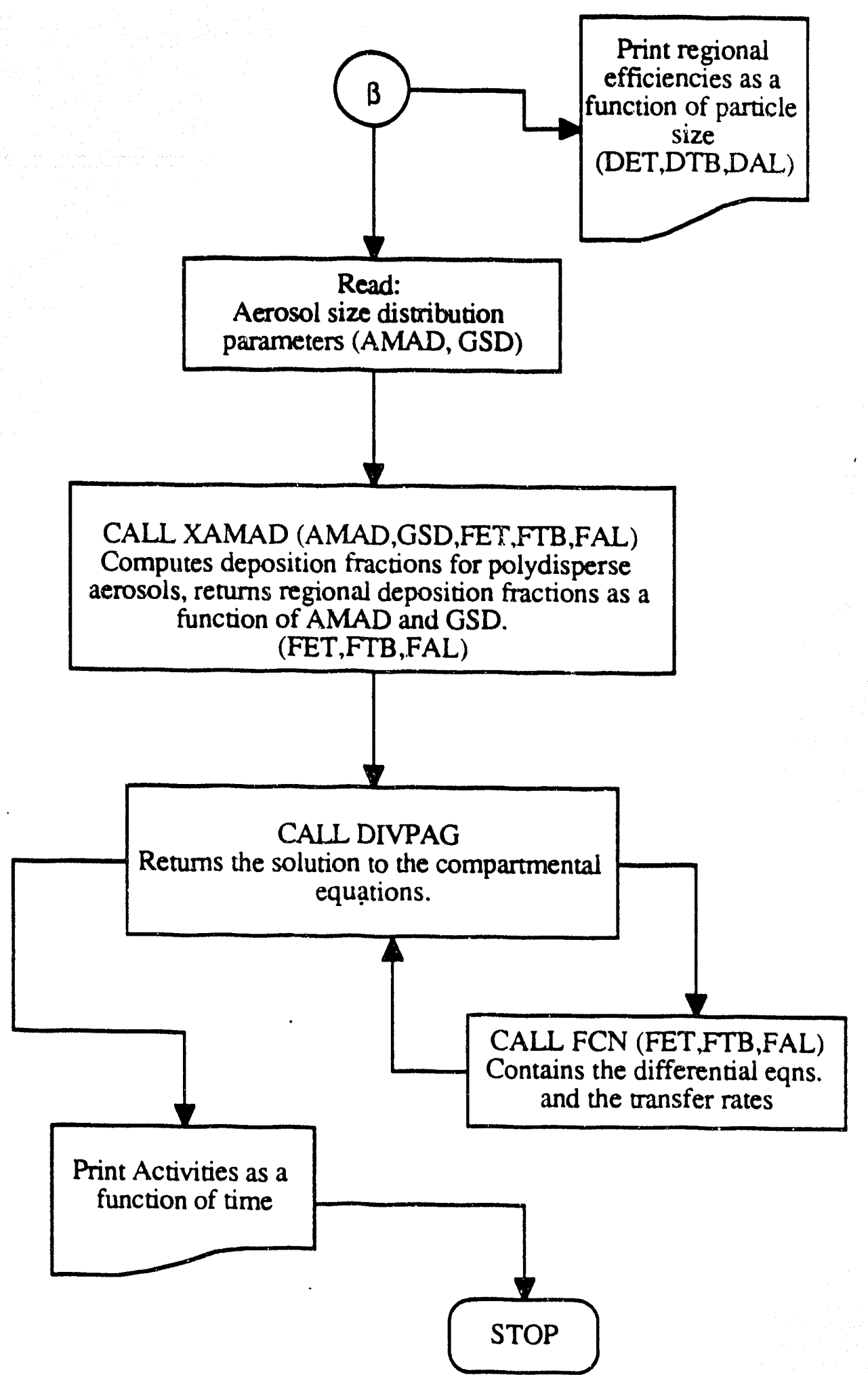

Figure 4.1 (Continued) 
1) Select wind speed of the air at the site of exposure. Typical values of wind speed of the air in working places rarely exceed $4 \mathrm{~m} \mathrm{~s}^{-1}$ but could reach $10 \mathrm{~m} \mathrm{~s}^{-1}$ or even higher at ground level in the outdoor environment. For practical purposes it may be assumed that the wind speed is equal to $1 \mathrm{~m} \mathrm{~s}^{-1}$ at indoor working places. The combination of this parameter with the aerodynamic particle size of the inhaled aerosol allows BIODEP to evaluate the inhalability efficiency according to the new concept of inspirabilty proposed by the American Conference of Govermental Industrial Hygienists (ACGIH 1985).

2) Select breathing mode. At this step, the interactive mode of BIODEP asks for the selection of one of two kind of breathers (nose breathers or mouth breathers).

3) Select age in months. At this time, BIODEP requires the age of the subject in a range 3 to 240 months.

4) Select aerodynamic and thermodynamic diameter limits. Here, BIODEP calls for the inferior and superior limits of particle sizes chosen between any value in the thermodynamic interval $0.00 \mathrm{i}$ to $0.1 \mu \mathrm{m}$, and any value in the aerodynamic interval 0.1 to $100 \mu \mathrm{m}$.

5) Select activity level. Four levels of physical activity are considered corresponding to total rest during sleeping, moderate activity during sitting, normal activity during light exercise, and total activity during the high level of exercise. When any one of these levels is selected, the computer code BIODEP interpolates the values of respiratory frequency, tidal volume, and functional residual capacity (needed for the calculation of deposition efficiencies and adjustment of the bronchial tree), as a function of the subject age corresponding to that specific level of physical activity.

As soon as the starting parameters are entered, BIODEP calls the subroutine GEOAJ to adjust the values of lengths and diameters of the bronchial tree derived from the Lovelace data base (Raabe 1976) to the corresponding values of normal lung volume of inflation. 
Next, these geometrical parameters are adjusted again to the comresponding values of length and diameter as a function of age to determine the ratios SFT,SFB, and SFA defined in Table 2.2 of Chapter 2. Next, BIODEP starts the evaluation of physical parameters such as Cuningham slip correction faccors, diffusion coefficients, and minute volume ventilation rates to prepare all values of aerodynamic parameters needed for the calculation of deposition efficiencies as a function of particle size. Before the call to subroutine EFFIC, the main program makes a discrimination between nasal and oronasal breathers depending on the values of the total minute volume ventilation rate (TMV) considering the volumetric flow of air in trachea. Therefore, with the knowledge of all the parameters mentioned above, BIODEP calls the subroutine EFFIC to start the evaluation of regional deposition efficiencies as a function of age, particle size, and level of physical activity after the inhalation of monodisperse aerosols. Finally, all regional efficiencies as a function of particle size are printed out over the thermodynamic and aerodynamic particle size interval specified at the input.

For the purposes of industrial hygiene applications and other experiments in which the size of the inhaled particles is well determined, it is sufficient to carry out an analysis of regional deposition efficiencies after the inhalation of monodisperse aerosols. However, the release of radioactive aerosols to the outdoor and indoor environments of the nuclear power industry and nuclear medicine facilities generally results in a polydisperse aerosol size distribution. Therefore, given a particular measurement of the activity aerosol size distribution of any radionuclide released to the environment of a specific working place under specific working conditions, it has been observed that the activity aerosol size distribution has generally a lognormal behavior. Consequently, the computer code BIODEP calls the subroutine XAMAD to assess the corresponding regional deposition efficiencies as a function of the characteristic parameters of a lognormal distribution (the activity median aerodynamic diameter AMAD and the geometrical standard deviation 
GSD). These regional depositions efficiencies as a function of AMAD and GSD are considered together with the initial intake of radioactive material as the initial conditions for a system of simultaneous differential equations which describe all the processes of biological clearance of radioactive material from the respiratory system. Finally, BIODEP calls the subroutine DIVPAG to solve the system of compartmental equations associated with the time-varying biokinetical distribution of Fig. 3.3 and returns the activity concentration of material as a function of time in every region of the respiratory tract.

Moreover, to compare the results obtained from the time-varying biokinetical distribution proposed in Fig. 3.3 with the results predicted by ICRP Publication 30, the computer code SAAM (Simulation Analysis and Modeling) was employed to reproduce the calculations of the lung compartmental distribution proposed by ICRP Publication 30 . The solution to any chain of compartments with constant transfer rates is possible through the use of the CONSAM editor which is another computer program designed to facilitate access to SAAM. Figure 4.2 depicts a flow chart of the main structure of the CONSAM editor which is a computer program used for the study and testing of mathematical models of biological systems, and more specifically, for kinetic models. CONSAM incorporates a text editor, a model processor, a graphics module, and solution and system saving facilities. Moreover, CONSAM is a conversational, or interactive, version of the SAAM modeling program. While SAAM was developed for the analysis of data within the context of a proposed model, CONSAM was designed to provide the user access to all the operational units of the SAAM program, but is not constrained to SAAM's batch style of operation. In summary, the use of BIODEP and CONSAM allowed a direct comparison of the time-varying biokinetic distribution of the respiratory system proposed here witn the classical approach of ICRP Publication 30 which considers a linear biokinetic distribution with constant transfer rates to represent the respiratory systern 


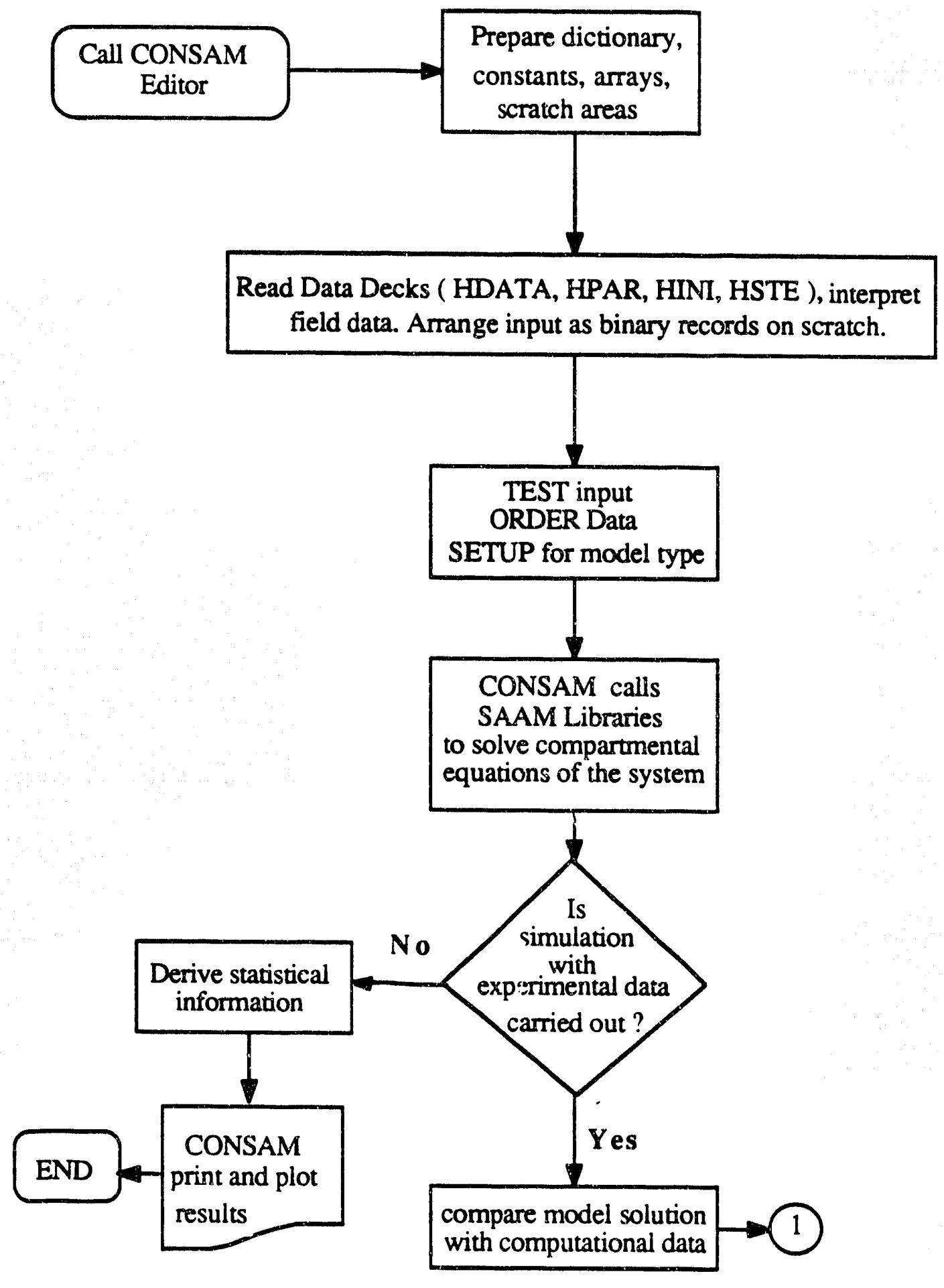

Figure 4.2 Flow chart diagram of the structure of CONSAM editor. 


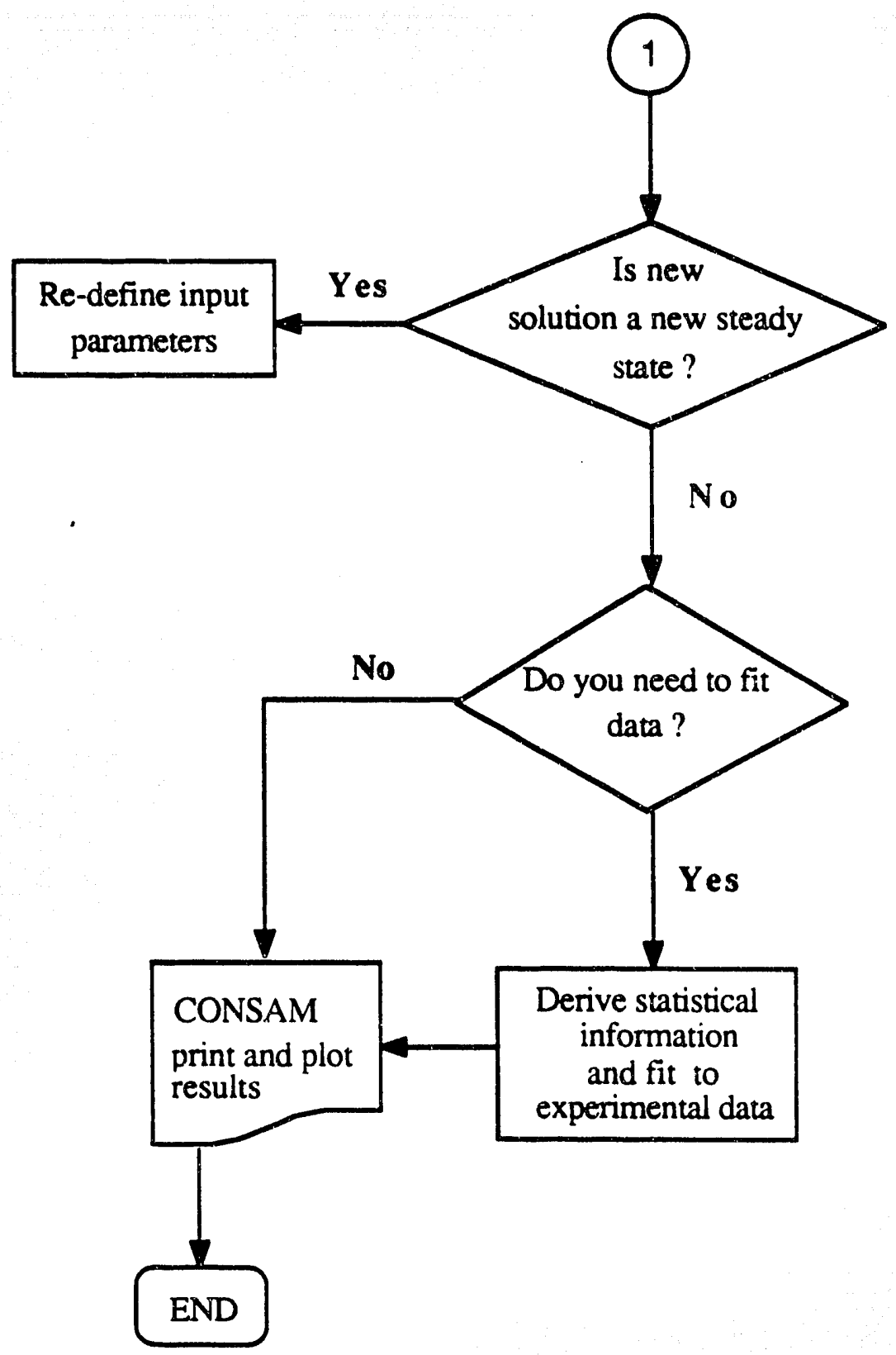

Figure 4.2 (Continued) 


\subsection{FRACTIONAL DEPOSITION AS A FUNCTION OF AGE AND PHYSICAL LEVEL OF ACTTVITY.}

From the analysis of the deposition model proposed in Chapter 2, it has been understood that a detailed knowledge on aerosol particle deposition in the human respiratory tract is required for a number of applications, such as the risk assessment due to inhaled particulate pollutants, radioactive aerosols, and the dose estimate of aerosol-administrated drugs in the treatment of respiratory diseases. Numerous experimental and theoretical investigations on this subject have been made in the past for healthy adults; however, ethical and legal reasons do not allow the development of any experimental work on deposition fractions within children or adolescents (Hofmann 1989). From experimental investigations brought about with adults, it has been shown that the amount and site of deposition depend upon three main factors: (1) particle characteristics such as particle size, shape, mass, density, and electric charge; (2) respiratory conditions such as tidal volume, breathing frequency, and the mode of breathing; and (3) airway geometry corresponding to the structure and dimensions of the airways. As a hurnan lung grows from birth to adulthood, both the airway geometry and respiratory conditions vary with age.

The lung of a child is not simply a proportionally smaller version of the adult lung. Each of the structural components (airways, alveoli, and blood vessels) has different growth patterns in number as well as in size. Reid (Reid 1977) has summarized the growth processes of the airways and alveoli in the following manner: 
1) All airway branches are present at the time of birth, and the shape of these branches are similar throughout the lifespan. The sizes of all the airways, however, increases as age progresses.

2) There are about 20 million primitive terminal sacs present in the lung at the time of birth. Alveoli and respiratory airways grow rapidly after birth, increasing in number until 8 years old, and increase in size until the growth of the chest wall is completed at adulthood. From these considerations the postnatal growth of the human lung can be subdivided into 2 periods: from birth up to 8 years it is characterized by the formation of new respiratory airways and the lining of these airways with alveoli. From 8 years onwards the structural development of the lung is completed and further growth occurs only by an increase of the linear dimensions.

In considering the change of airway geometry with age, BIODEP assumes that the tracheobronchial tree is fully developed at the time of birth, and the number of airways in this region remains constant during postnatal growth. Moreover, it is recognized that the structure of the alveolar region is strongly age dependent. Therefore, based on the observations of Dunnill (Dunnill 1962), the airways in generations 17 through 20 are complete at birth, while the number of airways from generations 21 through 25 increases with age. The lengths and diameters in each geneiation were calculated by assuming that the length to diameter ratio in any given generation is independent of age, which is equivalent to the assumption that linear airway dimensions at an age, $t$, are proportional to the cube root of the alveolar duct volume ratio reported by Dunnill. In addition to the geometrical changes of the bronchial tree as a function of age, changes of respiratory conditions such as tidal volume and breathing frequencies as a function of age were mathematically interpolated from the experimental data reported by Zapletal and Hofmann (Zapletal 1987, Hofmann 1989). 
The next table shows a summary of some of the physiological parameters associated with different levels of physical activity:

\begin{tabular}{|c|c|c|c|c|c|}
\hline $\begin{array}{l}\text { ACTIVTTY } \\
\text { LEVEL }\end{array}$ & $\begin{array}{l}\text { WIND SPEED } \\
(\mathrm{m} / \mathrm{sec})\end{array}$ & $\begin{array}{l}\text { BREATHING } \\
\text { MODE }\end{array}$ & $\begin{array}{l}\text { BREATHING } \\
\text { FREQUENCY } \\
\text { (/min) }\end{array}$ & $\begin{array}{l}\text { TDAL } \\
\text { VOUMME } \\
(\mathrm{ml})\end{array}$ & $\begin{array}{l}\text { FRC } \\
\text { (ml) }\end{array}$ \\
\hline SLEEP & 1 & nose & 12 & 625 & 3300 \\
\hline SITTING & 1 & nose & 12 & 750 & 3300 \\
\hline LIGHT EXERCISE & 1 & nose & 20 & 1250 & 3300 \\
\hline HEAVY EXERCISE & 1 & nose & 26 & 1920 & 3300 \\
\hline
\end{tabular}

Figure 4.3 shows the results obtained from the i pplication of the computer code BIODEP to assess regional deposition fractions for Reference Man under a light level of activity for different aerosol particle sizes. As shown in this figure, the probability of deposition in the extrathoracic region is highly favored for particles of very small sizes ( 1 to $5 \mathrm{~nm}$ ) and for large size particles in the aerodynamic region (5 to $20 \mu \mathrm{m}$ ). In fact, the deposition of very small size particles in the extrathoracical region is driven by the convective diffusive processes of ultrafine particles under the action of very high turbulent flows in the nose and the larynx. On the other hand, deposition of large aerosol particle sizes in this region is highly increased because particle inertia increases with the aerodynamic diarneter and thus the deposition of aerosol particles by the mechanism of inertial impaction is favored at the nose airways.

In consequence, deposition of ultrafine aerosol particles at the upper respiratory tract becomes an important subject of investigation for the industrial hygienist when the analysis of airborne emissions from autos and manufacturing industry such as smogs and metallurgic dusts are considered. Furthermore, the site and extent of absorption of these inhaled gases 

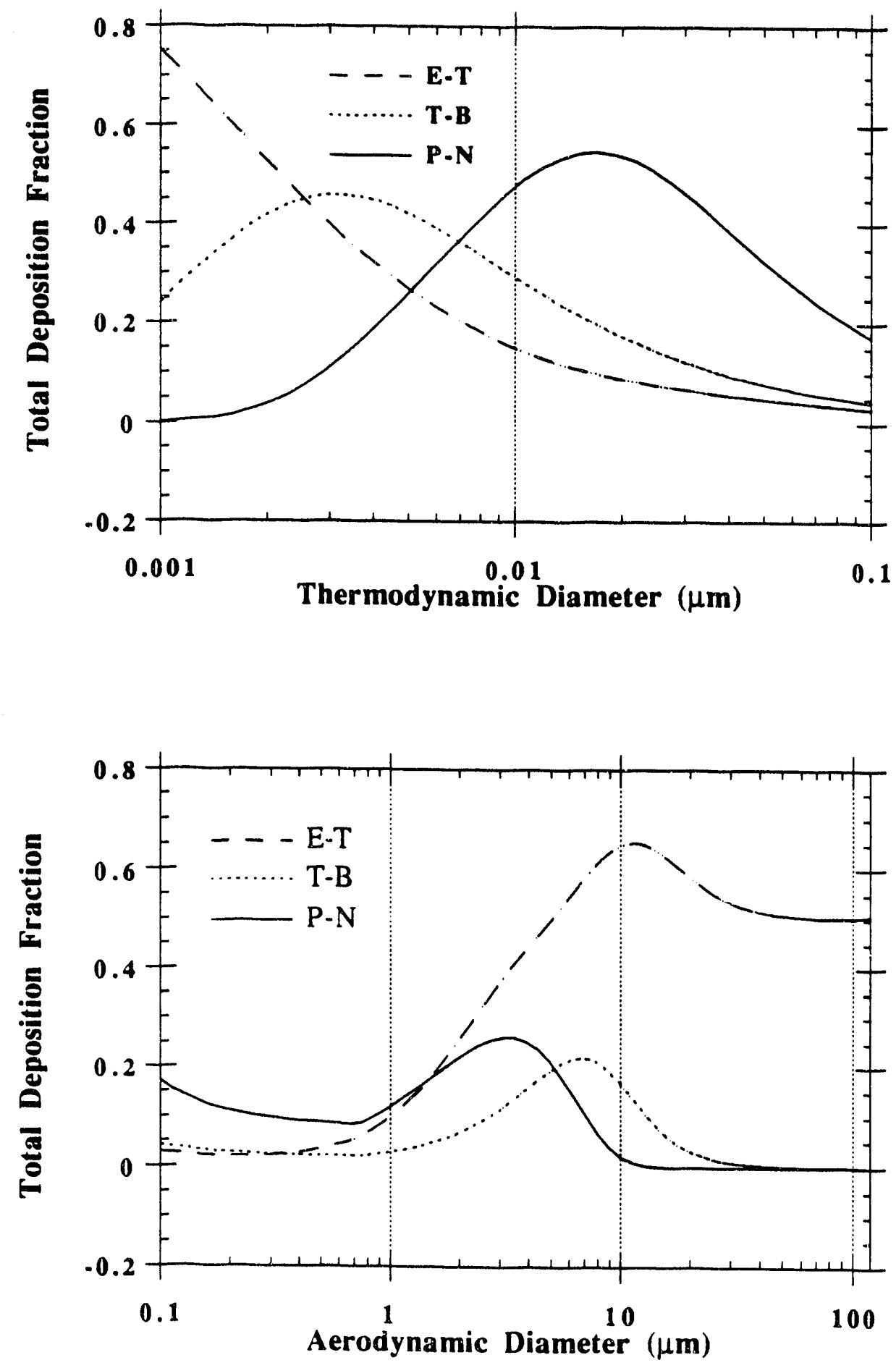

Figure 4.3 Regional deposition fractions for Reference Man (240 months) under a light level of activity for different aerosol size particles. 
and vapors are, for the most part, determined by their solubility characteristics in water. Highly soluble gases, such as, $\mathrm{SO}_{2}$ are largely absorbed in the upper respiratory tract, while those which are less soluble, such as, $\mathrm{NO}_{2}$ reach the lower airways. On the other hand, radioactive aerosols of large sizes such as uranium dioxides and uraniurn hexafluorides, released from the production of nuclear power plant fuel, are generally characterized by aerosol particle sizes of 6 to $10 \mu \mathrm{m}$, and therefore, have a high probability to be deposited in the upper respiratory tract. Of course, uranium hexafluorides are extremely soluble compared with uranium dioxides and they will pose a risk for bone surfaces once they reach the blood stream.

Deposition in the tracheobronchial region includes the mechanisms of impaction in the larger airways of the bronchial tree and sedimentation in the smaller airways. According to Fig. 4.3, tracheobronchial deposition decreases for particles larger than $8 \mu \mathrm{m}$; therefore, an increase of extrathoracic deposition in this size range shows that particles are already deposited in the upper respiratory tract during inspiration. In addition, there is no deposition in the tracheobronchial region for particles less than $2 \mu \mathrm{m}$ and greater than $0.1 \mu \mathrm{m}$. This is of extreme importance for the use of medical radioaerosols such as $\mathrm{Tc}^{99 m}(0.8 \mu \mathrm{m}$ MMAD) since it assures that almost all the inhaled aerosol is able to reach the alveolar region. Furthermore, the probability of deposition in the tracheobronchial region for inhaled particles in the range of $2 \mathrm{~nm}$ to $10 \mathrm{~nm}$ is increased again for the lower airways due to the decrease in air flow velocities and the decrease of particle sizes favoring once more the deposition of particles by the mechanisms of sedimentation and diffusion at these airways.

Finally, concerning with deposition of material in the alveolar region, Fig. 4.3 shows that when aerodynamic diameter is increased, more and more particles are deposited in the extrathoracical and tracheobronchial regions, and alveolar deposition decreases for particles larger than $3 \mu \mathrm{m}$ one then sees the characteristic bell-shape curve similar to that for tracheobronchial deposition in the aerodynamical particle size range. Moreover, particles 
larger than $10 \mu \mathrm{m}$ do not penetrate the alveolar region. Particles ranging from $70 \mathrm{~nm}$ to $2 \mu \mathrm{m}$ are almost exclusively deposited in the alveolar region which may be extremely helpful for studies of lung permeability of inhaled radiopharmaceuticals and for studies of alveolar clearance.

Figs. 4.4., 4.5, and 4.6 show a comparison of regional deposition efficiencies for Reference Man involved at four different levels of physical activity. As shown in Fig. 4.4, deposition fractions are decreased when the activity level is increased. Thus for very small aerosol sizes ( $1 \mathrm{~nm}$ to $10 \mathrm{~nm}$ ) this behavior is a consequence of the increase of the diffusion coefficient as the particle size diminishes. In other words, although the average flow rate increases with the increasing activity level, there is a predominant tendency of the particles to collide with the walls due to the action of increased Brownian motion as very small-sized aerosol particles flow through the nasal airways. In addition, for large aerosol sized particles in the aerodynamic range ( 1 to $10 \mu \mathrm{m})$ the deposition fraction is decreased as the level of physical activity is increased. This behavior is apparently contradictory because an increase of the average flow rate implies an increase of the impaction parameter $\mathrm{d}^{2}{ }_{\mathrm{ae}} \mathrm{Q}$ and therefore it should produce an increase of the deposition fractions by the mechanism of inertial impaction. Back in 1961, Pattle first observed that nasal deposition efficiency increased as a linear function of $\log \left(\mathrm{d}^{2}{ }_{a e} \mathrm{Q}\right)$ (Pattle 1961). The use of $\mathrm{d}^{2}{ }_{\mathrm{ae}} \mathrm{Q}$ as a normalizing parameter is reasonable when particles deposit by inertial impaction in an airway of fixed geometry where particle velocity is proportional to the air flow rate. However, since the oral airway dimensions change greatly with different breathing conditions, the velocity of a particle might not be proportional to the average flow rate over all breathing conditions associated with exercise. Therefore, it has been experimentally observed that the deposition efficiency in the upper respiratory airways changes inversely proportional to the average flow rate and thus an increase in physical activity will produce a decrease of extrathoracical deposition as shown in Fig. 4.4 . 

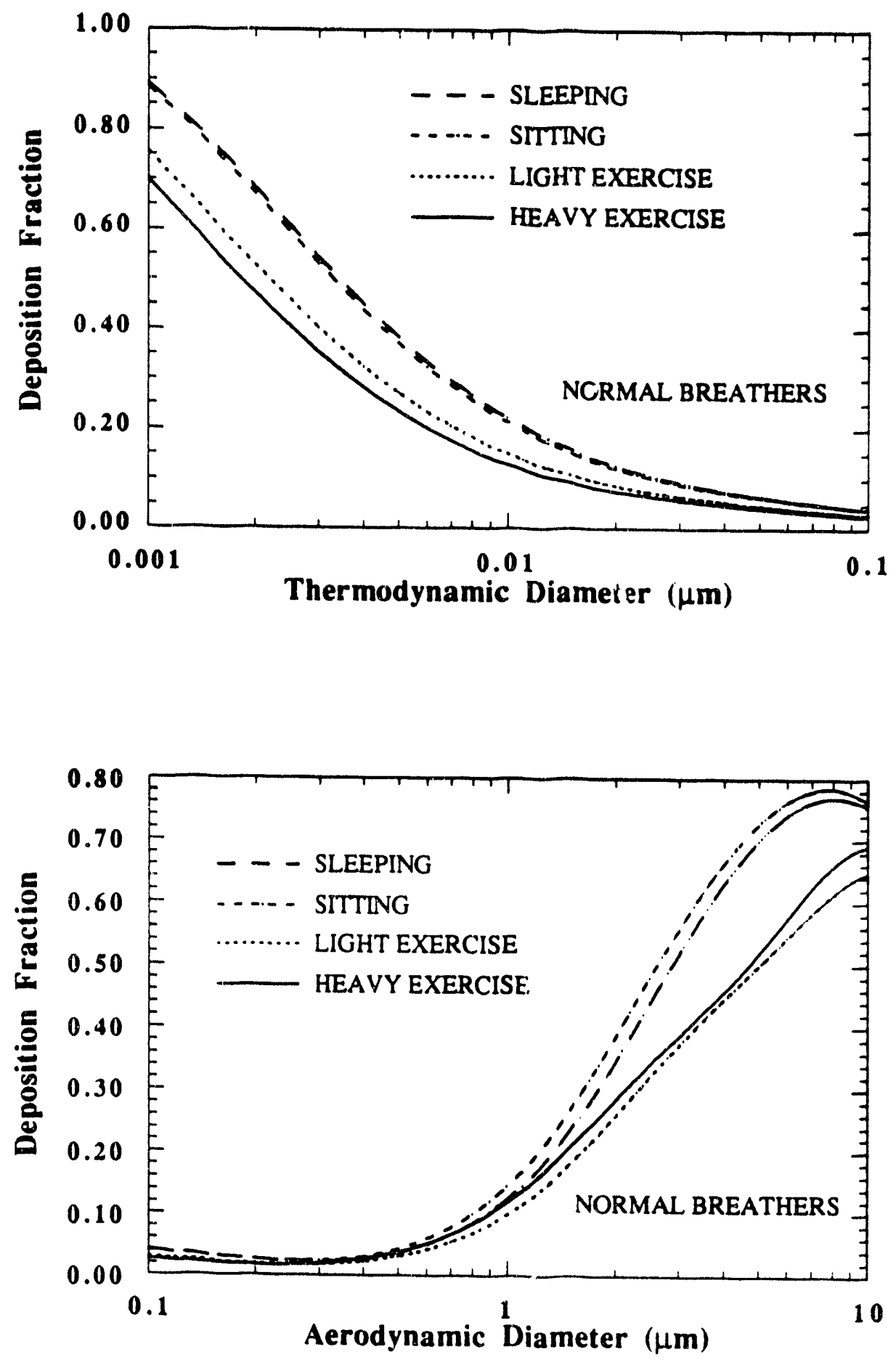

Figure 4.4 Regional deposition in extrathoracic region for Reference Man at four different levels of physical activity. 
Figure 4.5 shows a decrease of the fraction of material that is deposited in the tracheobronchial region for particles in the size range of $5 \mathrm{~nm}$ to $0.1 \mu \mathrm{m}$ when the level of activity is increased. This is correlated with the corresponding reduction of the mean residence time of aerosol particles in this region when the inspiratory flow rate is increased as a consequence of the increase of activity level. As a result, at high levels of activity the deposition by the mechanism of sedimentation is high $y$ reduced since the time that aerosol particles spent at the bronchial airways is not enough to allow them to reach their terminal velocities in comparison with those particles which flow slowly when the level of activity is reduced. In addition, there is also a reduction of the possibility of deposition by diffusion which is one of the most effective collection mechanisms for submicron-sized particles. However, for very small-sized particles in the range of 1 to $5 \mathrm{~nm}$ diffusion becomes predominant over sedimentation despite of the reduction in the associated mean residence time. On the other hand, for the aerodynamical range $(0.5$ to $10 \mu \mathrm{m})$ it is shown that deposition fractions are increased as the activity level increases, which is consistent with the increased effectiveness of the inertial impaction deposition mechanism at the upper airways of the bronchial tree resulting from the increase of the inertial impaction parameter $\mathrm{d}^{2}{ }_{\mathrm{ae}} \mathrm{Q}$ as the average flow rate is increased. In addition, this plot shows a three folded increase of the deposition fractions between the interval $(2$ to $6 \mu \mathrm{m}$ ) for the low and high levels of activity which may be important in risk-assessment protocols applicable to inhaled radioactive material, and to irritant and toxic substances, since mechanical lung clearance at these airways may not be fast enough compared with absorption of soluble materials to the blood.

Figure 4.6 shows an increase of deposition fractions in the alveolar region as a function of activity level for the reference man which describes a regular behavior for ultrafine aerosols between particle sizes of 1 to $30 \mathrm{~nm}$. Furthermore, this figure shows that regardless of the decrease of mean residence time in the alveolar region as the flow rate increases, the deposition by diffusion is the predorninant mechanism. At this region the flow 

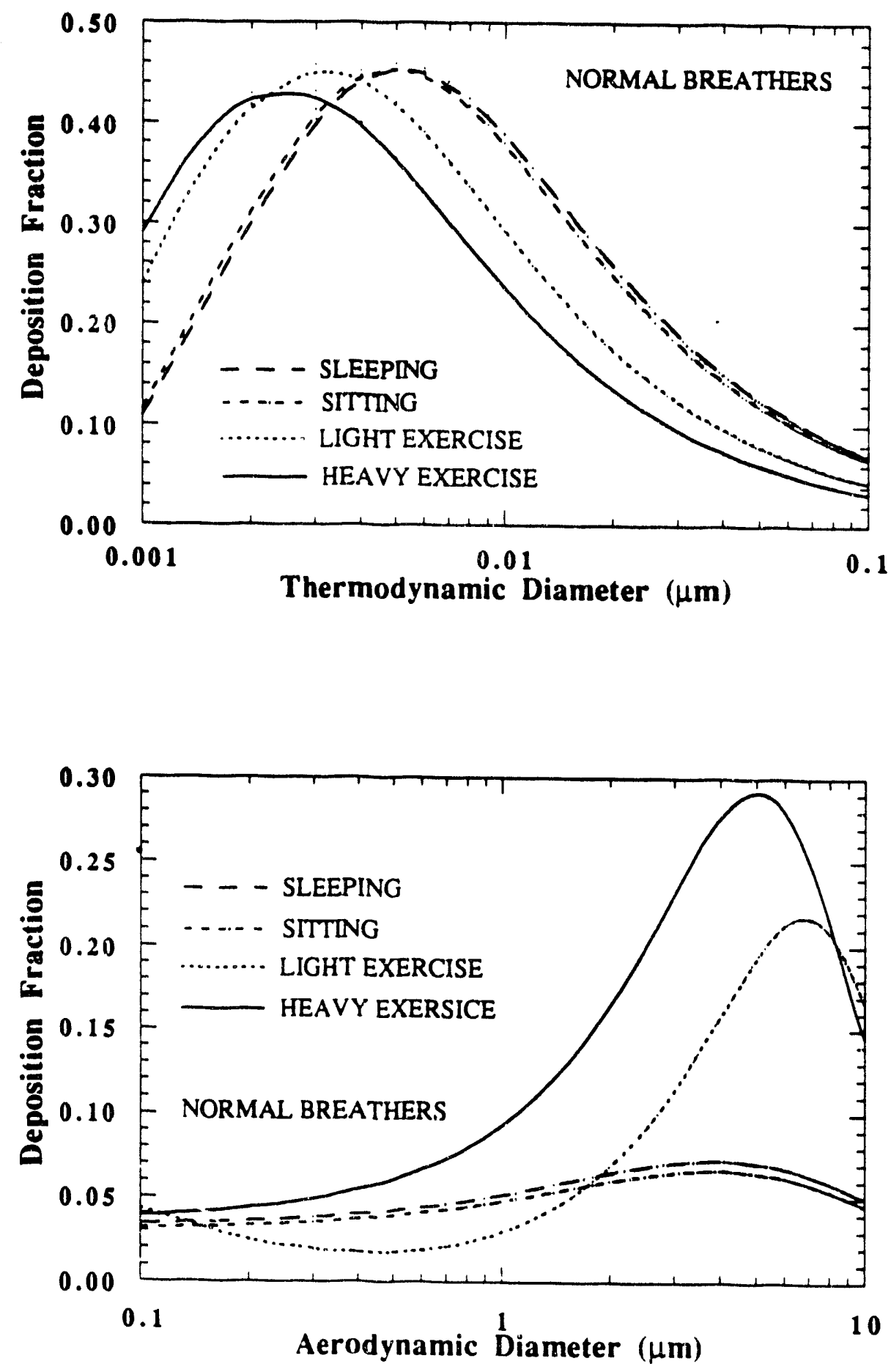

4.5 Regional deposition fraction in tracheobronchiolar region for Reference Man at four levels of physical activity. 

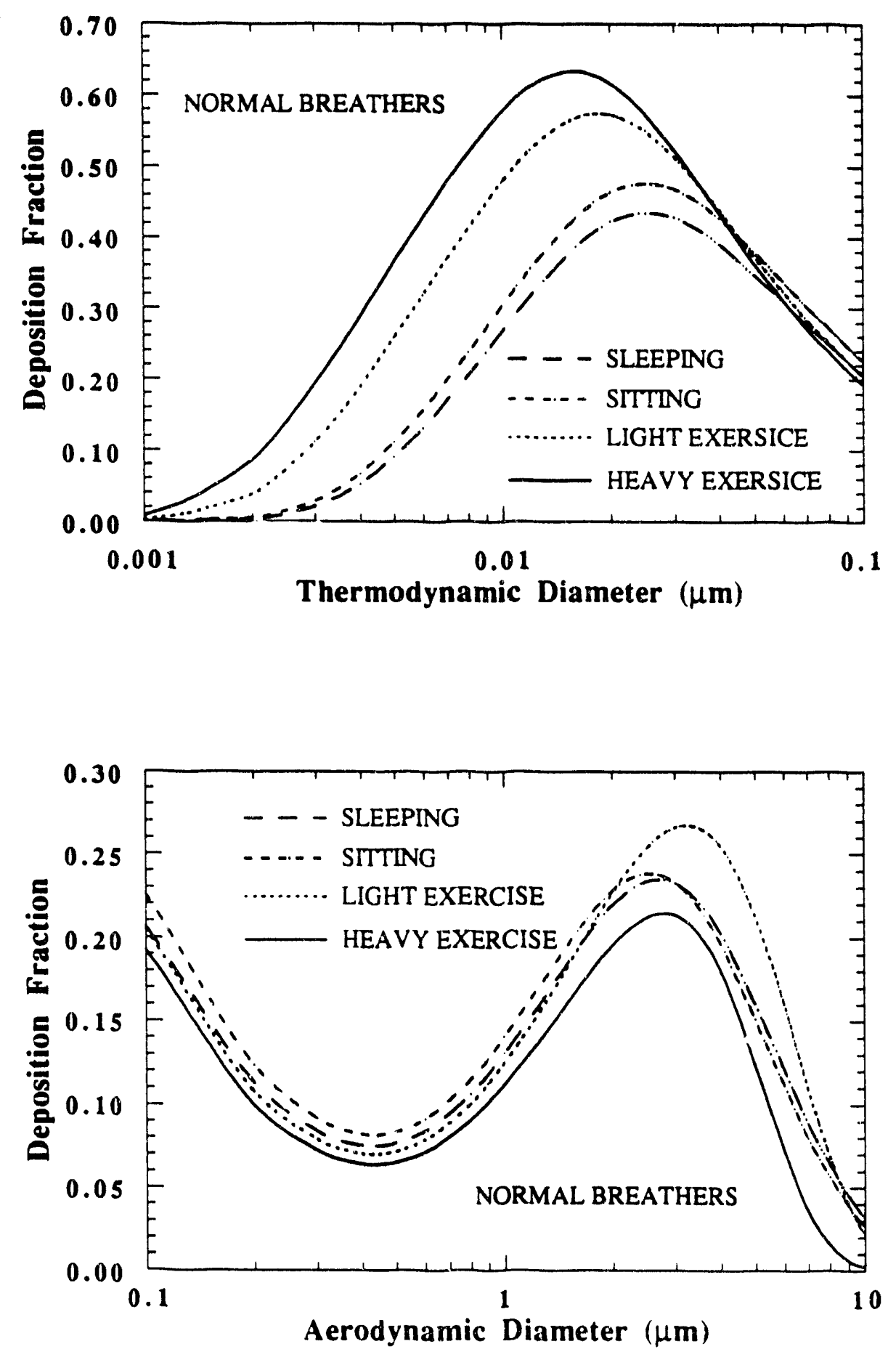

Figure 4.6 deposition fraction in the alveolar region for Reference Man at four levels of physical activity. 
of air is completely laminar and with very low Reynold's numbers; consequently, any increase in average particle velocity resulting from an increase in physical activity is very low compared with the increase of the molecular Brownian motion of very small-sized particles. In other words, the transport of particles by thermal diffusion exceeds the effects of gravitational forces at these flow regimes. Finally, for particles in the aerodynamic range there is not a regular pattern of behavior as a consequence of air mixing processes in the alveolar region.

In terms of deposition as a function of age, Figs. $4.7,4.8$, and 4.9 show the changes of regional depositions fractions as a function of particle size and age for one subject involved in light levels of physical activity. From these figures, it is shown that in the aerodynamic region for the case of the tracheobronchial and pulmonary regions, the values of regional deposition fractions are increased by a actor of three as the lung structures growth. Unfortunately a direct physical explanation of this behavior favoring inertial impaction and sedimentation mechanisms at these regions depends on too many factors at the same time. In other words, efficiency calculations at these regions depend on geometrical changes of the bronchial tree as a function of age, and volumetri- flow rates which at the same time depend on changes of breathing frequencies and tidal volumes as a function of age. For instance, during the development of the adjusting subroutines of the computer code BIODEP it was found that when the values of idal volume as a function of age increase monotonically in a quadratic fashion, the values of respiratory frequencies decreases monotonically as a function of age following an inverse power law; therefore, since the average flow rate is the product of these two parameters, there is no way to predict when the average flow rate multiplied by the factors SFT, SFB, or SFA (see Table 2.2 of Chapter 2) switches values to favor the mechanism of either inertial impaction or sedimentation as a function of age. This is the case of aerodynamic deposition in the extrathoracical region (Fig. 4.7) where inertial impaction results are greater for children than for adults which is in 

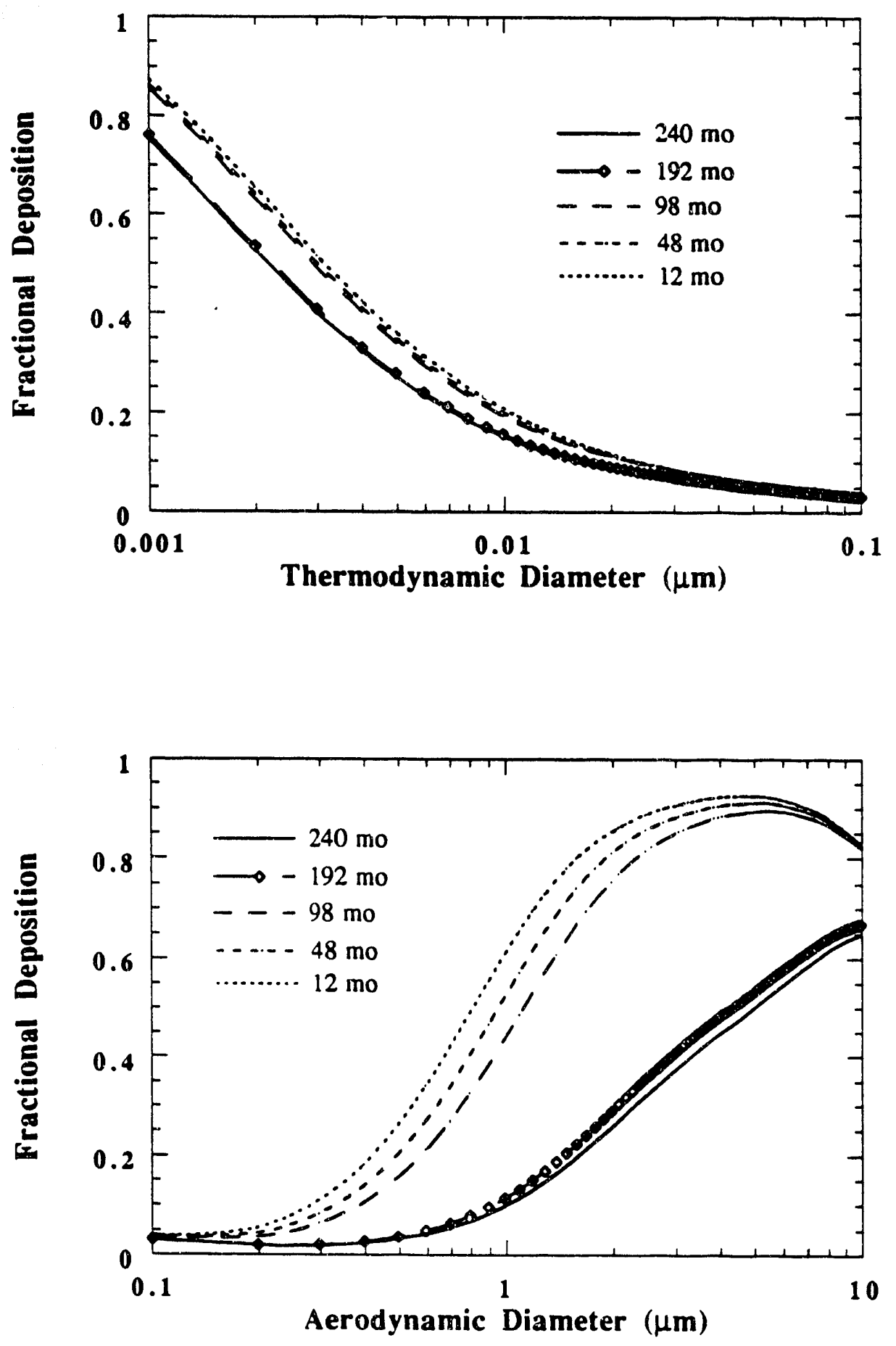

Figure 4.7 Deposition fraction as a function of age in extrathoracic region for subjects involved in light levels of activity. 

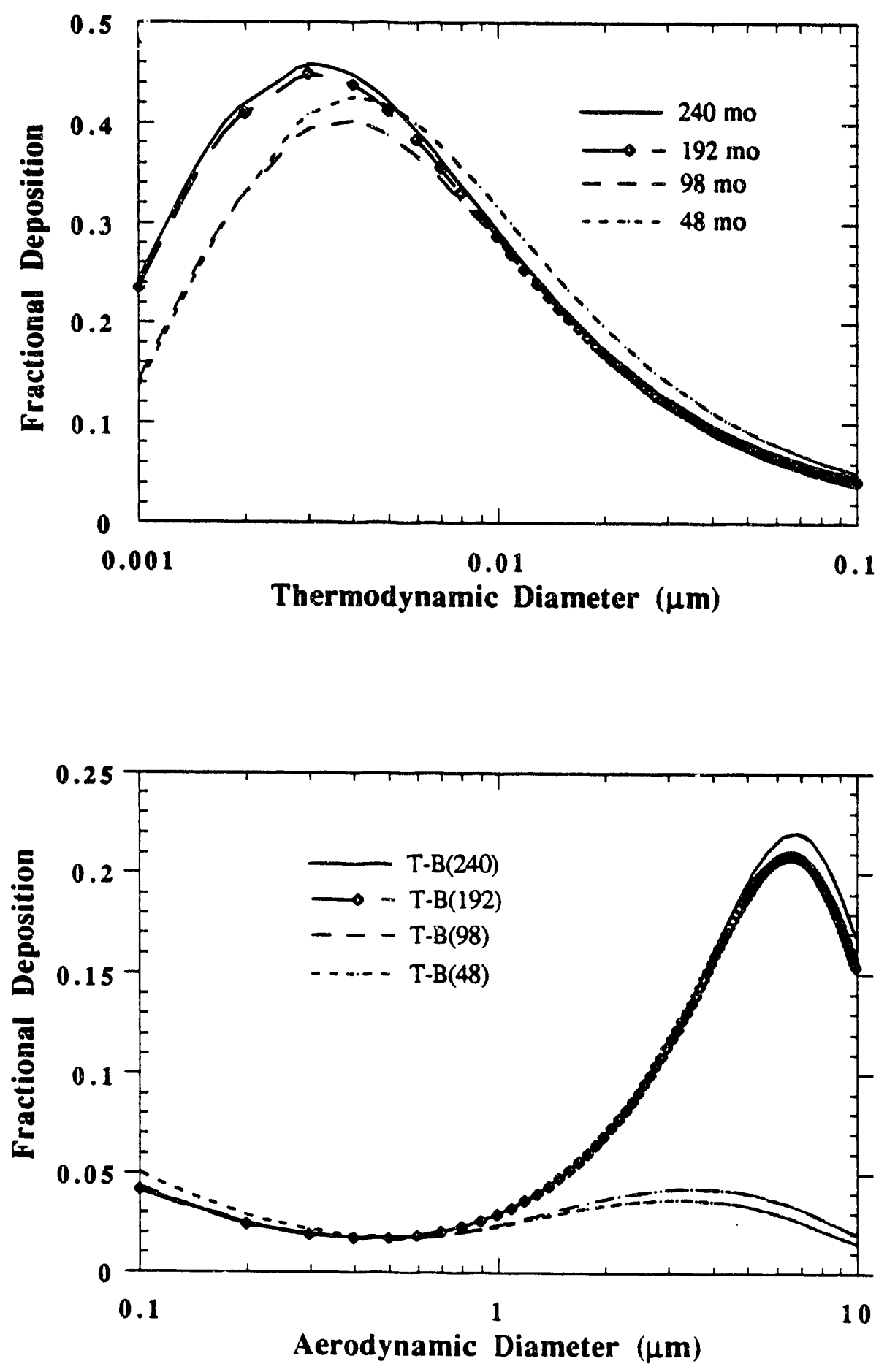

Figure 4.8 Deposition fractions as a function of age in tracheobronchial region for subjects involved in light levels of activity. 

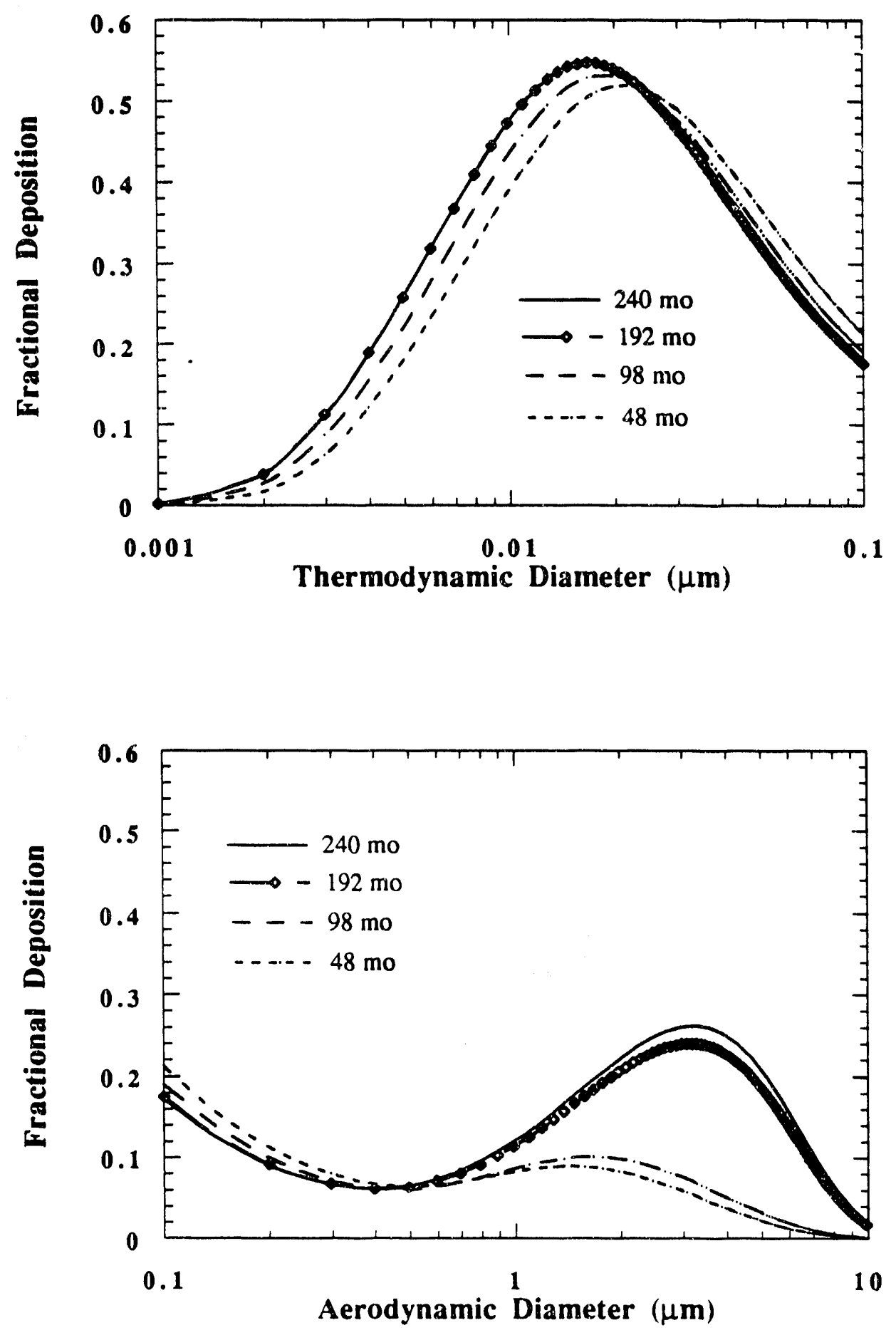

Figure 4.9 Deposition fractions as a function of age in pulmonary region for subjects involved in light levels of activity. 
direct contrast with the behavior of regional deposition in the tracheobronchial region (Fig. 4.8). These variations of regional deposition fractions as a function of age for the aerodynamic range may be used in combination with biokinetic analysis for the assessment of radiological and toxicological risks to the public associated with the accidental release of airborne contaminants such as radioactive aerosols from waste disposal facilities, industrial oil smokes, fly ashes, cement dust, and insecticide dusts. Moreover, in the thermodynamic aerosol size range, Figs. 4.7 to 4.9 show an average variation of $10 \%$ for very small-sized particles in all three regions of the respiratory tract for children and adults. In fact, this change is more remarkable at the tracheobronchial and alveolar regions for particles in a range of 2 to $10 \mathrm{~nm}$ which suggest the possibility that if increased diffusional processes favor the deposition of inhaled material for the adult, then a mature lung has a higher risk of damage after the inhalation of radioactive ultrafine aerosol particles than the inmature lung under the same conditions of biological clearance. 


\subsection{ACTIVITY CONCENTRATION FOR INHALED TRANSURANIC ELEMENTS.}

The estimation of activity concentrations at every region of the respiratory tract as a function of time after the inhalation of radioactive aerosols, was carried out through the application of the computer code BIODEP to the compartmental distribution proposed in Figure 3.3 of Chapter 3. In this process, the distribution of activity concentrations for transuranic compounds such as ${ }^{241} \mathrm{AmO}_{2},{ }^{240} \mathrm{Cm}_{2} \mathrm{O}_{3}, \mathrm{UO}_{2},{ }^{238} \mathrm{PuO}_{2},{ }^{239} \mathrm{PuO}_{2}$, and $\mathrm{UF}_{6}$, with the addition of $\mathrm{Nb}_{2} \mathrm{O}_{5}$, was performed considering the values of experimental measurements of the activity size distributions of aerosols released to the environments of working places in the nuclear power industry (Thind 1986), and by the application of new solubility functions $S(t)$ proposed by the NRC based on the latest results of human and animal inhalation exposures.

In addition, for the determination of regional deposition fractions as a function of AMAD (activity median aerodynamic diameter) and to set the initial conditions of the compartmental distribution shown in Fig. 3.3, direct measurements of activity aerosol size distributions were employed here because the use of AMAD is preferred over MMAD (mass median aerodynamic diameter). In the methodology proposed by ICRP Publication 30 it is recognized that the amount of radioactivity carried by an individual particle of a contaminated aerosol is not necessarily proportional to its mass. However, in those calculations, the regional deposition fractions versus MMAD reported by the Task Group in Lung Dynamics (ICRP 1966) were used interpreting the abscissa as AMAD. In this work AMAD is taken from direct measures of activity and is preferred over MMAD because it defines the potential release of activity to the environment. AMAD also provides a consistent unit to define size characteristics at a location where a mixture of radionuclides causes loss of proportionality between mass and activity. For instance, 
when a mixture of ${ }^{238} \mathrm{Pu}$ and ${ }^{239} \mathrm{Pu}$ is present at the working place, determination of the mass aerosol size distribution does not take into account that the specific activity of $238 \mathrm{Pu}$ is 274 times that of ${ }^{239} \mathrm{Pu}$. Consequently, from the measurement of the collected mass corresponding to a specific aerodynamic diameter, it is not possible to deduce what proportion of activity corresponds to each radionuclide.

Table 4.1 gives the parameters of the log-normal activity size distributions corresponding to the release of aerosols at different working places of the nuclear power industry and are considered to determining the activity concentrations in the respiratory system. These values were inputted to the computer code BIODEP to estimate the corresponding deposition fractions as a function of age, AMAD, and level of physical activity at every region of the respiratory tract. Therefore, for individuals involved in a light level of physical exercise, the values of the resulting regional deposition fractions computed by BIODEP are shown in Table 4.2. In addition, the set of solubility functions $S(t)$ (fractions of the lung burden transferred to blood each day) used to assess the concentration of activity as a function of time after one unit inhalation exposure can be summarized as shown below:

Americium dioxide $S(t)=0.048 \mathrm{e}^{-0.028 t}+0.002$

Curium oxide $S(t)=0.06 e^{-0.046 t}+0.02$

Niobium oxide $S(t)=0.00016 \mathrm{e}^{-0.04 t}+0.0001$

Uranium dioxide $S(t)=0.13 e^{-0.14 t}+0.0027$

Plutonium oxide $\mathrm{Pu}^{238} \mathrm{O}_{2} \quad \mathrm{~S}(\mathrm{t})=0.0023 \mathrm{e}^{-0.017 t}+0.0004$

Plutonium oxide $\mathrm{Pu}^{239} \mathrm{O}_{2} \quad \mathrm{~S}(\mathrm{t})=0.0014 \mathrm{e}^{-0.07 t}+0.00004$

Uranium hexaflouride $S(t)=1.2 e^{-0.53 t}+0.09$

The results of the computer simulations using the parameters described above to calculate the retention of material as a function of time, are shown in Figs. 4.10 to 4.14. 
Table 4.1 Parameters of the lognormal distributions used to assess the deposition fraction of transuranic elements at the different regions of the respiratory tract.

\begin{tabular}{|c|c|c|}
\hline $\begin{array}{c}\text { Radioactive } \\
\text { Compound }\end{array}$ & $\begin{array}{c}\text { AMAD } \\
\mu \mathrm{m}\end{array}$ & GSD \\
\hline $\mathrm{Nb}_{2} \mathrm{O}_{5}$ & 1.6 to 2.5 & 2.0 \\
$\mathrm{Cm}_{2} \mathrm{O}_{3}$ & 1.4 & 1.16 \\
$241 \mathrm{AmO}_{2}$ & 1.8 & 1.65 \\
$238 \mathrm{PuO}_{2}$ & 1.4 & 1.51 \\
$239 \mathrm{PuO}_{2}$ & 0.1 & 1.5 \\
$239 \mathrm{PuO}_{2}$ & 1.0 & 2.0 \\
$239 \mathrm{PuO}_{2}$ & 5.8 & 3.7 \\
$\mathrm{UO}_{2}$ & 6.1 & 2.1 \\
$\mathrm{UF}_{6}$ & 6.6 & 1.7 \\
\hline
\end{tabular}


Table 4.2 Fractional depositions at every region of the respiratory tract for subjects involved in the light exercise level of activity

\begin{tabular}{|c|c|c|c|c|c|c|}
\hline (AMAD, GSD) & Age in months & 12 & 48 & 96 & 192 & 240 \\
\hline \multicolumn{7}{|l|}{ Compound } \\
\hline $\mathrm{Nb}_{2} \mathrm{O}_{5}$ & DF(E-T) & 0.7547 & 0.7099 & 0.6609 & 0.2878 & 0.2578 \\
\hline \multirow[t]{2}{*}{$(2.0 .2 .0)$} & $\mathrm{DF}(\mathrm{T}-\mathrm{B})$ & 0.0244 & 0.2297 & 0.0327 & 0.0813 & 0.0829 \\
\hline & DF(P-N) & 0.0584 & $0.064:$ & 0.0747 & 0.1722 & 0.1861 \\
\hline $\mathrm{Cm}_{2} \mathrm{O}_{3}$ & $\mathrm{DF}(\mathrm{E} \cdot \mathrm{T})$ & 0.72 & 0.655 & 0.5832 & 0.1818 & 0.1589 \\
\hline \multirow[t]{2}{*}{$(1.4,1.16)$} & $\mathrm{DF}(\mathrm{T}-\mathrm{B})$ & 0.0253 & 0.0274 & 0.029 & 0.0426 & 0.0428 \\
\hline & $\mathrm{DF}(\mathrm{P}-\mathrm{N})$ & 0.0796 & 0.0842 & 0.0933 & 0.1512 & 0.1608 \\
\hline${ }^{238} \mathrm{PuO}_{2}$ & $D F(E-T)$ & 0.6964 & 0.6347 & 0.5691 & 0.1969 & 0.1735 \\
\hline \multirow[t]{2}{*}{$(1.4,1.51)$} & $D F(T-B)$ & 0.0257 & 0.028 & 0.0298 & 0.048 & 0.0483 \\
\hline & $\mathrm{DF}(\mathrm{P}-\mathrm{N})$ & 0.0745 & 0.079 & 0.0877 & 0.1518 & 0.1619 \\
\hline${ }^{239} \mathrm{PuO}_{2}$ & $D F(E-T)$ & 0.0418 & 0.0396 & 0.0381 & 0.0296 & 0.0291 \\
\hline \multirow[t]{2}{*}{$(0.1,1.50)$} & DF(T-B) & 0.0679 & 0.0506 & 0.0438 & 0.042 & 0.0431 \\
\hline & DF(P-N) & 0.2457 & 0.2118 & 0.1916 & 0.1768 & 0.1742 \\
\hline${ }^{239} \mathrm{PuO}_{2}$ & DF(E-T) & 0.5598 & 0.4901 & 0.4316 & 0.142 & 0.1261 \\
\hline \multirow[t]{2}{*}{$(1.0,2.0)$} & $\mathrm{DF}(\mathrm{T}-\mathrm{B})$ & 0.0226 & 0.0234 & 0.0245 & 0.0385 & 0.0389 \\
\hline & DF(P-N) & 0.073 & 0.0731 & 0.077 & 0.1227 & 0.1302 \\
\hline${ }^{239} \mathrm{PuO}_{2}$ & $D F(E-T)$ & 0.7291 & 0.7083 & 0.6852 & 0.4473 & 0.4271 \\
\hline \multirow[t]{2}{*}{$(5.8,3.7)$} & $\mathrm{DF}(\mathrm{T}-\mathrm{B})$ & 0.0111 & 0.011 & 0.0117 & 0.0177 & 0.0189 \\
\hline & $D F(P-N)$ & 0.0263 & 0.1298 & 0.0196 & 0.1006 & 0.1112 \\
\hline $\mathrm{UO}_{2}$ & $D F(E-T)$ & 0.814 & 0.801 & 0.7846 & 0.5184 & 0.4929 \\
\hline \multirow[t]{2}{*}{$(6.1,2.1)$} & $\mathrm{DF}(\mathrm{T}-\mathrm{B})$ & 0.0131 & 0.0165 & 0.0283 & 0.1336 & 0.1411 \\
\hline & DF(P-N) & 0.0105 & 0.012 & 0.0146 & 0.1161 & 0.1289 \\
\hline $\mathrm{UF}_{6}$ & DF(E-T) & 0.8318 & 0.8218 & 0.8092 & 0.5539 & 0.5276 \\
\hline \multirow[t]{2}{*}{$(6.6,1.7)$} & $D F(T-B)$ & 0.0177 & 0.0241 & 0.0291 & 0.1542 & 0.1633 \\
\hline & $D F(P-N)$ & 0.0076 & 0.0106 & 0.015 & 0.1086 & 0.1219 \\
\hline${ }^{241} \mathrm{AmO}_{2}$ & DF(E-T) & 0.7576 & 0.7081 & 0.6529 & 0.2543 & 0.2277 \\
\hline \multirow[t]{2}{*}{$(1.8,1.65)$} & $\mathrm{DF}(\mathrm{T}-\mathrm{B})$ & 0.027 & 0.0305 & 0.0334 & 0.0683 & 0.0691 \\
\hline & DF(P-N) & 0.0665 & 0.0734 & 0.0844 & 0.1755 & 0.1886 \\
\hline
\end{tabular}


In the case of relatively soluble and soluble transuranic bone seekers, such as Am and $\mathrm{UF}_{6}$, where the bone is the critical organ, values of cumulated activities, $\mathrm{U}_{\mathrm{s}}$, at the bone surfaces were estimated from the use of the biokinetic model of the respiratory tract proposed in Fig. 3.3 combined with the biokinetic distribution models proposed by ICRP Publication 54 and Lipsztein-Wrenn, respectively (ICRP1988; Fisher 1991). The radionuclide $\mathrm{Am}^{241}$ is principally produced artificially from normal rework of aged plutonium inventories. It is used in a variety of industrial applications such as (1) incorporation in neutron sealed sources to produce the ${ }^{4} \alpha_{2}+{ }^{9} \mathrm{Be}_{4}={ }^{12} \mathrm{C}_{6}+{ }^{1} n_{0}(\alpha, n)$ reaction. (2) In addition to the emitted neutrons, Am produces a $60-\mathrm{KeV}$ gamma ray which is also useful in density measurements and in a radiographic applications. The production and fabrication of these sources has led to accidental exposures via inhalation where the chemical form of the material is ${ }^{241} \mathrm{AmO}_{2}$ (Yesberger 1977). Curium isotopes are $\alpha$ emitting by-products of the burnup of light-water-moderated nuclear reactor fuel. Curium as been used in targets for the production of transcurium elements, and for this usage, they are converted into oxide powders such as $\mathrm{CmO}_{2}$ and $\mathrm{Cm}_{2} \mathrm{O}_{3}$. Accidental inhalation of these radioisotopes are treated with chelating DTPA agents to increase the excretion rate of fixed curium to tissues of the body (Sanders 1974). Niobium isotopes are beta and gamma emitters and are present in nuclear weapon fallout and in the fission products of nuclear reactors. $\mathrm{Nb}_{2} \mathrm{O}_{5}$ are sparingly soluble in mineral acids and are almost torally inert in solutions of nearly neutral $\mathrm{pH}$ which is typical of most biological fluids. Plutonium dioxides $\left({ }^{239} \mathrm{PuO}_{2},{ }^{238} \mathrm{PuO}_{2}\right)$ have been used in large quantities in the cycle of nuclear power ge neration and for military applications. Plutonium has also found extensive use as a thermoelectric power source for space flight and cardiac pacemakers; therefore, it poses a potential risk for accidental inhalation by workers and the general population. Miost of the reactors in the world are light water reactors (LWR) and require enriched $U^{235}$ produced by gaseous diffusion processes using. $\mathrm{UF}_{6}$ comes from the conversion of $\mathrm{U}_{3} \mathrm{O}_{8}$. The 
first resulting product in this process is $\mathrm{UO}_{2}$ which passes to $\mathrm{UF}_{4}$ when treated at high temperatures with fluorine gas which after another chemical reaction forms $\mathrm{UF}_{6} . \mathrm{A}$ biokinetic analysis of these materials is useful in assessing accidental inhalation exposures (Fisher 1991).

Figure 4.10 shows a computer simulation of the retention of $241 \mathrm{AmO}_{2}$ after the inhalation of one Becquerel as a function of the time and as a function of age. Before 150 days after inhalation exposure, this figure shows that, in the case of a polydisperse aerosol with AMAD greater than $1 \mu \mathrm{m}$ (the reference value of ICRP Publication 30 ), the methodology of ICRP 30 overpredicts retention of material in the lung since the model of deposition proposed here predicts a lower fraction of inhaled material reaching the tracheobronchial and pulmonary regions. However, after 150 days of exposure, the computer simulations showed a overestimation of retention of material in the lung for the model proposed here compared with the biokinetic model of ICRP Publication 30. Therefore, ICRP Publication 30 overpredicts total absorption due to a larger fraction of inhaled material deposited and absorbed from the nasopharyngeal and tracheobronchial compartments. In addition, the model proposed here (see Fig. 4.10) depicts a lower retention of inhaled material for children compared with adults. Since conservative assumptions are generally made in radiological protection, these differences are not of extreme importance. However, in an accidental or medical situation, the rate of absorption of americium for members of the general public might play an important role in deciding the length of chelation therapies after an environmental inhalation accident. Moreover, Fig. 4.10 shows that of the $26 \%$ of initially inhaled material that is deposited in the lung, about $50 \%$ is retained in the liver and $25 \%$ is retained in the bone making the last a critical organ due to its radiosensitivity to alpha particles. Finally, the cumulated activity, $\mathrm{U}_{\mathrm{S}}$, at the bone surfaces predicted by ICRP Publication 30 is lower by about $15 \%$ compared with the value of $U_{S}$ predicted by the model proposed here (see Table 4.4). On the other hand, the 
Table 4.4 Values of cumulated activity $U_{s}$ after the inhalation of one unit of activity for transuranic elements

\begin{tabular}{|c|c|c|c|}
\hline Compound & Critical organ & ICRP 30 & This Model \\
\hline${ }^{95} \mathrm{Nb}_{4} \mathrm{O}_{5}$ & LUNG & $7.1 \times 10^{6}$ & $1.7 \times 10^{7}$ \\
\hline${ }^{240} \mathrm{Cm}_{2} \mathrm{U}_{3}$ & LUNG & $3.5 \times 10^{5}$ & $2.6 \times 10^{5}$ \\
\hline${ }^{238} \mathrm{PuO}_{2}$ & LUNG & $1.8 \times 10^{7}$ & $6.6 \times 10^{6}$ \\
\hline${ }^{239} \mathrm{PuO}_{2}$ & LUNG & $1.9 \times 10^{7}$ & $1.47 \times 10^{7}$ \\
\hline $\mathrm{UO}_{2}$ & LUNG & $1.0 \times 10^{6}$ & $1.1 \times 10^{6}$ \\
\hline $\mathrm{UF}_{6}$ & BONE & $6.6 \times 10^{6}$ & $2.4 \times 10^{6}$ \\
\hline $241 \mathrm{AmO}_{2}$ & BONE & $3.5 \times 10^{7}$ & $4.0 \times 10^{7}$ \\
\hline
\end{tabular}


behavior of relatively insoluble ${ }^{240} \mathrm{Cm}_{2} \mathrm{O}_{3}$ shown in Fig. 4.11 depicts a lower retention of material in pulmonary tissues for the biokinetic model proposed here in comparison with the model of ICRP Publication 30; therefore, a higher absorption of this element should be expected to the blood increasing the risk to other organs of the body. The value of cumulated activity in lung tissues obtained from the model proposed here was about $24 \%$ lower than the value of $U_{S}$ reported by ICRP Publication 30; assuming the same value of SEE in both cases the dose to lung tissues proposed by ICRP 30 is overestimated by $24 \%$.

The retention of inhaled material in lung tissues for the case of highly insoluble material such as ${ }^{239} \mathrm{PuO}_{2}$ and $\mathrm{Nb}_{2} \mathrm{O}_{5}$ is shown in Figs. 4.11 and 4.13 where the processes of intermediate clearance from the lung are very closely approximated by both models before 100 days after inhalation exposure. A typical crossover showing an underestimation of retained material in lung tissues char acteristic of ICRP 30 is shown in comparison with the model proposed here for slow clearance processes of inhaled aerosols particles. As a matter of fact, both radionuclides show a longer total retention of material when compared with the model of retention of ICRP Publication 30; however, it was found that the $\mathrm{U}_{\mathrm{S}}$ value for ${ }^{239} \mathrm{PuO}_{2}$ computed by the model proposed here was $22 \%$ lower than the value computed by ICRP Publication 30 , and the $U_{S}$ value for Niobium Oxide computed by BIODEP was $240 \%$ higher than the $U_{\mathrm{s}}$ value estimated by ICRP 30 .

In addition, for aerosol size distributions with AMAD greater than $1 \mu \mathrm{m}$, the retention of material in the adult was greater than the retention of material in children. However, for very small aerosol sized particles with AMADs close to $0.1 \mu \mathrm{m}$, the retention of inhaled material is higher for children than adults giving a $41 \%$ increase in $U_{s}$ values for kids 1 -year old as compared to the adult Reference Man. Since for all subjects of different ages, the mechanical and absorptive clearance rates used for the model proposed here were assumed the same, the difference between $U_{S}$ values comes only from tne increase of regional deposition fractions as a function of age for very small-sized 
aerosol particles at the pulmonary region. Moreover, Figs. 4.12 and 4.14 show that the retention in lung tissues of relative insoluble uranium dioxides and soluble uranium hexafluorides computed by the time-varying approach proposed here, is in a good agreement with the nodel of clearance of ICRP Publication 30. For instance, the value of cumulated activity calculated in $\mathrm{UO}_{2}$ differs by only $10 \%$ over the value proposed by ICRP 30 , and the $U_{S}$ value of cumulated activity for soluble $U_{6}$ in the pulmonary region differs by $18 \%$ over the value predicted by ICRP 30 . In addition, Fig. 4.14 also depicts a high tendency of $U_{F}$ to move to the kidneys and bone surfaces giving a $63 \%$ lower $U_{S}$ value for the model proposed here as compared with ICRP 30.

Finally, to include the new estimations of the $U_{S}$ values shown in table 4.4 inside the same radiation protection philosophy of ICRP Publication 30, estimates of ALIs (Annual Limit of Intake) and DACs ( Derived Air Concentration) were performed considering the lung as the critical organ. The committed dose equivalent is directly calculated as:

$$
\mathrm{H}_{50}(\mathrm{~S} \rightarrow \mathrm{T})_{\mathrm{i}}=\mathrm{U}_{\mathrm{s}} \times \mathrm{SEE}\left(1.6 \times 10^{-10} \mathrm{MeV} \cdot \mathrm{Kg}^{-1}\right)_{\mathrm{i}}
$$

where $U_{S}$ is the number of transfornations of radionuclide $j$ in the source organ $S$ over the 50 years following intake, and SEE is the specific effective energy for radiation type i.

Therefore, in terms of the new recommendations of ICRP Publication 60 (ICRP 1990), the tissue weighting factor wr for the lung is equal to 0.13 and the Annual Limit of Intake for stochastic effects according to the new limitations suggested by this new methodology is defined as follow:

$$
\mathrm{ALI}\left(\mathrm{Bq} \cdot \mathrm{yr}^{-1}\right)=\frac{0.02\left(\mathrm{~Sv} \cdot \mathrm{yr}^{-1}\right)}{\mathrm{w}_{T} \mathrm{H}_{50, \mathrm{~T}}\left(\mathrm{~Sv} \cdot \mathrm{Bq}^{-1}\right)}
$$


Considering that the minute volume ventilation rate for the Reference Man is equal to $1.5 \mathrm{~m}^{3} \mathrm{hr} r^{-1}$, the values of Derived Air Concentration are defined by the following equation:

$$
\operatorname{DAC}\left(\mathrm{Bq} \cdot \mathrm{m}^{-3}\right)=\frac{\mathrm{ALI}\left(\mathrm{Bq} \cdot \mathrm{yr}^{-1}\right)}{\left(2000 \mathrm{hr} \cdot \mathrm{yr}^{-1}\right) \cdot\left(1.5 \mathrm{~m}^{3} \cdot \mathrm{hr}^{-1}\right)}
$$

Table 4.5 depicts the new values of ALIs and DACs proposed here after the inhalation of one unit expostire of any of the transuranic elements analyzed in this report. For comparison, the values proposed by ICRP Publications 30 and 61 (ICRP 1979; ICRP 1991) are also shown. 
Table 4.5 Annual Limits of Intake and Derived Air Concentrations for transuranic elements.

\begin{tabular}{|c|c|c|c|c|c|}
\hline Radioactive & ICRP 30 & ICRP 61 & This model & ICRP30 & This model \\
\hline Compound & ALI(Bg/yr) & ALI $(\mathrm{Bg} / \mathrm{yr})$ & ALI $(\mathrm{Bg} / \mathrm{yr})$ & $\mathrm{DAC}\left(\mathrm{Bg} / \mathrm{m}^{3}\right)$ & $\mathrm{DAC}\left(\mathrm{Bg} / \mathrm{m}^{3}\right)$ \\
\hline $95 \mathrm{Nb}_{2} \mathrm{O}_{5}$ & $4 \times 10^{7}$ & $1 \times 10^{7}$ & $4.3 \times 10^{4}$ & $2 \times 10^{4}$ & 14.5 \\
\hline $240 \mathrm{CmO}_{3}$ & $2 \times 10^{4}$ & $1 \times 10^{4}$ & $2.8 \times 10^{4}$ & 8 & 9.2 \\
\hline $239 \mathrm{PuO}_{2}$ & 500 & 300 & 604 & 0.2 & 0.2012 \\
\hline $\mathrm{UO}_{2}$ & $3 \times 10^{4}$ & $1 \times 10^{4}$ & $9.8 \times 10^{3}$ & 10 & 3.3 \\
\hline $\mathrm{UF}_{6}$ & $5 \times 10^{4}$ & $9 \times 10^{4}$ & $7.6 \times 10^{3}$ & 20 & 2.6 \\
\hline $241 \mathrm{AmO}_{2}$ & 200 & 300 & 344 & 0.08 & 0.115 \\
\hline
\end{tabular}



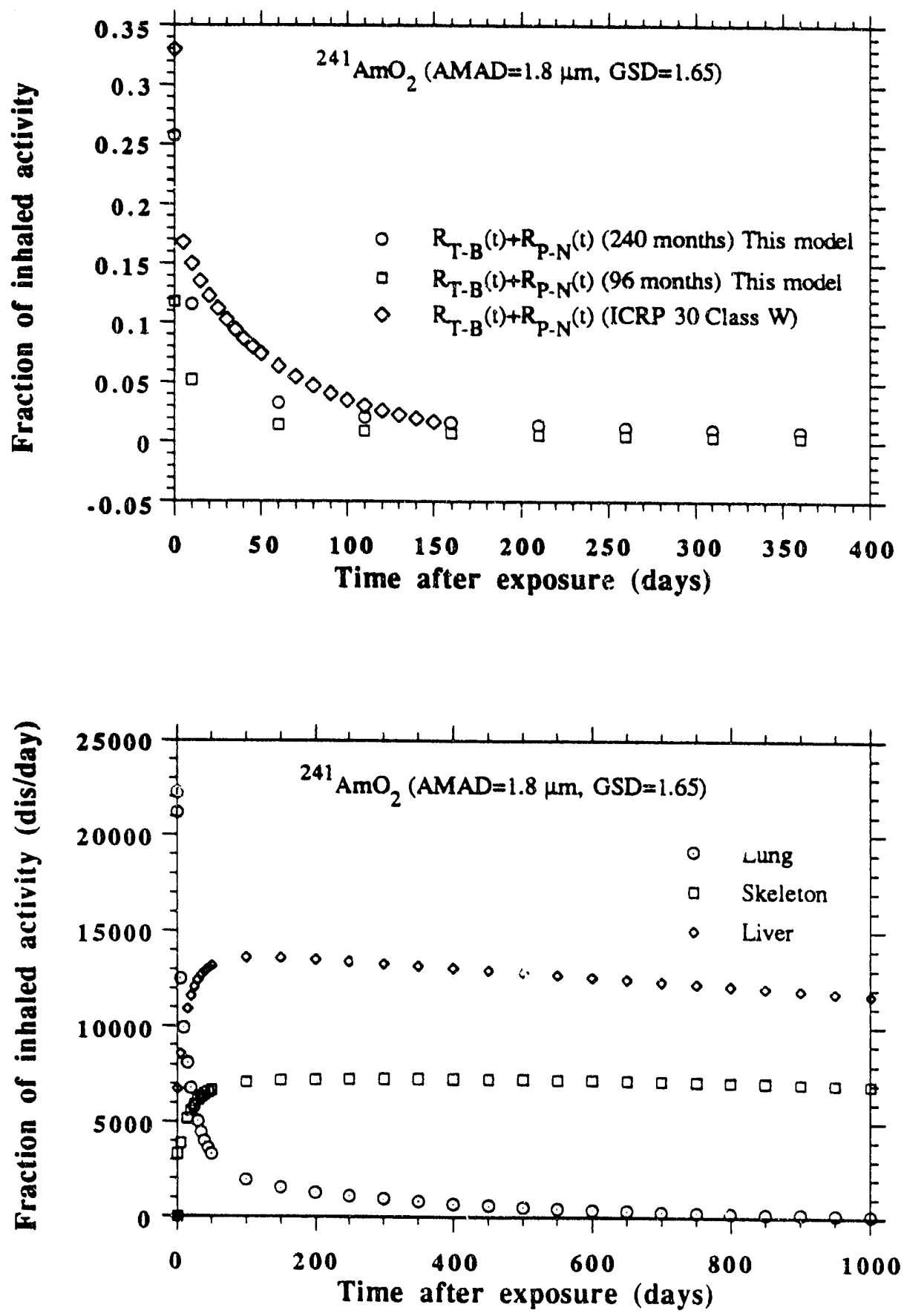

Figure 4.10 Retention of ${ }^{241} \mathrm{~A} \mathrm{mO}_{2}$ in the lung and other organs of the human body after the inhalaton of $1 \mathrm{~Bq}$. 

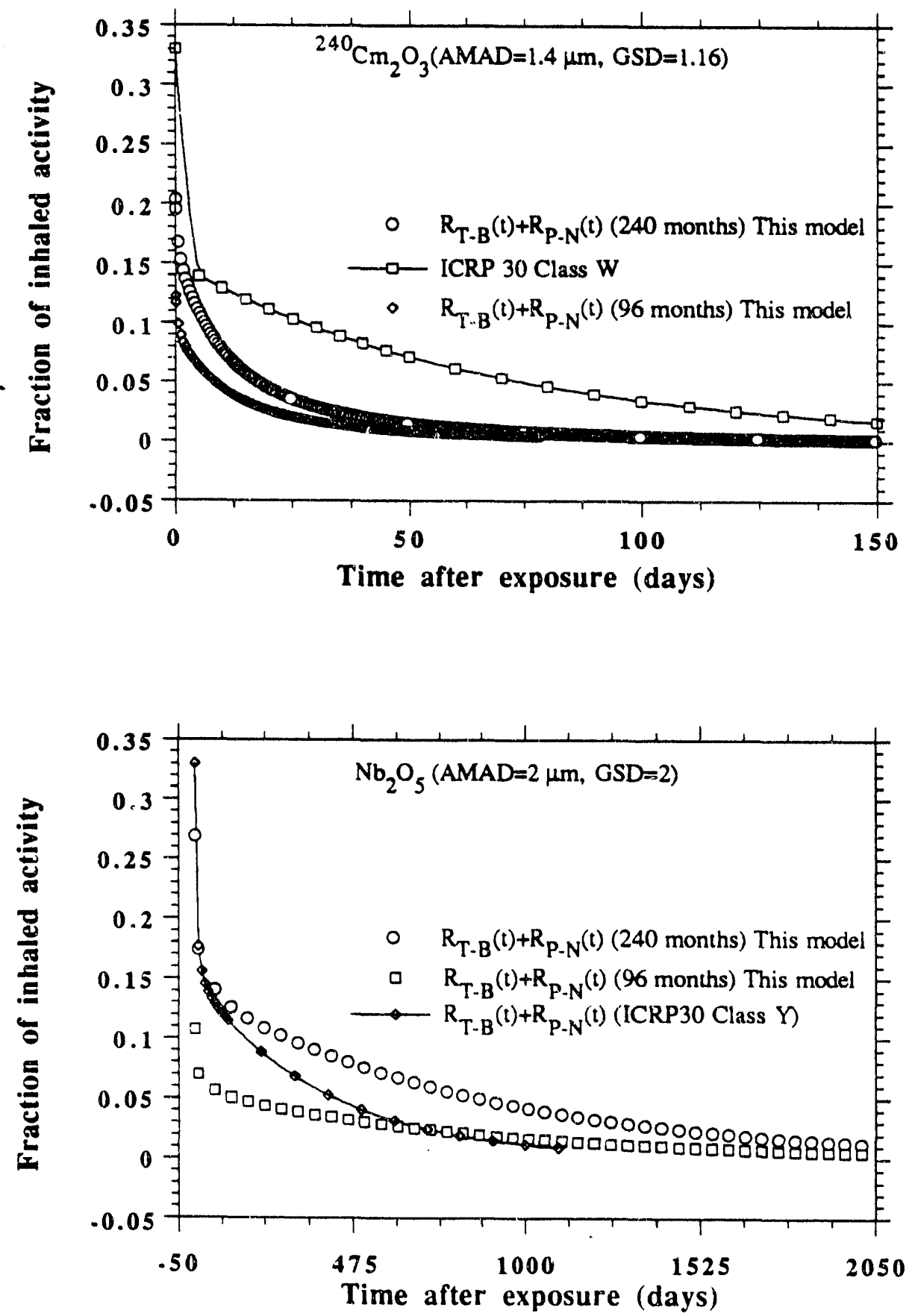

Figure 4.11 Pulmonary retentions of ${ }^{240} \mathrm{Cm}_{2} \mathrm{O}_{3}$ and ${ }^{95} \mathrm{Nb}_{2} \mathrm{O}_{5}$ after the inhalation of $1 \mathrm{~Bq}$. 

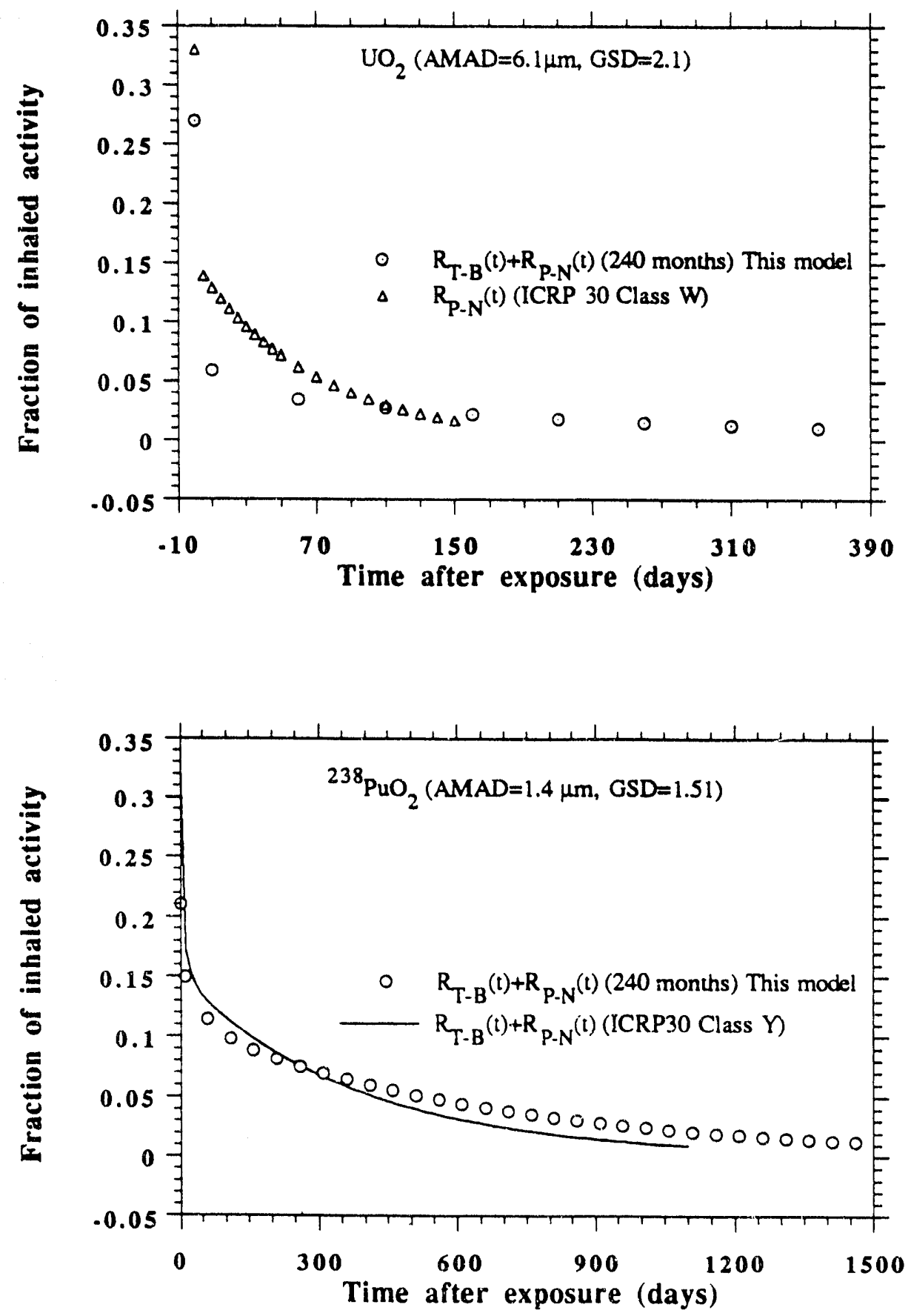

Figure 4.12 Pulmonary retentions of $\mathrm{UO}_{2}$ and ${ }^{238} \mathrm{PuO}_{2}$ after the inhalation of $1 \mathrm{~Bq}$. 

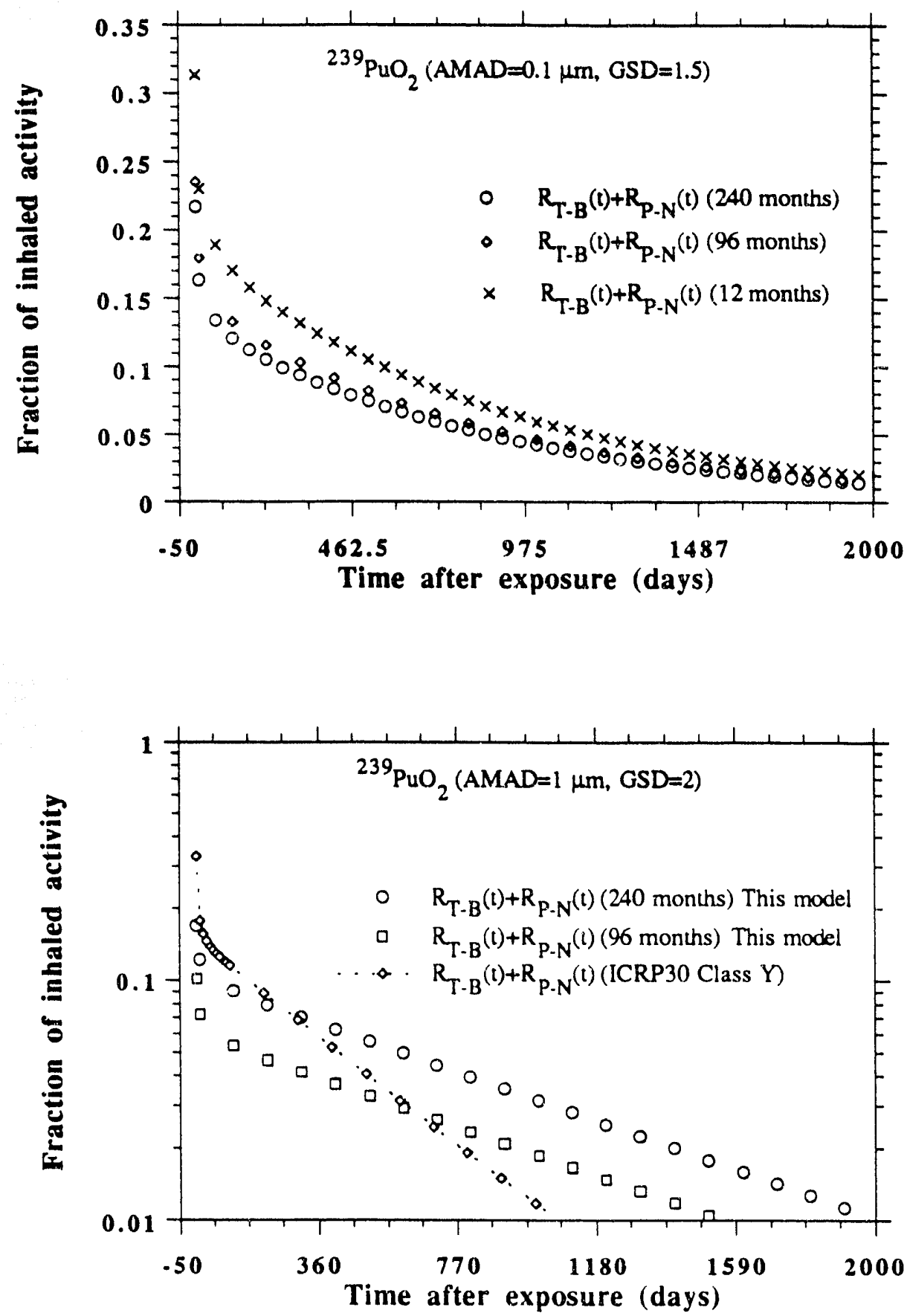

Figure 4.13 Pulmonary retention of ${ }^{239} \mathrm{PuO}_{2}$ after the inhalation of $1 \mathrm{~Bq}$. 

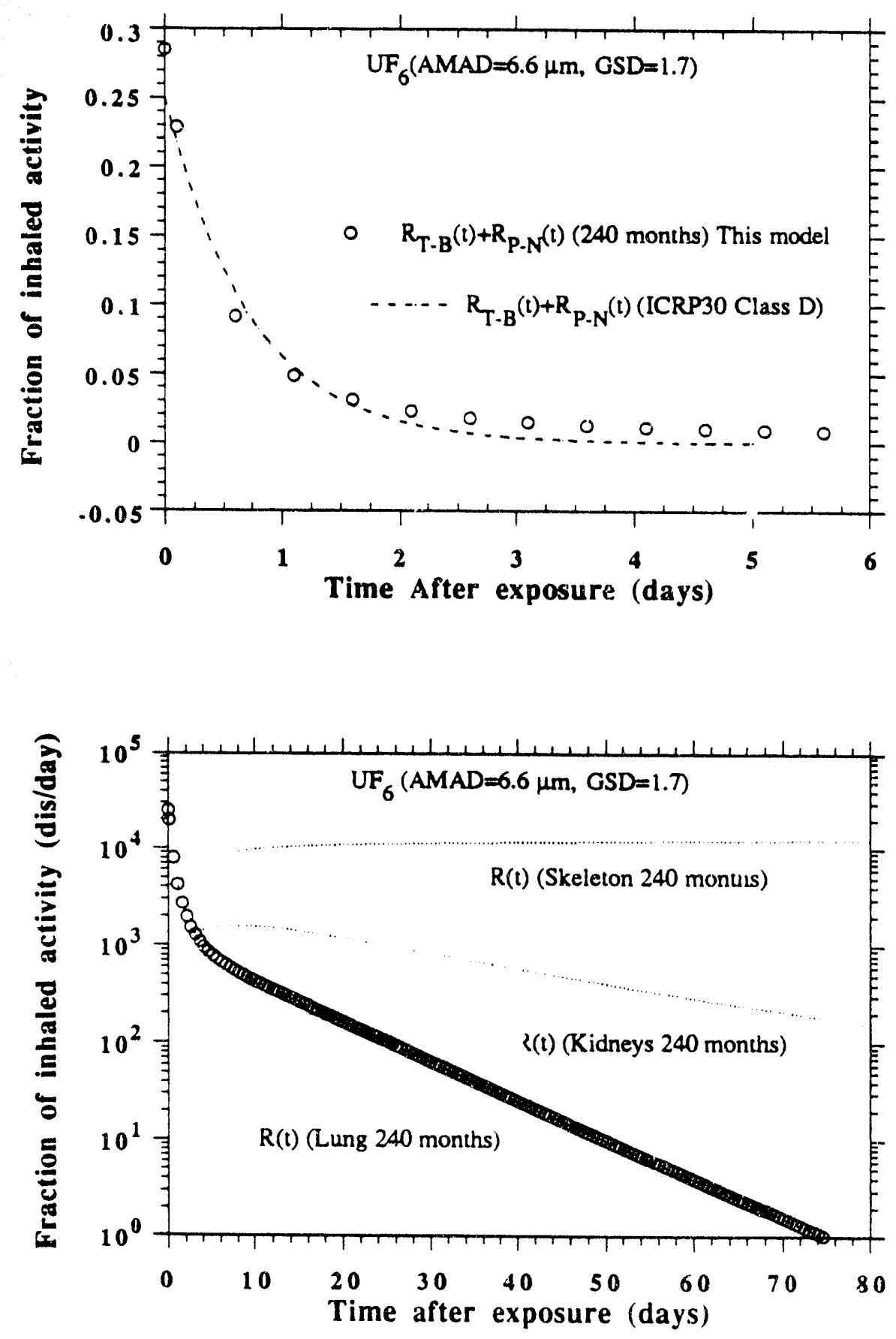

Figure 4.14 Retention of $\mathrm{UF}_{6}$ in the lung and other organs of the human body after the inhalation of $1 \mathrm{~Bq}$. 


\section{CHAPTER 5 CONCLUSIONS}

The results obtained in this work show that regional deposition efficiencies of inhaled particles are highly dependent on the level of physical activity in all the spectrum of thermodynamic and aerodynamic aerosol particle sizes; also it was shown that for particles in the aerodynamic size range, the values of regional deposition efficiencies at the inner regions of the lung are highly dependent on age. In addition, the shape of regional deposition efficiency curves as a function of particle size have a similar behavior for all ages; thus, any variation of the airway geometry and respiratory physiological parameters such as tidal volumes and breathing frequencies due to age difference do not cause a change in the fundamental mechanisms of deposition. Thus, for all the cases of physical activity and age dependency, the deposition of ultrafine aerosol particles ( 1 to $10 \mathrm{~nm}$ ) is highly enhanced by diffusive processes in all regions of the respiratory tract, and for very large aerosol size particles ( 1 to $10 \mu \mathrm{m}$ ) this behavior is repeated again due to impaction and sedimentation mechanisms.

Although the results presented at this work, are the result of computer simulations based on different sources of experimental data, the structure of the computer simulation code BIODEP is flexible enough to the acquisition of any kind of new experimental information in terms of biokinetic analysis and regional deposition parameters. In addition, since the design of BIODEP was intended for easy access to the users, then with exception of the subroutine DIVPAG, at this moment, the modular design of BIODEP using FORTRAN 77 allows the implementation of all the subroutines of BIODEP to be used in a interactive mode with any microcomputer. 
The model of lung clearance used in this work describes fairly accurate the retention in lung tissues of compounds of very low in vivo solubility and cytotoxicity after a single inhalation exposure. However, for biological active toxic particles like $\mathrm{SiO}_{2}$ and asbestos, clearance could be quite different. The use of semiempirical solubility functions employed in this work are not analogous to the intrinsic chemical solubility used by ICRP Publication 30. The semiempirical solubility used here represents the experimental end result of the action of physico-chemical and biological factors that play a role converting aerosol particles to a chemical form that is absorbed into blood, since biological processes such as macrophage uptake, intracellular chemical environment, cell turnover, chemotropism, may be more important than intrinsic chemical solubility in determining the rate at which material can leave the pulmonary region. Therefore, the description of retention of insoluble and relative insoluble transuranic elements assuming a competitive behavior between mechanical and absorptive processes through the use of $M(t)$ and $S(t)$ is more close to the real behavior of these compounds with the model proposed in this work than with the model of clearance proposed by ICRP Publication 30. The retention of insoluble radioactive transuranic elements is underestimated by about $24 \%$ in the model proposed here when compared with the model of ICRP Publication 30. In addition, the retention in lung tissues of uranium dioxide and uranium hexafluoride compounds is underestimated by $15 \%$ and $25 \%$ in the model of ICRP Publication 30 compared with the model of clearance proposed here. However, the retention $U_{6}$ on bone surfaces is overestimated by $165 \%$ in the model of ICRP Publication 30 compared with the model proposed here.

In summary, the use of the new recommendations of ICRP Publication 60 in combination with the new values of cumulated activity proposed here, give a very close agreement with ICRP Publication 30 when the values for ALI and DAC for insoluble transuranic compounds are estimated. On the other hand, there is not an agreement 
between ICRP Publication 30 and the model proposed here when the analysis of soluble and relative soluble compounds is considered. 


\section{REFERENCES}

Adamson, I. Y.; Bowden, D. H. Dose response of pulmonary macrophagic system to various apriculates and its relationship to transepithelial passage of free particles. Exp. Lung Res. 2:165-175; 1981.

Bailey , M. R.; Fry, F. A.; James, A. C. Long-term retention of particles in the human respiratory tract. J. Aer. Science. 16:295-305; 1985.

Bailey, M. R.; Kreyling, W. G.; Andre, S.; Batchelor, A.; Collier, C. G.; Drosselmeyer, E.; Ferron, G. A.; Foster, P.; Haider, B.; Hogdson. A.; Masse, R.; Metivier, H.; Morgan, A.; Müller, H. L.; Patrick, G.; Pearman, I.; Pickering, S.; Ramsden, D.; Stirling, C.; Talbot, R. G. An interspecies comparison of the lung clearance of inhaled monodisperse cobalt oxide particles_part I: objectives and summary results. J. Aerosol Sci. 20-2:169$188 ; 1989$.

Beeckmans, J. M. The deposition of aerosols in the res 1 iratory tract. Canadian Journal of Phisiology and Pharmacology. 43:157-172; 1965.

Berman, M.; Weiss, M. F. SAAM Manual, U.S. Department of Health, Education and Welfare. Washington D.C.: Publication No.(NIH) 78-180,1978; 1978.

Bowes, S. M. I.; Swift, D. L. Deposition of inhaled particles i: the oral airway during oronasal breathing. Aerosol Science and Technolcgy. 11:157-167; 1989.

Brain, J. D. The effects of increased particles on the number of alveolar macrophages. In: Inhaled particles III, edited by WH Walton Old Woking, U.K.: Unwin Bros; Vol.1; 209-223; 1971.

Chan, T. L.; Lippmann, M. Experimental measurements and empirical modeling of the regional deposition of inhaled particles in humans. Am. Ind. Hyg. Assoc. J. 41:399-409; 1980.

Cheng, Y.; Yamada, Y.; Yeh, H. Deposition of ultrafine aerosols in a human oral cast. Aerosol Science and Technology. 12:1075-1081; 1990. 
Cuddihy, R. G. Mathematical models for predicting clearance of inhaled radioactive materials. Brussels: Commission of the European Communities Report; EUR 9384; 167 $179 ; 1984$.

Cuddihy, R. G.; Boecker, B. B.; Griffith, W. C. Modelling the deposition and clearance of inhaled radi, snuclides. In: Biological implication of radionuclides released from nuclear industries (International Energy Atomic Agency). Vienna: Vol.II; 77-90; 1979.

Diel, J. H.; Mewhinney, J. A. Fragmentation of inhaled $\mathrm{Pu}^{238} \mathrm{O}_{2}$ particies in lung. Health Phys. 44-2:135-143; 1983.

Dundford, D. W.; Johnson, J. R. GENMOD-A program for internal dosinetry calculations. Scientific Document Distribution Office: Chalk River Nuclear Laboratories; Report AECL-9434; 1987.

Dunnill, M. S. Posnatal growth of the lung. Thorax. 17:329-333; 1962.

Egan, M. J.; Nixon, W.; Robinson, N. I.; James, A. C.; Phalen, R. F. Inhaled aerosol transport and deposition calculations for the ICRP task group. J. Aerosol Sci. 20:1301$1304 ; 1989$.

Findeisen, W. "Über das Absetzen kleirner, in der Luft Suspendierten Teilchen in der menschilichen Lunge bei der Atmung". Pflüger Arch. f.d. ges. Phisiol. 236:367-379; 1935.

Fisher D.R. Modified biokinetic model for uranium from analysis of acute exposure to UF6. Health Phys. 60:335-342; 1991.

Fuchs, N. A. The mechanics of aerosols. First printing. Oxford: Pergamon Press; 1964.

Gradon, L. Diffusional particle deposition in the human nose and mouth. Aerosol Science and Technology. 11:213-220; 1989.

Guilmette R. A. Morphometry of human nasal airways in vivo using mãnetic resonance imaging. J. of Aerosol Med. 2:365-377; 1989.

Guilmette R.A.; Mewhinney J.A. A biokinetic model of inhaled Cm compounds in dogs: application to human exposure data. Health Phys. 57 Supp.1:187-198; 1989. 
Haefeli-Bleuer, B.; Weibel, E. R. Morphometry of the human pulmonary acinus. The Anatomical Record. 220:401-414; 1988.

Hansen, J. E.; Ampaya, E. P. Human air space shapes, sizes, areas, and volumes. J. Applied Physiol. 38-6:990-995; 1975.

Hofmann, W.; Martonen, T. B.; Graham, R. C. Predicted deposition of nonhygroscopic aerosols in the human lung as a function of subject age. J. of Aerosol Med. 2:49-68; 1989.

Horsfield, K.; Dart, G.; Olson Dan E.; Filley, G. F.; Cumming, G. Modeis of the human bronchial tree. J. of Applied Physiology. 31-2:207-217; 1971.

Ingham, D. B. Dffusion of aerosols from a stream flowing through a cylindrical tube. Aerosol Science. 6:125-132; 1975.

International Commision of Radiological Protection. 1990 Recommendations of the International Commision of Radiological Protection. ICRP Publication 60. Oxford: Pergamon Press; Annals Of the ICRP 21(1-3); 1991.

International Commision of Radiological Protection. Annual limits on intake uf radionuclides by workers based on the 1990 recommendations. ICRP Publication 61. Oxford: Pergamon Press; Annals of the ICRP 21(4); 1991.

International Commision of Radiological Protection Task Group on Lung Dynamics. Deposition and retention models for internal dosimetry of the human respiratory tract. Health Phys. 12:173-207; 1966.

International Commision of Radiological Protection. Individual monitoring for intakes of radionuclides by workers: design and interpretation. ICRP Publication 54. Oxford: Pergamon Press; 1988.

International Commission of Radiological Protection. Limits for intakes of radionuclides by workers. ICRP Publication 30. Oxford: Pergamon Press; Part 1. Ann. ICRP 2 (3/4); 1979.

International Commision of Radiological Protection. The metabolism of compounds of plutonium and other actinides. ICRP Publication 19. Oxford: Pergamon Press; 1972. 
International Commision of Radiological Protection. Report of commitee II on permisible dose for internal radiation. ICRP Publication 2. Oxford: Pergamon Press ; 1959.

Jacquez, J. A. Compartmental Ana' 'sis in biology and medicine. Second edition. Michigan: The University of Michigan Press; 1985.

James, A. C. Lung dosimetry. In: Nazzarof, W.W.; Nero, A.V. eds. Radon and its decay products in indoor air. New York: John Wiley; 259-309; 1988.

James, A. C.; Birchall, A.; Cross, F. T.; Cuddihy, R. G.; Johnson, J. R. The current approach of the ICRP Task Group for modeling doses to respiratory tract. Health Phys. 57 Sup. 1:271-282; 1989.

Johnson, J. R.; Milencoff, S. A comparison of excretion and retention between the current ICRP lung model and a proposed new model. Health Phys. 57 Sup. 1: 263-270; 1989.

Kanapilly G.M. Simulants of lung fluid. Health Phys. 39:349-346; 1980.

Kannapilly, G. M. Alveolar microenvironment and its relationship to the retention and transport into blood of aerosols deposited in alveoli. Health Phys. 32:89-100; 1977.

Kreyling, W. G.; Ferron, G. A.; Haider, B. Metabolic fate of inhaled Co aerosols in beagle dogs. Health Phys. 51:73-795; 1986.

Landahl, H. D. On the removal of air-borne droplets by the human respiratory tract: I. The lung. Bulletin of Mathematical Biophysics. 12:43-56; 1950.

Lee, P. S.; Gerrity, T. R.; Hass, F. J. A modei of tracheobronchial clearance of inhaled particles in man and a comparison with data. IEEE Trans. Biomed. Eng. BME-26 (11):624-630; 1979.

Lim, T. P. K. Physiology of the lurg. First printing. Sprinfield,Illinois: Charles C Thomas; 1983.

Mercer. T.T. On the role of particle size in the dissolution of lung burdens. Health Phys. 13:1211-1221; 1967. 
Morrow, P. E. Clearance kinetics of inhaled particles. In: Respiratory defense mechanisms, part II, edited by JD brain, DF Proctor, and LM Reid. New York: Marcel Dekker; 491 543; 1977.

Pattle, R. In: C. Davis ed. Inhaled particles and vapours. Oxford: Pergamon Press; 301-311; 1961.

Raabe, O. G.; Yeh, H. C.; Schum, G. M.; Phalen, R. F. Tracheobronchial morphometry: human, dog,rat,hamster. Albuquerque, New Mexico: Lovelace Foundation for Medical Education and Research; LF-53; 1976.

Reid, L. The lung: Its growth and remodeling in health and disease. Am. J. Roentgenol. 129:777-788; 1977.

Rudolf, G.; Köbric, R.; Stahlhofen W. Modelling and algebraic formulation of regional aerosol deposition in man. J. of Aerosol Sci. 21:403-406; 1990.

Sanders S.M. Excretion of $\mathrm{Am}^{241}$ and $\mathrm{Cm}^{244}$ following two cases of accidental inhalation. Health Phys. 27:359-365; 1974.

Scherer, P. W.; Shendalman, L. H.; Greene, N. M.; Bouhuys, A. Measurement of axial diffusivities in a model of the bronchial airways. J. of Applied Physiol. 38-4:719-723; 1975.

Schlesinger, R. B. Deposition and clearance of inhaled particles. In: Mc Clellan, R.O.; Henderson, R.F. eds. Concepts in inhalation toxicology. New York: Hemisphere; 165$195 ; 1988$.

Sorokin, S. P.; Brain, J. D. Pathways of clearance in mouse lungs exposed to iron oxide aerosols. Anat. Rec. 181:581-600; 1975.

Stahlhofen, W.; Gebhart, J.; Heyder, J. Experimental determination of the regional deposition of aerosol particles in the human respiratory tract. Am. Ind. Hyg. Assoc. J. 41:385-398; 1980.

Stanley, P. J.; Wilson, R.; Greenstone, M. A.; Mackay, I. S.; Cole, P. J. Abnormal nasal mucociliary clearance in patients with rhinitis and its relationship to concomitant chest disease. Br. J. Dis. Chest. 79:77-82; 1985. 
Swift, D. L.; Proctor, D. F. A dosimetric model for particles in the respiratory tract. In: Dogson, J.; Mc Callum, R.I.; Bailey, M.R.; Fisher, D.R., eds. Inhaled particles VI. (sup. to Ann. Occup. Hyg.). 1035-1044; 1988.

Thind, K. S. Determination of particle size for airborne $\mathrm{UO}_{2}$ dust at a fuel fabrication work station and its implication on the derivation and use of ICRP Publication 30 Derived Air Concentration values. Health Phys . 51:97-105; 1986.

Vincent, J. H.; Mark, D.; Miller, B. G.; Armbruster, L.; Ogden, T. L. Aerosol inhalability at higher windspeeds. J. Aerosol Sci. . 21-4:577-586; 1990.

Weibel, E. R. Morphometry of the human lung. First printing. New York: Springer-Verlag;

Yeh, H.; Schum, G. M. Models of human lung airways and their application to inhaled particle deposition. Bulletin of Math Biology. 42:461-480; 1980.

Yesberger, G. R. Handford americium contamination accident. Health Phys. 33:676; 1977.

Zapletal, A. Lung function in children and adolescents. First printing. New York: Kasrger; 1987. 

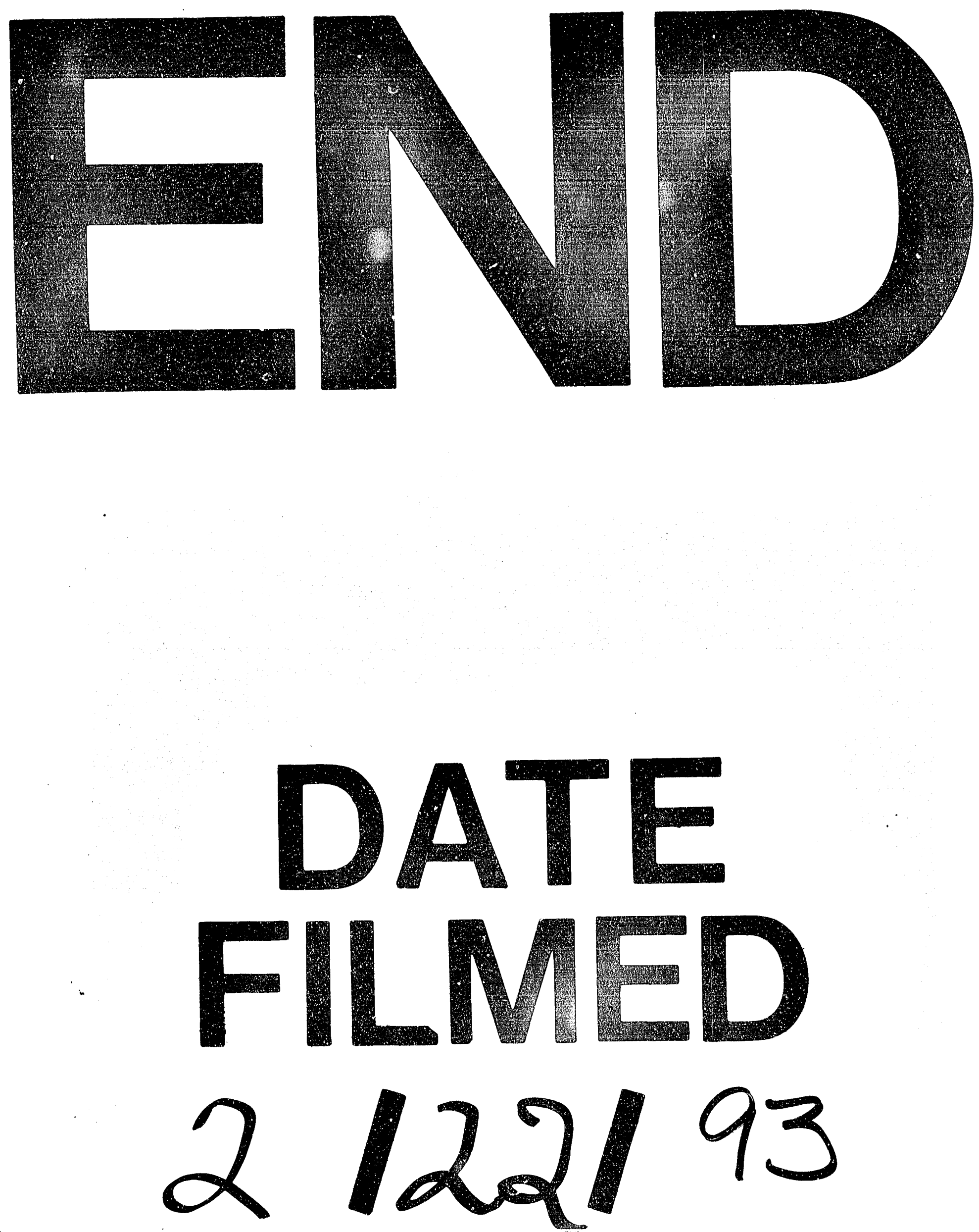
